San Jose State University

SJSU ScholarWorks

Master's Theses

Master's Theses and Graduate Research

1989

\title{
Investigation of the defects in GaAs single crystal substrates and the methods of revealing the defects by chemical etching
}

James Young

San Jose State University

Follow this and additional works at: https://scholarworks.sjsu.edu/etd_theses

\section{Recommended Citation}

Young, James, "Investigation of the defects in GaAs single crystal substrates and the methods of revealing the defects by chemical etching" (1989). Master's Theses. 3237.

DOI: https://doi.org/10.31979/etd.2dc6-3x4m

https://scholarworks.sjsu.edu/etd_theses/3237

This Thesis is brought to you for free and open access by the Master's Theses and Graduate Research at SJSU ScholarWorks. It has been accepted for inclusion in Master's Theses by an authorized administrator of SJSU ScholarWorks. For more information, please contact scholarworks@sjsu.edu. 


\section{INFORMATION TO USERS}

The most advanced technology has been used to photograph and reproduce this manuscript from the microfilm master. UMI films the text directly from the original or copy submitted. Thus, some thesis and dissertation copies are. in typewriter face, while others may be from any type of computer printer.

The quality of this reproduction is dependent upon the quality of the copy submitted. Broken or indistinct print, colored or poor quality illustrations and photographs, print bleedthrough, substandard margins, and improper alignment can adversely affect reproduction.

In the unlikely event that the author did not send UMI a complete manuscript and there are missing pages, these will be noted. Also, if unauthorized copyright material had to be removed, a note will indicate the deletion.

Oversize materials (e.g., maps, drawings, charts) are reproduced by sectioning the original, beginning at the upper left-hand corner and continuing from left to right in equal sections with small overlaps. Each original is also photographed in one exposure and is included in reduced form at the back of the book.

Photographs included in the original manuscript have been reproduced xerographically in this copy. Higher quality $6^{\prime \prime} \times 9^{\prime \prime}$ black and white photngraphic prints are available for any photographs or illustrations appearing in this copy for an additional charge. Contact UMI directly to order.
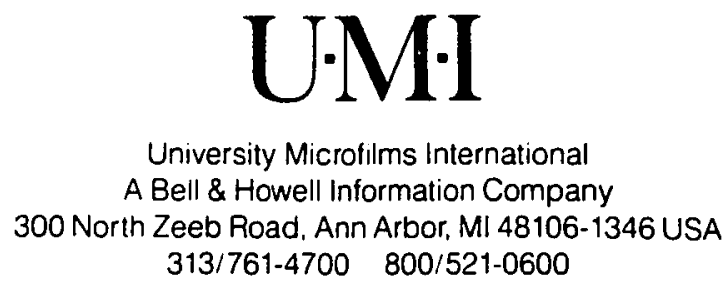


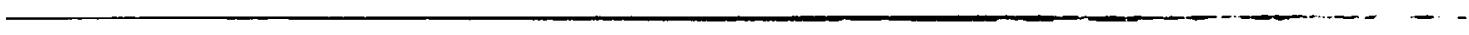


Order Number 1939663

Investigation of the defects in GaAs single crystal substrates and the methods of revealing the defects by chemical etching

Young, James, M.S.

San Jose State University, 1989 



\title{
INVESTIGATION OF THE DEFECTS IN GaAs SINGLE CRYSTAL SUBSTRATES AND THE METHODS OF REVEALING THE DEFECTS BY CHEMICAL ETCHING
}

\author{
A Thesis \\ Presented to \\ The Faculty of the Department of Materials Engineering \\ San Jose State University
}

\author{
In Partial Fulfillment \\ of the Requirement for the Degree \\ Master of Science
}
By
-. James Young

December, 1989 


\section{APPROVED FOR THE DEPARTMENT OF MATERIALS ENGINEERING}

alim ln $Y_{1} \ldots t$

Dr. Don W. Chung, Prof. of Mat. E., Thesis Advisor

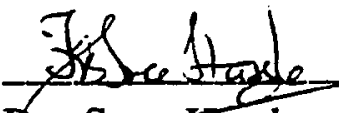

Dr. Sree Harsha, Chairman of Mat. E.

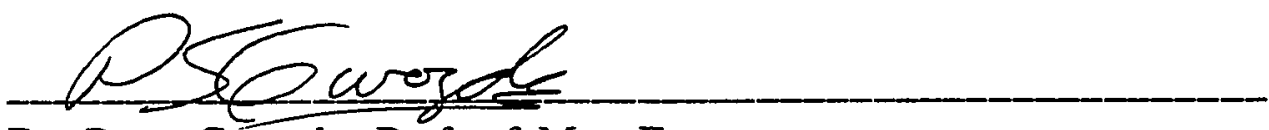

Dr. Peter Gwozdz, Prof. of Mat. E.

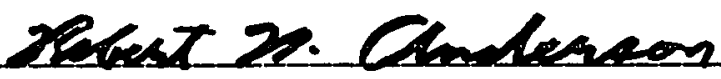

Dr. Robert Anderson, Prof. of Mat. E.

APPROVED FOR THE UNTVERSITY

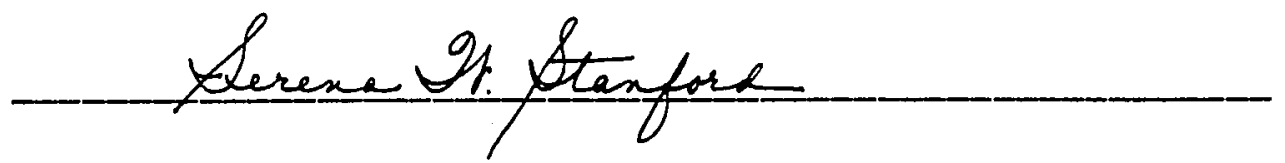




\begin{abstract}
INVESTIGATION OF THE DEFECTS IN GaAs SINGLE CRYSTAL SUBSTRATES AND THE METHODS OF REVEALING THE DEFECTS BY CHEMICAL ETCHING
\end{abstract}

\author{
by James Young
}

Emphasis is placed on the practical aspects of the etching of Vertical Gradient Freeze (VGF) grown GaAs single substrates, including procedures for the preparation of polished substrates and for the revelation of defects by selective attack. Basic information on the crystallography of GaAs and its effects on the structures of defects is considered.

The defect etching methods used in this work concentrated on four types: $\mathrm{A} / \mathrm{B}$ etching $\left(\mathrm{AgNO}_{3}+\mathrm{H}_{2} \mathrm{O}+\mathrm{CrO}_{3}+\mathrm{HF}\right)$, 3:1:1 $\mathrm{H}_{2} \mathrm{SO}_{4}: \mathrm{H}_{2} \mathrm{O}_{2}: \mathrm{H}_{2} \mathrm{O}$ photo-etching, $\mathrm{KOH}$ etching and hydroxide eutectic $(\mathrm{KOH}+\mathrm{NaOH})$ etching. The different etch structures (features) were produced on the GaAs single substrates by different etching methods. Complex etch features resulting from the attack of particular etchants at substrate surfaces are interpreted in terms of defect structures. Those defects include dislocations, precipitates, growth striations, impurity segregation and even antiphase domains.

The effect of the different dopants to etching performance is also reported in this work, in which there exist different characteristics between the doped GaAs materials and the undoped GaAs materials. 


\section{ACKNOWLEDGEMENTS}

I would like to thank my thesis advisor, Professor D. W. Chung for his advice and enthusiasm, as well as my committee members whose guidance and support were essential to the completion of this study.

I wish to express my appreciation to Dr. Morris Young and his Company (American Xtal Technology) for providing the material supports, the facilities and the environment necessary for my study.

It is a pleasure to thank Dr. W. R. Chung (Professor of Industrial Technology Department at SJSU), Mr. J. Eveland (Technician of Materials Engineering Department), and other people for their great help at various stages throughout the course of this work. 


\section{TABLE OF CONTENTS}

page

LIST OF TABLES $\ldots \ldots \ldots \ldots \ldots \ldots \ldots \ldots \ldots \ldots \ldots \ldots \ldots \ldots \ldots \ldots \ldots$

LIST OF FIGURES $\ldots \ldots \ldots \ldots \ldots \ldots \ldots \ldots \ldots \ldots \ldots \ldots \ldots \ldots \ldots \ldots \ldots$

1. INTRODUCTION $\quad \ldots \ldots \ldots \ldots \ldots \ldots \ldots \ldots \ldots \ldots \ldots \ldots \ldots \ldots$

2. BACKGROUND $\quad \ldots \ldots \ldots \ldots \ldots \ldots \ldots \ldots \ldots \ldots \ldots \ldots \ldots \ldots \ldots \ldots \ldots \ldots$

2.1. Crystallography of GaAs .............. 5

2.2. Defect Structures in GaAs $\ldots \ldots \ldots \ldots \ldots \ldots \ldots \ldots$

2.2.1. Point Defects $\ldots \ldots \ldots \ldots \ldots \ldots \ldots \ldots \ldots$

2.2.2. Line Defects (dislocations) $\ldots \ldots \ldots \ldots \ldots$

2.2.3. Surface Defects (stacking faults) . . . . . . 13

2.2.4. Volume Defects ....................

2.2.4.1. Precipitates $\ldots \ldots \ldots \ldots \ldots \ldots \ldots$

2.2.4.2. Precipitates and dislocations $\ldots \ldots \ldots 15$

2.2.4.3. Growth striation $\ldots \ldots \ldots \ldots \ldots 16$

2.2.5. Work Damage. . . . . . . . . . . . . . 16

2.3. Defect Etching Compositions $\ldots \ldots \ldots \ldots \ldots \ldots \ldots$

2.3.1. Nitric Acid ........................ . . . .

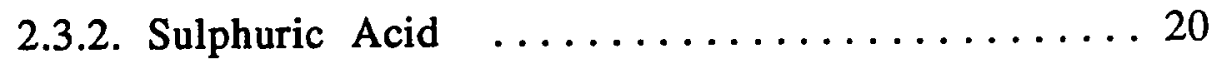

2.3.3. Chromium Trioxide $\ldots \ldots \ldots \ldots \ldots \ldots \ldots 21$

2.3.4. Potassium Hydroxide $\ldots \ldots \ldots \ldots \ldots \ldots . \ldots 23$ 


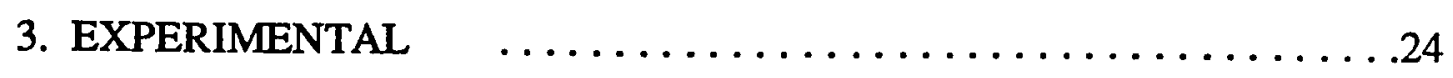

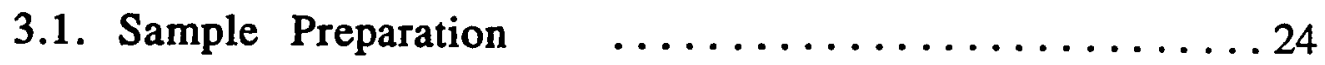

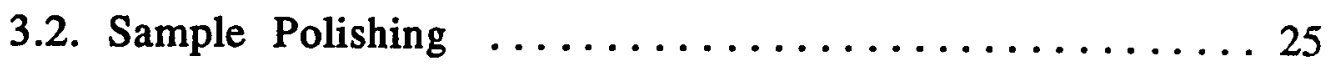

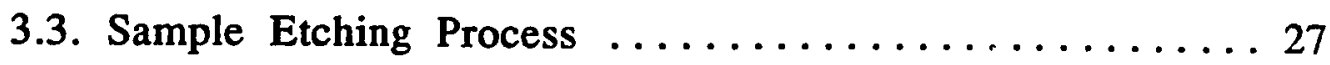

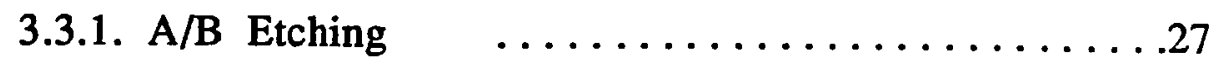

3.3.2. 311 Photo-etching $\ldots \ldots \ldots \ldots \ldots \ldots \ldots 28$

3.3.3. $\mathrm{KOH}$ Etching $\quad \ldots \ldots \ldots \ldots \ldots \ldots \ldots \ldots \ldots \ldots \ldots .28$

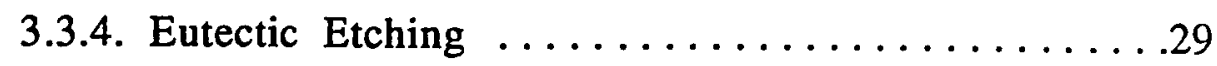

4. RESULTS AND DISCUSSION $\quad \ldots \ldots \ldots \ldots \ldots \ldots \ldots \ldots \ldots \ldots \ldots \ldots \ldots \ldots \ldots$

4.1. A/B Etching $\ldots \ldots \ldots \ldots \ldots \ldots \ldots \ldots \ldots \ldots \ldots \ldots \ldots \ldots \ldots \ldots \ldots \ldots \ldots$

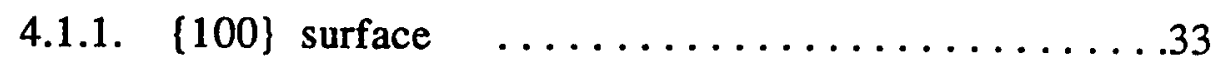

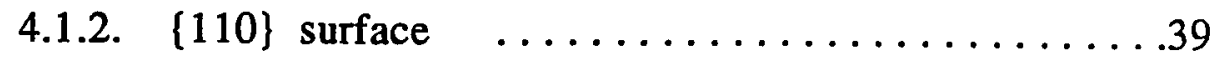

4.1.3. $\{111\}$ Ga surface $\ldots \ldots \ldots \ldots \ldots \ldots \ldots \ldots \ldots$

4.1.4. $\{111\}$ As surface $\quad \ldots \ldots \ldots \ldots \ldots \ldots \ldots .48$

4.1.5. Summary $\ldots \ldots \ldots \ldots \ldots \ldots \ldots . \ldots \ldots$

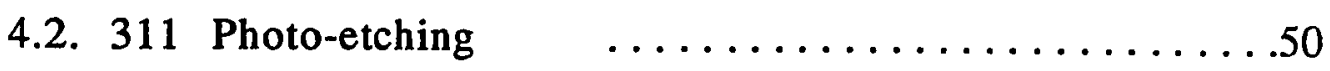

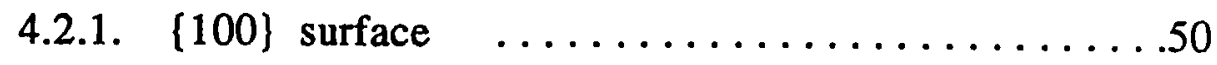

4.2.2. $\{110\}$ surface $\ldots \ldots \ldots \ldots \ldots \ldots \ldots \ldots \ldots \ldots \ldots \ldots \ldots \ldots \ldots$

4.2.3. $\{111\} \mathrm{Ga}$ surface $\ldots \ldots \ldots \ldots \ldots \ldots \ldots \ldots 6$

4.2.4. $\{111\}$ As surface $\quad \ldots \ldots \ldots \ldots \ldots \ldots \ldots 6 \ldots \ldots$

4.2.5. Summary $\ldots \ldots \ldots \ldots \ldots \ldots \ldots .64$

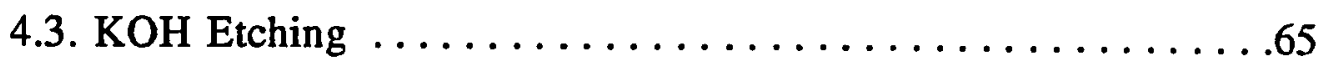

4.3.1. $\{100\}$ surface $\ldots \ldots \ldots \ldots \ldots \ldots \ldots \ldots 6$

4.3.2. $\{110\}$ surface $\ldots \ldots \ldots \ldots \ldots \ldots \ldots \ldots \ldots$ 
4.3.3. $\{111\} \mathrm{Ga}$ surface $\ldots \ldots \ldots \ldots \ldots \ldots \ldots \ldots \ldots$

4.3.4. $\{111\}$ As surface $\quad \ldots \ldots \ldots \ldots \ldots \ldots \ldots .79$

4.3.5. Summary $\quad \ldots \ldots \ldots \ldots \ldots \ldots \ldots \ldots$

4.4. Eutectic Etching $\ldots \ldots \ldots \ldots \ldots \ldots \ldots \ldots \ldots \ldots \ldots \ldots \ldots$

4.4.1. $\{100\}$ surface $\ldots \ldots \ldots \ldots \ldots \ldots \ldots \ldots$

4.4.2. $\{110\}$ surface $\ldots \ldots \ldots \ldots \ldots \ldots \ldots \ldots .91$

4.4.3. $\{111\} \mathrm{Ga}$ surface $\ldots \ldots \ldots \ldots \ldots \ldots \ldots \ldots . . \ldots 1$

4.4.4. Summary $\ldots \ldots \ldots \ldots \ldots \ldots \ldots \ldots$

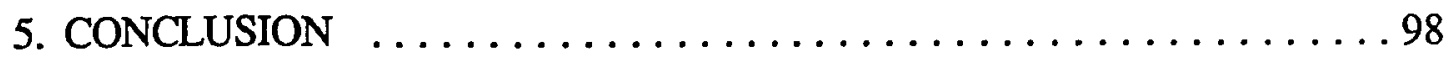

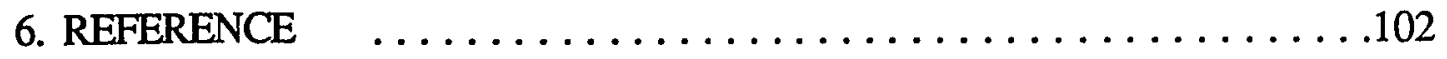

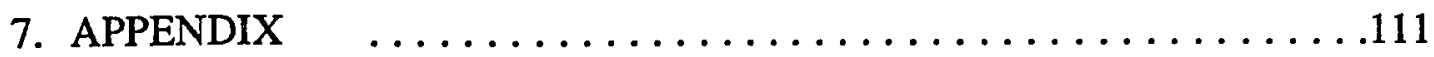




\section{TABLES}

Table 1. The etched samples with different crystallographic orientations and growth conditions by the different etching

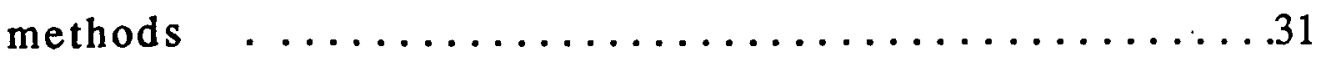

Table 2. Summary of etched structures in GaAs single crystal by $A / B$ etching

Table 3. Summary of etched structures in GaAs single crystal

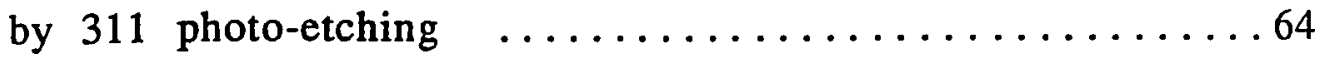

Table 4. Summary of etched structures in GaAs single crystal

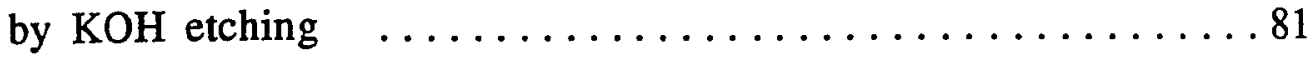

Table 5. Summary of etched structures in GaAs single crystal

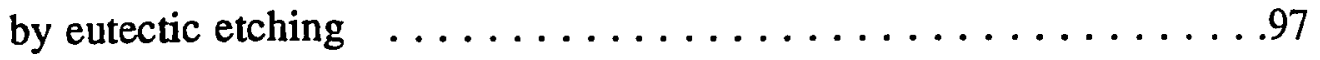

Table 6. Etching rates with different etchants $\ldots \ldots \ldots \ldots 10 \ldots$ 


\section{FIGURES}

Figure 1. Unit cube of GaAs crystal lattice $\ldots \ldots \ldots \ldots \ldots$

Figure 2. View of GaAs along $[\overline{1} 1 \overline{1} 2] \quad \ldots \ldots \ldots \ldots \ldots \ldots \ldots$

Figure 3. Schematic pictures of the atomic arrangements around shuffle set dislocations in a GaAs crystal $\ldots \ldots \ldots .10$

Figure 4. $60^{\circ}$ dislocations in the GaAs lattice $\ldots \ldots \ldots \ldots \ldots$

Figure 5. Schematic pictures of the atomic arrangements around glide set dislocations in a GaAs crystal $\ldots \ldots \ldots \ldots 12$

Figure 6. Typical microstructures on the $\{100\}$ surfaces by $A / B$

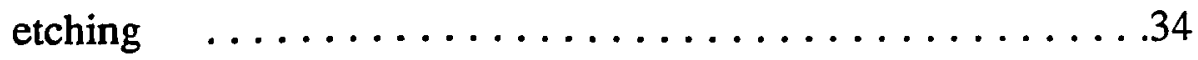

Figure 7. Dislocation etch structures due to dislocations parallel to and inclined to the surfaces $\ldots \ldots \ldots \ldots \ldots \ldots$

Figure 8. Dislocation etch structures with features of grooves (G) and ridges $(\mathrm{R})$ by $\mathrm{A} / \mathrm{B}$ etching $\ldots \ldots \ldots \ldots \ldots \ldots \ldots \ldots$

Figure 9. Polygonized dislocation arrays -.. lineage

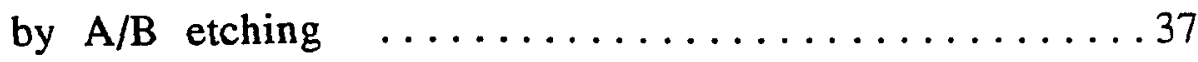

Figure 10. Typical etch structures on $\{110\}$ surfaces by $A / B$ etching

Figure 11. Growth striations on $\{110\}$ surfaces by $A / B$ etching 
Figure 12. Decoration of a dislocation lying in $\{110\}$ surface Small As-precipitates can be observed. . . . . . . .41

Figure 13. Typical etch structures on $\{111\} \mathrm{Ga}$ surfaces by $\mathrm{A} / \mathrm{B}$ etching $\quad \ldots \ldots \ldots \ldots \ldots \ldots \ldots \ldots \ldots \ldots \ldots \ldots \ldots$

Figure 14. Typical etch structures on $\{111\}$ As surfaces

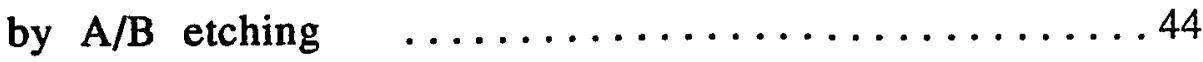

Figure 15. Straight dislocation lines lying in $\{111\}$ As surface, along $<110>$ and $<112>$ directions $\ldots \ldots \ldots \ldots \ldots \ldots$

Figure 16. Growth striations and precipitates on $\{111\}$ As surface by

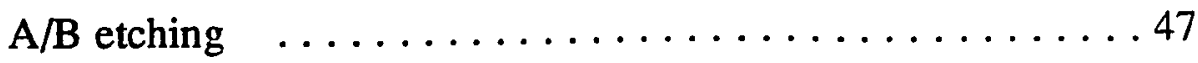

Figure 17. Typical etch structures on $\{100\}$ surface

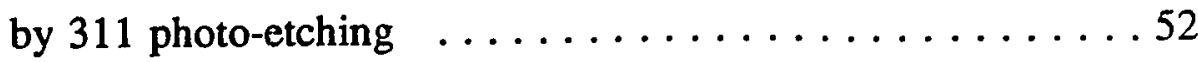

Figure 18. Etch structures on $\{110\}$ surfaces by 311 photo-etching $\ldots \ldots \ldots \ldots \ldots \ldots \ldots \ldots \ldots \ldots \ldots \ldots \ldots$

Figure 19. Etch structures on the undoped and Cr-doped $\{110\}$ surfaces by 311 photo-etching. Precipitates decorate the dislocation lines. . . . . . . . . . . . . . 53

Figure 20. Two crossed dislocation lines on $\{110\}$ undoped GaAs sample. The dislocations have a $<112>$ axis.

Figure 21. Growth striations on $\{110\}$ surfaces by 311 photo-etching 
Figure 22. Typical etch structures on $\{111\} \mathrm{Ga}$ surface by 311 photo-etching $\ldots \ldots \ldots \ldots \ldots \ldots \ldots \ldots \ldots$

Figure 23. Etch structures on $\{111\} \mathrm{Ga}$ surfaces of the $\mathrm{Zn}$-doped and undoped GaAs materials by 311 photo-etching

Figure 24. Growth striations on $\{111\} \mathrm{Ga}$ and $\{111\}$ As surfaces by 311 photo-etching $\ldots \ldots \ldots \ldots \ldots \ldots \ldots \ldots \ldots \ldots \ldots \ldots \ldots \ldots \ldots \ldots$

Figure 25. Typical etch structures on $\{111\}$ As surfaces by 311 photo-etching $\ldots \ldots \ldots \ldots \ldots \ldots \ldots \ldots \ldots \ldots$

Figure 26. Etch structures on $\{111\}$ As surfaces by 311 photo-etching. The precipitates can be revealed on dislocation lines.

Figure 27. Typical etch pits on undoped SI $\{100\}$ surface by $\mathrm{KOH}$ etching

Figure 28. Dislocation distribution on $\{100\}$ surface of undoped SI GaAs material by $\mathrm{KOH}$ etching

Figure 29. Etch Pit Density (EPD) maps of Si-doped SC GaAs

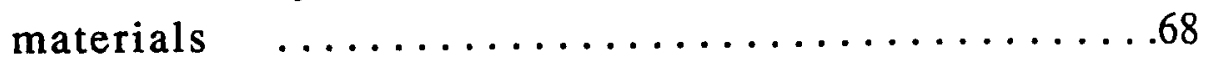

Figure 30. Dislocation-free crystal obtained from high Si-doped $\left(\mathrm{n}_{\mathrm{c}}>10^{18}\right)$ SC GaAs material by $\mathrm{KOH}$ etching .71

Figure 31. EPD map of $\mathrm{Zn}$-doped $\{100\}$ surface $\ldots \ldots \ldots \ldots \ldots . \ldots 71$ 
Figure 32. EPD distribution of Cr-doped and undoped SI GaAs material, $\{100\}$ surface $\ldots \ldots \ldots \ldots \ldots \ldots \ldots \ldots \ldots \ldots$

Figure 33. The longitudinal variation (along the growth direction) of the dislocation density by $\mathrm{KOH}$ etching

Figure 34. Dislocation etch pits on $\{110\}$ surface by $\mathrm{KOH}$ etching .................... 74

Figure 35. Special polygonal raise structures on $\mathrm{Cr}$-doped $\{100\}$ surface by $\mathrm{KOH}$ etching $\ldots \ldots \ldots \ldots \ldots \ldots$

Figure 36. Typical etch pits on the $\{111\} \mathrm{Ga}$ surface

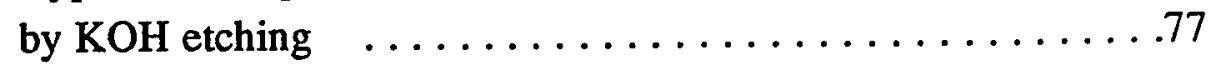

Figure 37. Triangular mounts and flower-like structures on $\{111\}$ As surface by $\mathrm{KOH}$ etching $\ldots \ldots \ldots \ldots .78$

Figure 38. Polygonal pits on $\{111\}$ As by $\mathrm{KOH}$ etching .78

Figure 39. Polygonal, crystal-like etch structures (black pits) on $\{111\}$ As surface by eutectic etching $\ldots \ldots \ldots \ldots . \ldots 3$

Figure 40 . Etch pits on $\{111\} \mathrm{Ga}$ surface of undoped SI GaAs by eutectic etching $\ldots \ldots \ldots \ldots \ldots \ldots \ldots \ldots \ldots . \ldots \ldots$

Figure 41. Dislocation etch pits and surface roughness on Si-doped, $\{100\} \mathrm{GaAs}$ by eutectic etching $\ldots \ldots \ldots \ldots \ldots 6$ 
Figure 42. Typical etch structures on $\{100\}$ surface by eutectic etching

Figure 43. Surface morphology on $\{100\}$ surfaces by eutectic etching

Figure 44 . Etch pits on $\{110\}$ surface by eutectic etching .................... 92

Figure 45 . Etch structures on $\{111\} \mathrm{Ga}$ surface by eutectic etching $\ldots \ldots \ldots \ldots \ldots . \ldots \ldots$

Figure 46 . Etch pits on Si-doped $\{111\} \mathrm{Ga}$ surface. The needle-like ridges cover the whole picture. . . . . . . . . . . .94 


\section{INTRODUCTION}

Gallium arsenide (GaAs) is an important semiconductor material. The high mobility and high saturated drift velocity (compared to silicon) allow that GaAs semiconductor devices to operate at microwave frequencies where silicon devices are unable to function. GaAs devices are more radiation tolerant than silicon MOS devices. ${ }^{(1)}$ These advantages imply that there is a rapidly growing demand for GaAs devices in communication, radar, electronic warfare, direct satellite broadcast electronics and highspeed computers. ${ }^{(1)}$

Defects are present in all semiconductors and they control or influence many of their most useful properties; hence, the proper characterization of crystal defects is an essential part of semiconductor crystal growth studies, device failure analysis and many other solid state investigations. For example, the fundamental physical properties of a crystalline semiconductor are often investigated by first analyzing defects present in an as-grown crystal. In the electronics industry defects often play a pivotal role in governing the performance, reliability and lifetime of solid state devices. The defects may be introduced at the various steps of production but also may appear during the working periods of the devices. Grown-in vacancies, impurities, dislocations, doping or 
stoichiometry inhomogeneities, and surface damages on the materials may all be included in defect categories.

For GaAs devices, the defects on the substrates directly affect the device performance. A good example of effect of dislocations on device performance is the case of the GaAs LED. In this device the substrate is eventually removed and only the LPE layers remain to contribute to the device. However, dislocations initially present in substrate propagate into the epi-layers. These dislocations deleteriously affect the light emitting efficiency and lifetime of the devices. Therefore, the investigation and study of defects of GaAs single crystal are important for studying GaAs materials.

The defects of GaAs single crystal substrate, according to Stirland et al, ${ }^{(2)}$ can be classified as point defects, line defects, surface defects, volume defects and work damage (in processing). The defects can be revealed by use of etchants (chemical solutions). Before a specimen can be examined optically, it usually must be etched to reveal defects. Furthermore, etching is often an essential step in sample preparation for most other analytical techniques. For these reasons, the method of revealing defects, such as wet chemical etching, is an important step to characterize and study defects of materials. 
Etching can be defined quite simply as the removal of surface materials. The etchants used for revealing defects are called defect etches, which are divided into two types by Faust. ${ }^{(3)}$ The first type of etchants produces etch pits which are faceted and the surrounding surface does not necessarily have a polished finish (e.g., $\mathrm{KOH}$ and hydroxide eutectic $(\mathrm{KOH}+\mathrm{NaOH}))$. The faceted pit provides a means of orienting the surface by optical goniometry. The second type of defect etchants produces the dislocation etch pits which are not faceted and the surrounding surface is polished (e.g., A/B etch).

Besides the chemical etching methods, the defects can be revealed and investigated by other observational methods and spectroscopic measurements which include: optical microscopy, transmission electron microscopy (TEM), ${ }^{(4)-(7)}$ scanning electron microscopy (SEM)-cathodoluminescence, ${ }^{(6)-(9)}$ X-rays topography, $(8),(10)-(11)$ deep level transient spectroscopy (DLTS), ${ }^{(12)}$ infrared transmission microscopy, ${ }^{(13)}$ infrared light scattering topography, ${ }^{(14)}$ and so on.

The objective of an investigation of defects in the Vertical Gradient Freeze (VGF) grown GaAs single crystals is to concentrate on classifying and characterizing the defects of GaAs single crystal under wet chemical etching, with the observation of an optical microscope. The basic information on the crystallography of GaAs 
and its effects on the structures of defects is considered, with particular reference to the reactions of etching solution at the defects. The effect of the different dopants to etching performance is also considered, in which there exist distinct characteristics for the different doped materials. Meanwhile, various etchants for revealing defects are described and classified. Complex etch features resulting from the attack of particular etchants at substrate surfaces are interpreted in terms of defect structures. Correct surface treatment is necessary prior to the application of certain defect etches for their successful operation. 


\section{BACKGROUND}

\subsection{CRYSTALLOGRAPHY OF GaAs}

During chemical reaction controlled etching, the crystallography of the surface and the presence of strain or chemical inhomogeneities will locally affect the reaction or dissolution rate. III-V compounds show anisotropic etch rates.

GaAs belongs to the cubic non-centrosymmetrical space group F $\overline{4} 3 \mathrm{~m}$, i.e., it has the sphalerite (zincblende) structure (Fig.1). This is the same as the diamond structure except that two types of atoms are present: each Ga (group III) atom has four As (group V) atoms as nearest neighbors and vice versa. The III-V compound bonding is essentially covalent, with $\mathrm{sp}^{3}$ hybridized orbitals in tetrahedral array connecting the two atom species. The GaAs crystal structure can thus be considered as a network of $\langle 111\rangle$ direction bonds linking alternating $\mathrm{Ga}$ and As atoms in space. We shall adopt the convention introduced by Gatos and Lavine ${ }^{(15)}$ that group III atoms are designated as $\mathrm{A}$ atoms and group $\mathrm{V}$ atoms as $\mathrm{B}$ atoms.

Figure 2 shows the view of the GaAs crystal lattice along $\langle 112\rangle$. The atomic arrangement imposes a polarity on the lattice in all crystallographic directions except $\langle 100\rangle$ and $\langle 110\rangle$. This polarity is 


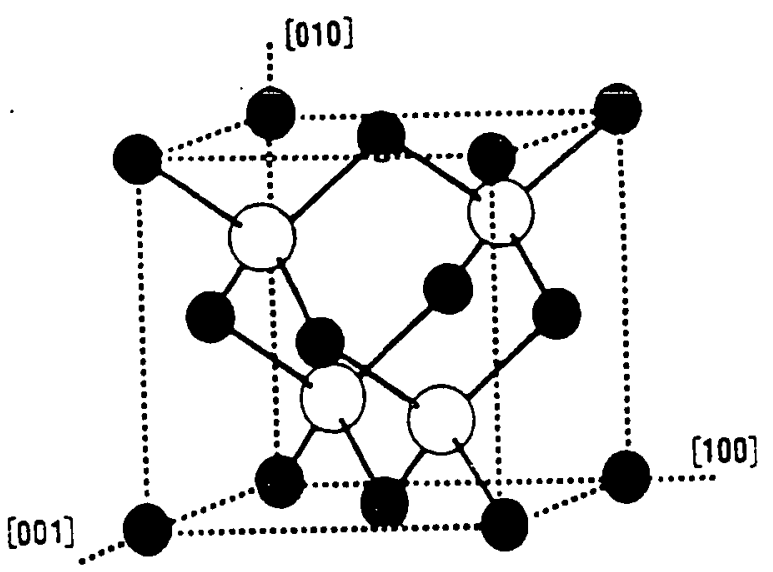

Figure 1. Unit cubic of GaAs crystal lattice. ${ }^{(1)}$

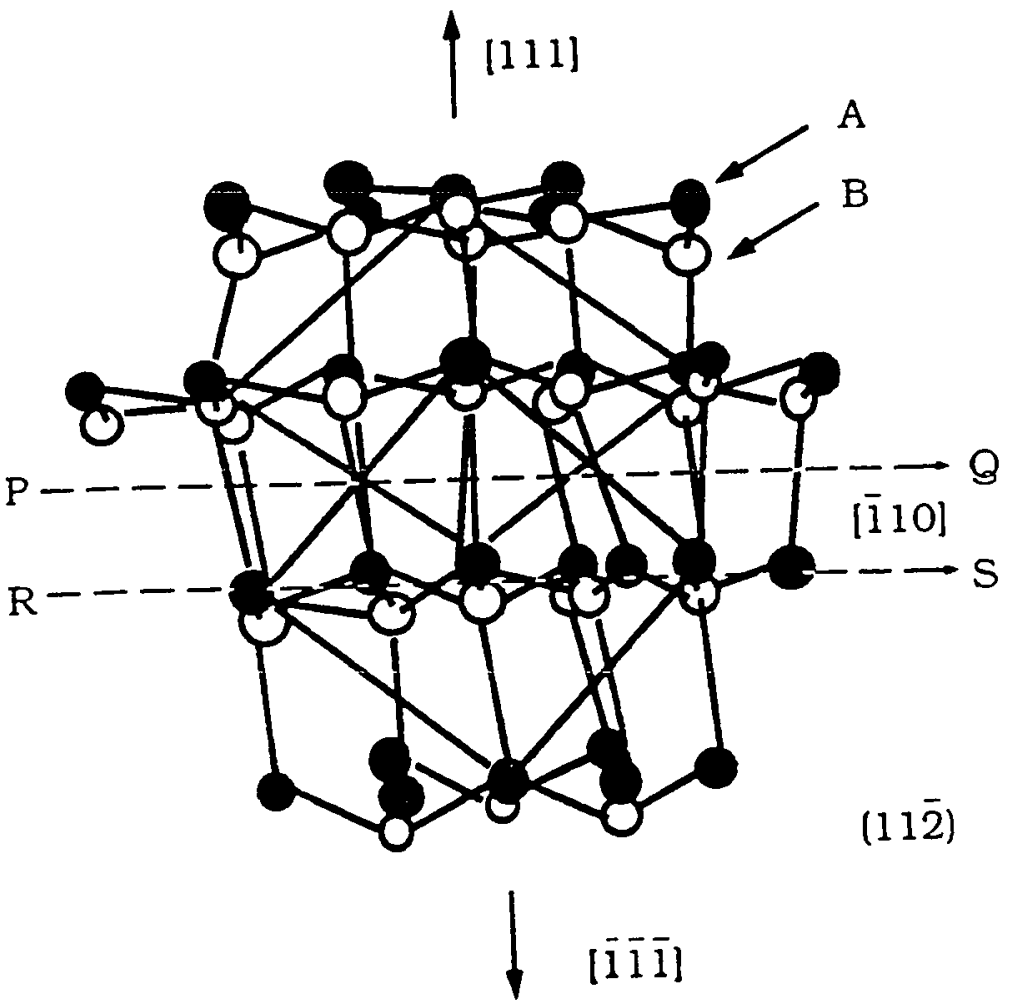

Figure 2. View of GaAs along [i12]; black sphere = Ga atoms (A type); white sphere $=$ As atoms $\left(B\right.$ type). ${ }^{(2)}$ 


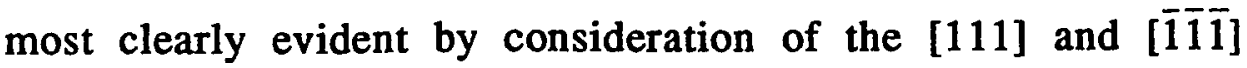
directions in the structure. Along the [111] direction the atoms

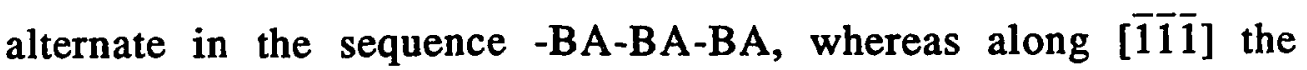

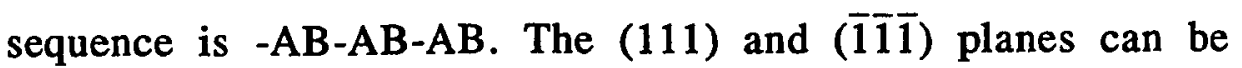
considered as double sheets of (BA) or ( $A B)$ atoms, with each atom triply bonded to its neighbors within the double sheet. The bonding between one double sheet and the next double sheet is a single bond per atom (see PQ on Fig.2), so that it is expected that (111) or (īi $\overline{1})$ surfaces will terminate at such positions. Surfaces formed by cutting along RS (Fig.2) would require three broken bonds per atom and are not expected to be stable. ${ }^{(15)}$ Thus the lack of a center of symmetry in the sphalerite structure manifests itself in the differing chemical

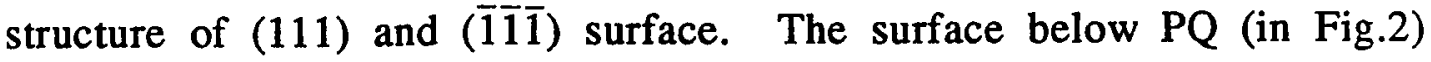
consists of $A(\mathrm{Ga})$ atoms and is specified as $\{111\} \mathrm{Ga}$ surface; surface above PQ consists of $B$ (As) atoms and is specified as $\{111\}$ As surface.

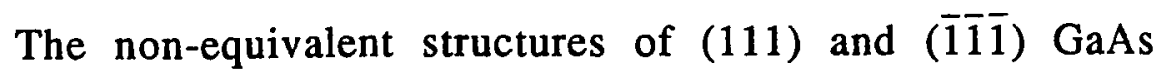
surfaces are revealed by their different behavior in a variety of etchants. White and Roth ${ }^{(16)}$ found that opposite faces of (111) GaAs slices were attacked differently in an etchant consisting of 2:1:2 $\mathrm{HCl}: \mathrm{HNO}_{3}: \mathrm{H}_{2} \mathrm{O}$. The A side gave many etch pits, whereas the opposite B side showed dark patches ( probably reaction products adhering the surface). By the X-rays diffraction analysis, White and Roth were able to establish that the $\mathrm{A}$ face ((111) face) corresponded with the 
the Ga-rich face, and the B face ((111) face) corresponded with the As-rich face.

\subsection{DEFECT STRUCTURE IN GaAs}

Defect structures in GaAs single crystal substrate can be classified as point defects, line defects, surface defects, volume defects, and work damage.

\subsubsection{Point Defects}

The most numerous defects expected to be present in GaAs single crystals are point defects. The compositional range for the sphalerite structure phase in GaAs extends from 49.998 to 50.009 at.\% As. This corresponds to concentrations of $4 \times 10^{18}$ As vacancies $\mathrm{cm}^{-3}$ and $2 \times 10^{19} \mathrm{Ga}$ vacancies $\mathrm{cm}^{-3}$, respectively, ${ }^{(17)}$ assuming that non-stoichiometry results in As vacancies or Ga vacancies only. Otherwise, antisite defects (native atomic disorders) are the most prominent and characteristic representatives of nature point defects in III-V compounds. Their concentration depends critically on the stoichiometry conditions during crystal growth. Typical $\mathrm{As}_{\mathrm{Ga}}$ anion antisite concentrations in LEC-grown bulk material are in the $10^{15}$ $10^{16} \mathrm{~cm}^{-3}$ range. ${ }^{(18)}$ The study of point defects is a current popular 
subject in the defect research of GaAs single crystals. It is beyond the scope of this project to discuss the variety of point defect types which have been proposed theoretically.

It is not possible to detect individual point defects by etching techniques. However, when a grown crystal is cooled from the growth temperature, it becomes supersaturated with vacancies. If there are no vacancy sinks available in the bulk, these vacancies may form clusters or aggregates which may be revealed by etching methods.

\subsubsection{Line Defects (dislocations)}

Dislocations that are active in a GaAs crystal under stress have Burger vectors of $(a / 2)<1 \overline{1} 0\rangle$ and glide along the $\{111\}$ planes. Dislocations in a crystal with sphalerite structure prefer to lie along $<110>$ directions for energetic reasons. ${ }^{(12)}$ So, most commonly observed dislocations in such a crystal are of the $60^{\circ}$ type or the screw type. Schematic pictures of atomic arrangements about a $60^{\circ}$ dislocation and a screw dislocation are shown in Fig.3. The core structure of a $60^{\circ}$ dislocation contains atoms with dangling or "broken" bonds and the [1ํㅣㄹ axis of dislocation lies along a set of identical type atoms in GaAs. Thus two forms can occur, as shown in Fig.4 at (a) and (b), depending on whether the broken bonds belong 


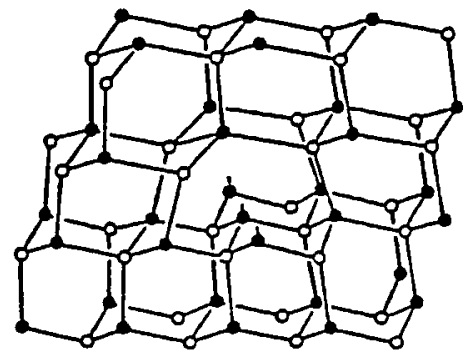

(a)

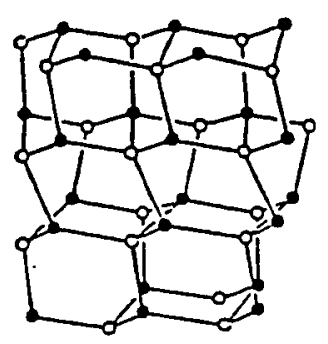

(b)

Figure 3. Schematic pictures of the atomic arrangements around shuffle set dislocations in a GaAs crystal. (a) a $60^{\circ}$ dislocation, (b) a screw dislocation. (12)

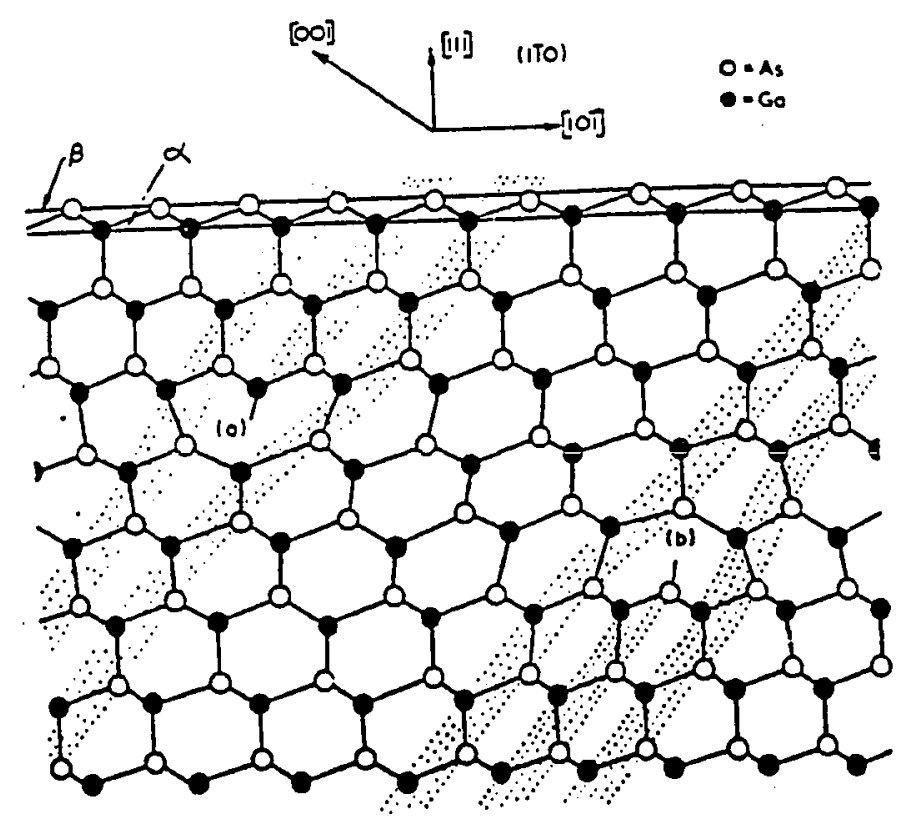

Figure 4. $60^{\circ}$ dislocations, at (a) and (b), in the GaAs lattice. ${ }^{(2)}$ 
to $\mathrm{Ga}$ or As atoms. Dislocation of Fig. 4 at (a) is called the $\alpha(\mathrm{Ga})$ dislocation and that of Fig.4 at (b) is the $\beta$ (As) dislocation. ${ }^{(19)}$ The dotted lines in Fig.4 represent a possible choice for the extra (double) half-planes of Ga-As atoms which make up the dislocations, and it can be seen that the $\alpha$ dislocation is a positive dislocation, whereas the $\beta$ dislocation is negative.

Dislocations described above are also called "shuffle" dislocations by Hirthe and Lothe, ${ }^{(20)}$ who named the two sets "shuffle" and "glide." Observations on dislocations in GaAs crystals by means of high resolution transmission electron microscopy have revealed that "glide" dislocations in GaAs crystals are dissociated into extended dislocations accompanying narrow strips of stacking faults between partial dislocations. ${ }^{(21)}$ Actual atomic arrangement around glide $60^{\circ}$ and screw dislocations that are dominant in a GaAs crystal may be those schematically shown in Fig.5. Dislocations of this type are "glide" dislocations. 


\section{2}

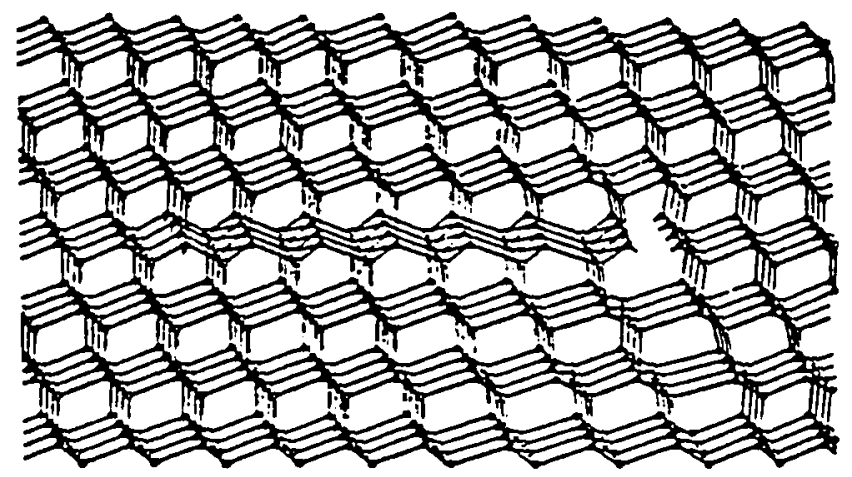

(a)

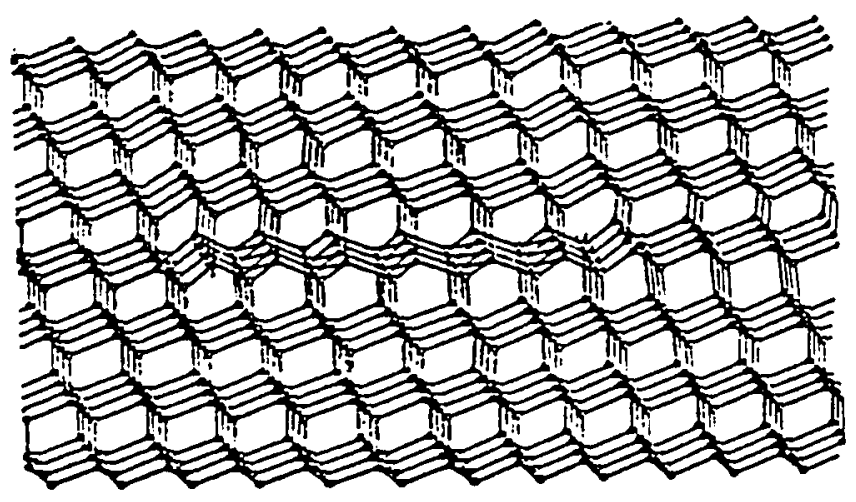

(b)

Figure 5. Schematic pictures of the atomic arrangements around glide set dislocations in a GaAs crystal. (a) a $60^{\circ}$ dislocation, (b) a screw dislocation. ${ }^{(21)}$ 


\subsubsection{Surface Defects (stacking faults)}

Stacking faults in the diamond lattice can be formed by the aggregation of pairs of vacancies, or pairs of interstitials, to result in either the removal of part of a double $\{111\}$ atom sheet or the insertion of an additional double $\{111\}$ sheet. The former produces intrinsic stacking faults; the latter, extrinsic stacking faults. Narrow strips of stacking faults between partial dislocations have been revealed in in GaAs crystal by high resolution TEM. ${ }^{(21)}$ A stacking fault in the sphalerite structure is defined at the narrow interatomic plane. Consequently, an interatomic plane has a higher density of interatomic bonds. The analysis of stacking faults is similar to that given above for dislocations and shows that in geometric terms two types of faults might be expected to exhibit differing chemical behavior (e.g. etching behavior), although no experimental evidence is known to support this view.

\subsubsection{Volume Defects}

\subsubsection{Precipitates}

Some investigations have dealt with the detection and analysis of precipitation phenomena in GaAs, covering a wide range of 
precipitate compositions and sizes ranging from hundreds of microns to a few angstroms. The detection method used for large precipitates has often been infrared transmission microscopy ${ }^{(13),(22)}$ or X-rays topography. (8),(23) The direct determination of the crystallographic structure of smaller precipitates usually involves TEM in conjunction with electron diffraction analyses. Comprehensive details of these techniques have been given by Hirsch et al. ${ }^{(24)}$

Eckhardt ${ }^{(25)}$ was one of the first authors to determine the composition of precipitates in as-grown undoped GaAs crystals by electron diffraction. The precipitates were $\alpha-\mathrm{Ga}_{2} \mathrm{O}_{3}$ crystallite formed by the reaction of GaAs with quartz containers used in the crystal growth process.

Detection by etching methods is not possible in all cases, owing to the lower resolution available. In general, etching reveals the locations of the precipitates but can not identify their compositions. Some works have shown that the impurity aggregates can be revealed by etching heavily Te-doped $\left(>10^{18} \mathrm{~cm}^{-3}\right)$ GaAs. As a result, two different shaped etching pits are exhibited. ${ }^{(23)}$ Massive triangular-shaped inclusions in both $\{111\} \mathrm{Ga}$ and $\{111\}$ As faces were found to be less soluble in various etchants, and hence, were elevated above the surrounding matrix. Electron probe X-ray microanalysis of the inclusions indicated that they were a Te-Ga 
complex. A second type showed numerous flat-bottomed saucershaped pit ("s-pits") after etching. These pits occurred at densities of about $10^{5}-10^{7} \mathrm{~cm}^{-2}$, with a maximum diameter of approximately 10 $\mu \mathrm{m}$, and were associated with micro-precipitates of $\mathrm{Te}$ (or $\mathrm{Te}-\mathrm{Ga}$ complex). Stirland et al. ${ }^{(2)}$ had found s-pits were formed by the A/B etchant in (001) GaAs crystals doped with $\mathrm{Te}$, Se or Si to approximately $10^{18} \mathrm{~cm}^{-3}$.

\subsubsection{Precipitates and Dislocations}

The stress field around certain types of dislocation can attract impurities to them. This causes an impurity atmosphere to be formed in the vicinity of the dislocations, and if the solubility limit is exceeded the impurity may precipitate out as a separate phase. The dislocations are said to be "decorated" by the impurity, and the effects are often observable by etching. Stirland et al. ${ }^{(2)}$ thought that the dislocations were acting as sinks for the impurities, and it was expected that the dislocations would show an increased impurity content at their cores. $\mathrm{He}$ and his co-workers have found that the impurity decoration of dislocations can be observed on (001) etched surface of Te-, Cr-, and Se-doped GaAs. 


\subsubsection{Growth Striations}

Another form of impurity aggregation can take place during the growth of crystals, and this form occurs as striations. These are a record of the shape and progress of the freezing interface during crystal growth. Coarse structure in pulled crystals matches the rotation and life rates during growth, but a fine structure is also present. Hurle ${ }^{(26)}$ has shown that when a melt is subjected to a temperature gradient, thermal oscillations are set up, and growth advances in a non-smooth fashion. Since growth striations represent a useful built-in record of the solid-liquid interface shape at any point on the crystal, they are widely employed in studying defects and inhomogeneities related to the interface shape.

The growth striations can be revealed by suitably selective etching. Miyazawa ${ }^{(27)}$ has described a chemical etching process for evaluating growth striations in an LEC-grown, undoped, semiinsulating GaAs bulk crystal.

\subsubsection{Work Damage (in processing)}

No precise definition of working damage can be given. It is probable that it includes many of the defects described previously, plus those defects produced in processing. 
Damage can be introduced in GaAs by cutting, lapping, chemical/mechanical polishing, scribing, tweezer handling, ion implantation and various device processes such as bonding of contacts, mounting and encapsulation.

It was always essential to remove preparation damage from GaAs substrates if they are subsequently to be used for epitaxial growth or assessment. In order to effect this removal economically, it was necessary to know the damage depth, which in general varied considerably with the procedures which have introduced the damage.

\subsection{DEFECT ETCH COMPOSITIONS}

Wet chemical etching is today's vital process not only in semiconductor defect analysis, but in all semiconductor processing from evaluation through pattern delineation for device production. Semiconductor etches can be classed as selective (also called preferential) or polishing. The defect etches usually belong to the selective etches. The ideal selective etches usually act upon a highly 
defective but mirror-like surface only at strain or chemical heterogeneities, such as dislocations and impurity striations.

Etches for GaAs are usually oxidizing solution in concentrations which prevent the deposition of arsenious oxide. ${ }^{(29)}$ Oxidation is essentially an electrochemical process in which localized anodic and cathodic area exist at the semiconductor surface. The $\mathrm{Ga}$ and $\mathrm{As}$ atoms go into solution at anodic sites on the surface. It follows that the more anodic an area the faster will be its dissolution and as a consequence an etch pit will form. The etching rate may bear some relationship to the defects present in the material, its crystallographic orientation and the surface finish. ${ }^{(28)}$ The action of etches in removing material is actually the same. One component of the etch oxidizes the surface while another complexes the oxidized species to make it soluble in the etching solution; a third agent is normally added as diluent.

The dissolution rate can be controlled by the diffusion of reactants to the semiconductor surface and the reaction products away from the surface. The activation energy for this diffusion controlled dissolution process is usually low and of the order ${ }^{(43)}$ of 5

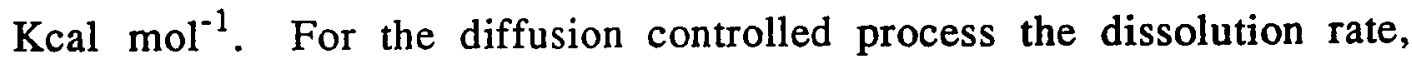
$\mathbf{d m} / \mathbf{d t}$, is equal to ${ }^{(62)}$

$$
\mathrm{dm} / \mathrm{dt}=\mathrm{DAC} / \delta
$$


where $\mathbf{D}$ is the diffusion coefficient of the diffusing species, $\mathbf{A}$ the area, $\mathbf{C}$ the concentration of the reacting species (the oxidizing agent in this case), and $\delta$ the effective thickness of the boundary (Nernst) layer. Slight variations in the etch composition or lowering the etch temperature can reduce the dissolution rate so that the etch becomes reaction rate controlled. ${ }^{(43)}$ In this case, the dissolution rate $(d m / d t)$ is $^{(62)}$

$$
\mathbf{d m} / \mathbf{d t}=\mathbf{k A C}
$$

where $\mathbf{k}$ is the reaction constant, $\mathbf{A}$ the area and $\mathbf{C}$ the concentration.

Because many of the etchants devised for revealing defects in GaAs contain an oxidizing agent, it is convenient to group the defect etches under the headings of the particular oxidizing reagents present in the solution.

\subsubsection{Nitric Acid}

Concentrated nitric acid will attack GaAs low-index surfaces, but it is unsuitable as a defect etchant because crystals of $\mathrm{As}_{2} \mathrm{O}_{3}$ precipitate over the surfaces. ${ }^{(29)}$ Dilute nitric acid does not suffer from this disadvantage because the $\mathrm{As}_{2} \mathrm{O}_{3}$ remains in solution. Stirland et al. ${ }^{(2)}$ suggested that alterations to the $\mathrm{HNO}_{3}: \mathrm{H}_{2} \mathrm{O}$ ratio do not affect the characteristic shapes of the $\{111\} \mathrm{Ga}$ etch pits, which consist of terraced triangular pyramids with sides parallel to $<110\rangle$ 
substrate directions, but that they do alter the etching times required to produce particular-sized etch pits at a constant temperature $\left(60^{\circ} \mathrm{c}\right)$.

Addition of hydrochloric acid alters the pit shapes. ${ }^{(30)}$ Their etchant consists of $2: 1: 2 \mathrm{HCl}: \mathrm{HNO}_{3}: \mathrm{H}_{2} \mathrm{O}$, which produced circular etch features on $\{111\} \mathrm{Ga}$ surface.

Richards and Crocker suggested that acidic oxidizing agents $\left(\mathrm{AgNO}_{3}\right)$ were too reactive to develop well-formed pits on $\{111\} \mathrm{As}$ surfaces. $^{(31)}$ They found that effective etch for both $\{111\} \mathrm{Ga}$ and \{111\}As surfaces could be obtained by using $\mathrm{Ag}$ ions (from $\mathrm{AgNO}_{3}$ solution) to inhibit the rapid attack of an $\mathrm{HNO}_{3}: \mathrm{HF}$ mixture. This etch produced triangular pits on $\{111\}$ As surfaces and circular pits on $\{111\} \mathrm{Ga}$ surfaces.

The growth striation was revealed by etching the Sn-doped GaAs specimens in 3:1:4 $\mathrm{HNO}_{3}: \mathrm{HF}: \mathrm{H}_{2} \mathrm{O}$. Also the same composition was used by Miyazawa to reveal growth striations in undoped, semiinsulating GaAs bulk crystal. ${ }^{(27)}$

\subsubsection{Sulphuric Acid}

The work of Iida and Ito dealing with a range of 
$\mathrm{H}_{2} \mathrm{SO}_{4}: \mathrm{H}_{2} \mathrm{O}_{2}: \mathrm{H}_{2} \mathrm{O}$ compositions showed that, although large regions of the compositional "phase diagram" give good polish finishing, compositions with high $\mathrm{H}_{2} \mathrm{O}$ proportions produced cloudy surfaces. ${ }^{(32)}$ They suggested that this cloudiness was due to the formation of small pits which may have been influenced by crystalline defects in the substrates. Stirland et al. have found that a $3: 1: 1 \mathrm{H}_{2} \mathrm{SO}_{4}: \mathrm{H}_{2} \mathrm{O}_{2}: \mathrm{H}_{2} \mathrm{O}$ composition will produce etch pits on the $\{111\} \mathrm{Ga}$ face. ${ }^{(2)}$ The $3: 1: 1$ etch composition is normally used as an etch polish, especially for (001) surface. However, some defect features are present under effects of illumination of sample surface on the etching action of solution. Kuhn-Kuhenfeld has found that intense local illumination can entirely alter the way in which $3: 1: 1 \mathrm{H}_{2} \mathrm{SO}_{4}: \mathrm{H}_{2} \mathrm{O}_{2}: \mathrm{H}_{2} \mathrm{O}$ attacks (001) surfaces. $^{(33)} \mathrm{He}$ was able to reveal dislocations, striations and precipitates with excellent resolution, even in undoped or semiinsulating samples.

\subsubsection{Chromium Trioxide}

The most widely used defect etch for (001) GaAs surface is that due to Abrahams and Buiocchi, commonly referred to as the $A / B$

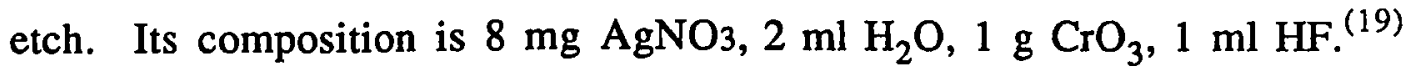
This etch can be used to etch all low-index crystallographic faces. Both $\alpha(\mathrm{Ga})$ and $\beta$ (As) dislocations (Section 2.2.2) could be revealed at $\{111\}$ surfaces. The $A / B$ etch can also reveal striations and 
stacking faults on (001) surfaces. Stirland et al. ${ }^{(2)}$ have found that $s$ pits are formed by the A/B etchant in Te-, Se- and Si-doped GaAs, and that the $\mathrm{A} / \mathrm{B}$ etchant can produce characteristic etch pits ("boat pits") at working damaged area of (001) substrates. Brown and Warwick have found that grooved etch features and ridges are produced at dislocation when (001) substrates of undoped semiinsulating GaAs are etched in $\mathrm{A} / \mathrm{B}$ etchant, and that the different etch rates exist on these areas. ${ }^{(6)}$

The Sirtl etch, a mixture of chromic acid and hydrofluoric acid, has been used for revealing the defects of GaAs. ${ }^{(34)}$ Meieran used the Sirtl etch to delineate striations on $\{111\} \mathrm{Ga}$ and $\{111\}$ As faces after a 2 minute application. ${ }^{(35)}$ Olsen et al. found that the Sirtl etch produced rectangular hillocks on (001) and $(00 \overline{1})$ GaAs surfaces. ${ }^{(36)}$ They argued that the directions given by the unequal sides of hillocks, which lay parallel to [110] and [1ํㅣ directions, could be used to distinguish between these two directions on the (001) plane.

Cardwell and Stirland developed an etchant for (001) GaAs surfaces which consisted of 3:3:1 $\mathrm{CrO}_{3}: \mathrm{HF}: \mathrm{HNO}_{3}{ }^{(37)}$ This etchant produced approximately circular etch hillocks at emergent dislocations. 


\subsubsection{Potassium Hydroxide}

The etch is a single component etchant consisting of molten $\mathrm{KOH}$ maintained at $300^{\circ} \mathrm{c}$. Immersion for 2-3 minutes was sufficient to develop etch pits on $\{111\} G a,\{111\} A s$ and $\{001\}$ surfaces. The characteristically shaped six-sided pits are elongated along one of the $<110>$ directions in the (001) surface. Subsequently etch temperatures of $450^{\circ} \mathrm{c}$ have also been used. ${ }^{(38)}$

A pre-etch polish should be given in bromine-methanol or bromine-acetic acid mixtures for $\mathrm{KOH}$ etching. Other pre-etch polishes such as $3: 1: 1 \quad \mathrm{H}_{2} \mathrm{SO}_{4}: \mathrm{H}_{2} \mathrm{O}_{2}: \mathrm{H}_{2} \mathrm{O}$ consistently inhibited the action of the molten $\mathrm{KOH}^{(2)}$

Recently a new eutectic etchant (1:1 KOH: $\mathrm{NaOH})$ has been developed to reveal defects in GaAs for evaluating the wafer quality. ${ }^{(39)}$ The etched surface shows additional distinct patterns other than the features formed by the commonly used molten $\mathrm{KOH}$ etchant. The pyramid and rectangular-shaped patterns are revealed by the eutectic etchant. ${ }^{(40)-(41)}$ Surface roughness was observed in In-, B-, or Si-doped crystals, while the surface of undoped crystals was found to be smooth. ${ }^{(40)}$ Specially mentioned here, antiphase domains have been observed in single crystal GaAs using the eutectic etch. $^{(42)}$ 


\section{EXPERIMENTAL}

\subsection{SAMPLE PREPARATION}

The GaAs single crystals used in this study included undoped and $\mathrm{Cr}$-doped semi-insulating (SI), Si-doped " $n$ " type, and Zn-doped "p" type semi-conducting (SC) grown in $<100\rangle$ direction by the Vertical Gradient Freeze (VGF) method. This new growth method has the advantages of simple technique, low costs, and low dislocation density (low etch pit density). Those 2" GaAs crystal ingots were cut to approximate 20 mil. slices along the different crystallographic orientations. The crystallographic surfaces include the most common low-index orientation surfaces such as $\{100\},\{110\},\{111\}$ As and $\{111\} \mathrm{Ga}$ faces.

The experimental etching specimens for the study were included: high purity undoped SI and $\mathrm{Cr}$-doped SI GaAs single crystals which have $>10^{7} \Omega-\mathrm{cm}$ resistivity, the Si-doped crystals with carrier concentrations range from $10^{16}-10^{18} \mathrm{~cm}^{-3}$, and the $\mathrm{Zn}$-doped crystal has $\mathrm{Zn}$ concentration of $>10^{19} \mathrm{~cm}^{-3}$. 


\subsection{SAMPLE POLISHING}

It is necessary to remove superficial work damage before employing defect etchants to reveal the intrinsic defect content of a sample. Usually work damage will be removed by a pre-defect etch treatment, which essentially will be a polish etch (free Etch). Unfortunately, there is evidence that some of the pre-etch treatments affect the performance of the subsequent defect etchants revealing defects. It has been mentioned (Section 2.3.4) that a molten $\mathrm{KOH}$ etch did not operate successfully on (001) surfaces which had been pre-treated in 3:1:1 $\mathrm{H}_{2} \mathrm{SO}_{4}: \mathrm{H}_{2} \mathrm{O}_{2}: \mathrm{H}_{2} \mathrm{O}$ or in solutions containing $\mathrm{HNO}_{3}{ }^{(2)}$

The specimens of this objective were, generally, polished by a mechano-chemical (MC) polishing method consisting of $10 \%$ brominemethanol solution for all low-index orientations with the exception of the $\{111\} \mathrm{Ga}$ surface. Prior to bromine-methanol $\left(\mathrm{Br}_{2}-\mathrm{CH}_{3} \mathrm{OH}\right) \mathrm{MC}$ polishing, the surfaces of samples were first lapped by alumina powder removing 50-100 $\mu \mathrm{m}$ thickness, and then cleaned in water. After bromine-methanol MC polishing, the surfaces of samples were removed 25-50 $\mu \mathrm{m}$ and were mirror-like. Afterwards the polished samples were successively rinsed in deionized water and dipped in methanol $\left(\mathrm{CH}_{3} \mathrm{OH}\right)$. Residual surface damage of the specimens, except those samples for $\mathrm{KOH}$ etching, was removed by use of a polishing 
etchant composed of $4: 1: 1 \mathrm{H}_{2} \mathrm{SO}_{4}: \mathrm{H}_{2} \mathrm{O}_{2}: \mathrm{H}_{2} \mathrm{O}$ for 5-10 minutes at a temperature of $45^{\circ} \mathrm{c}$. The etched samples were dried in a nitrogen gas flow and stored for the next etching steps.

The $\{111\} \mathrm{Ga}$ faces cannot be polished to mirror-like surface by bromine-methanol MC polishing; the $\{111\} \mathrm{Ga}$ surfaces were opaque and rough after $\mathrm{Br}_{2}-\mathrm{CH}_{3} \mathrm{OH} \mathrm{MC}$ polishing. Regarding the difference in the etching behavior between the $\{111\}$ As planes and $\{111\} \mathrm{Ga}$ planes, it has been proposed that the $\{111\}$ As planes are quite reactive chemically because of having an unshared pair of electrons, whereas the $\{111\} \mathrm{Ga}$ planes are not so reative. ${ }^{(43)}$ Dyment and Rozgonyi, also have discussed limitations of the bromine-methanol procedure; firstly it is unable to polish the $\{111\} \mathrm{Ga}$ face nonpreferentially, and secondly its comparatively rapid ageing characteristics result in non-reproducible polishing rates with time. ${ }^{(44)}$ My procedure was primary MC polishing by using a mixture of $5 \% \mathrm{Br}_{2}-\mathrm{CH}_{3} \mathrm{OH}$ and $3.0 \mu \mathrm{m}$ alumina powders, and then final mechanical polishing by using $1.0 \mu \mathrm{m}$ diamond paste. After polishing, the mirror-like surfaces with some scratches were obtained which were good enough for defect etching requirement and etched sample analysis. 


\subsection{SAMPLE ETCHING PROCESS}

According to the literature research, four kinds of popular and useful etching methods were chosen for this project which were $A / B$ etching, 3:1:1 $\mathrm{H}_{2} \mathrm{SO}_{4}: \mathrm{H}_{2} \mathrm{O}_{2}: \mathrm{H}_{2} \mathrm{O}$ photo-etching, $\mathrm{KOH}$ etching and eutectic etching (1:1 KOH:NaOH). The etching processes are described as follows:

\subsection{1. $\mathrm{A} / \mathrm{B}$ etching}

The A/B etchant consists of a solution of $2 \mathrm{ml} \mathrm{H}_{2} \mathrm{O}, 8 \mathrm{mg} \mathrm{AgNO}_{3}$, $1 \mathrm{~g} \mathrm{CrO}_{3}$, and $1 \mathrm{ml} \mathrm{HF}{ }^{(19)}$ The components of solution are added in the order listed; if the order is changed, difficulty is experienced in dissolving all the $\mathrm{AgON}_{3}$. After a preliminary polish in 3:1:1 $\mathrm{H}_{2} \mathrm{SO}_{4}: \mathrm{H}_{2} \mathrm{O}_{2}: \mathrm{H}_{2} \mathrm{O}$ to remove any superficial work damage, the specimens were etched in fresh $\mathrm{A} / \mathrm{B}$ solution at room temperature for 5 minutes with constant solution agitation. Because a precipitate $\left(\mathrm{Ag}_{2} \mathrm{CrO}_{4}\right)$ formed ${ }^{(19)}$ as the reaction proceeded, the stirring led to a uniform attack of the specimen surface. After etching, the specimens were immediately cleaned in flow water, and then dipped in methanol to remove the water. 


\subsubsection{Photo-etching 3:1:1 $\mathrm{H}_{2} \mathrm{SO}_{4}: \mathrm{H}_{2} \mathrm{O}_{2}: \mathrm{H}_{2} \mathrm{O}$}

Polished samples gripped by the plastic clips were put into a $500 \mathrm{ml}$ glass beaker filled with the $3: 1: 1 \mathrm{H}_{2} \mathrm{SO}_{4}: \mathrm{H}_{2} \mathrm{O}_{2}: \mathrm{H}_{2} \mathrm{O}$ solution, where the light of the illuminator (650W DXK lamp) could illuminate onto the sample surfaces. After 5 minutes illumination the samples were immediately taken from the beaker, cleaned in flow water and dipped in methanol.

Short etch and exposure times of typically 5 minutes were sufficient for maximum resolution. It did not matter if the GaAs sample was kept in the etchant for a limited time before exposure, but it was quite important that the etching action be stopped at the same time as the illumination. ${ }^{(33)}$

\subsection{3. $\mathrm{KOH}$ etching}

The polished samples were first put into a platinum basket, which is convenient for sample taking from the molten $\mathrm{KOH}$, and then the basket with samples was put into a Ni crucible. After filling the solid KOH etchant into the crucible and making sure that the samples could be immersed in molten $\mathrm{KOH}$, the crucible was heated to $400^{\circ} \mathrm{c}$ and maintained at this temperature for 5 minutes. Then the samples 
were removed from etchant, cooled to room temperature, and rinsed in flow water.

In the original formulation by Grabmaier and Watson ${ }^{(45)}$ an etch temperature of $300^{\circ} \mathrm{c}$ and a time of $2-3$ minutes were suggested; subsequently etch temperatures of $450^{\circ} \mathrm{c}^{(38)}$ have also been used. For this particular etching experiment, an etch temperature of about $400^{\circ} \mathrm{c}$ and time of approximately 5 minutes were employed, and satisfactory etching results were obtained.

\subsubsection{Eutectic etching $(\mathrm{KOH}+\mathrm{NaOH})$}

The etching procedure was similar to that of $\mathrm{KOH}$ etching. The polished samples were etched with an eutectic etchant $(\mathrm{KOH}: \mathrm{NaOH}$ 1:1) for 30 minutes at $350^{\circ} \mathrm{c}$.

The appendix in this thesis lists the material safety data for some etching chemicals used in this work. It is offered solely for your consideration, investigation, and verification. 
For the purpose of this project, several groups of experiments were designed and done depending to the crystallographic orientation and the growth conditions with the different etching methods. All the etched samples of GaAs single crystal were summarized in Table 1.

The etched surfaces were examined using optical Nomarski microscopy. A large numbers of pictures were taken by the microscope camera. 


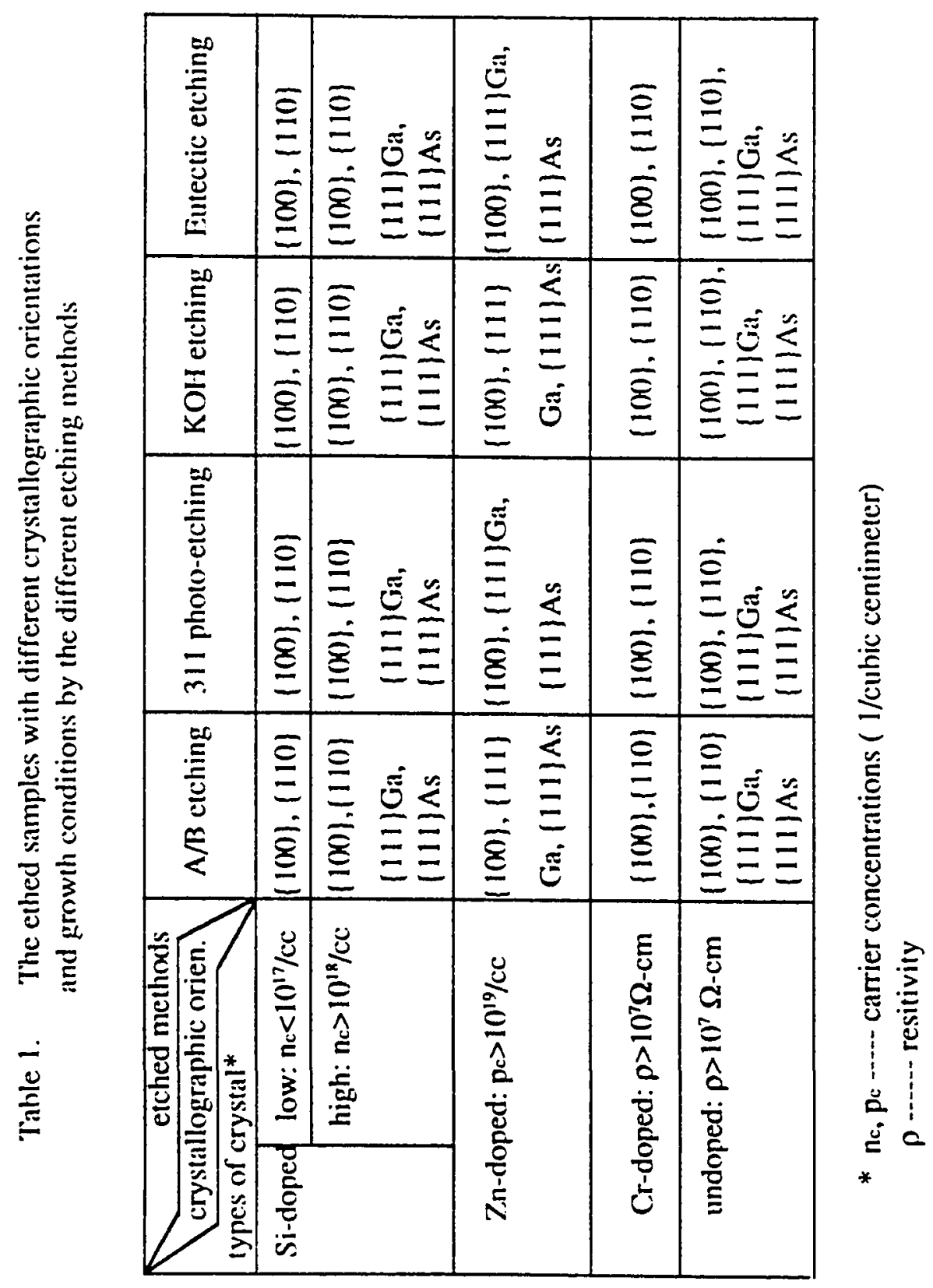




\section{RESULTS AND DISCUSSION}

This chapter sets experimental results and discusses the characteristic features of the etched surfaces of the specimen (e.g. etch pits), depending on the different defect etching methods.

\subsection{A/B ETCHING}

The etchant selectively attacks dislocations on $\{100\},\{110\}$ and also the $\{111\} \mathrm{Ga}$ and $\{111\}$ As faces of GaAs. The striking feature of this etchant is that in addition to producing pits at emergent dislocations, the dislocation lines themselves are also made visible on these faces.

The A/B etchant produced lines (largely parallel to $<110>$ directions) or etching "tails." The lines were assumed to be dislocations nearly parallel to the surfaces. The tails consisted of strings of overlapping pits of increasing diameters and were believed to be due to dislocations inclined to the surfaces, impurity segregation having caused enhanced local attack and pit formation along the dislocations. 


\subsection{1. $\{100\}$ Surface}

Typical microstructures of the $\{100\}$ GaAs faces are in Fig.6. Dislocations nearly normal to $\{100\}$ are revealed as oval etch pits or hillocks (Fig.6 (a) and (c)) or conical etch pits or hillocks (Fig.6 (c)). The orientation of the dislocation is indicated by the absence of tailing in the proximity of the etch hillocks. The typical sizes of etch pits or hillocks are 2-8 $\mu \mathrm{m}$ in one dimension. Average etched thickness of one side is $13-14 \mu \mathrm{m}$ after 5-minute etching, and etching rates are approximately linear. Since dislocation axes ${ }^{(46)}$ in the zincblende structure are parallel to $\langle 110\rangle,\langle 112\rangle$, or $\langle 100\rangle$, it appears the present axes are parallel to $\langle 100\rangle$. Examples of inclined and parallel dislocations on etched surfaces are shown in Fig.6 (c) and Fig.7, in which relatively long dislocation segments lying in a $\{100\}$ plane are seen.

Other features are also produced at dislocations when $\{100\}$ surfaces of undoped or $\mathrm{Cr}$-doped $\mathrm{GaAs}$ are etched in the $\mathrm{A} / \mathrm{B}$ etch. These features include grooves (G), and ridges (R) (Fig.8). Brown and Warwick ${ }^{(47)}$ have shown that a groove corresponds to a dislocation surrounded by a matrix with a relatively slower etch rate, whereas a ridge corresponds to a dislocation surrounded by a matrix with a 


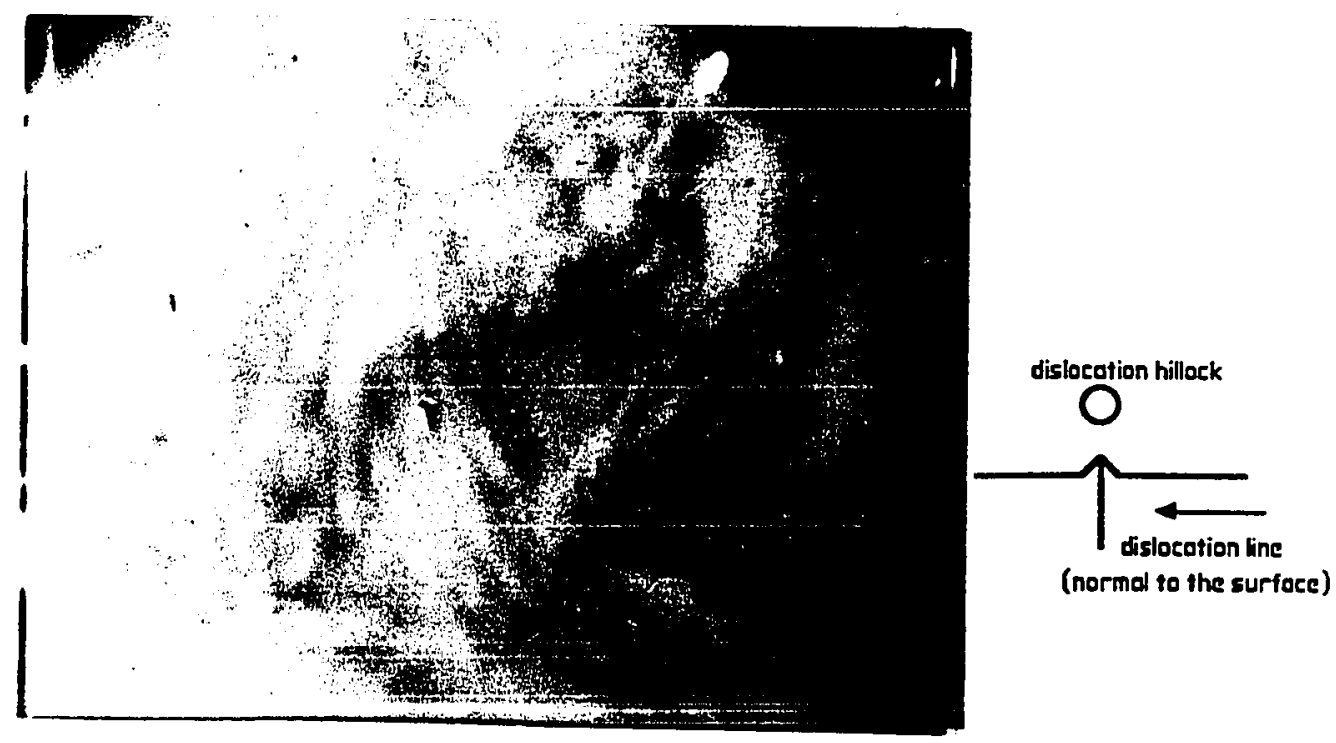

Figure 6. (a)

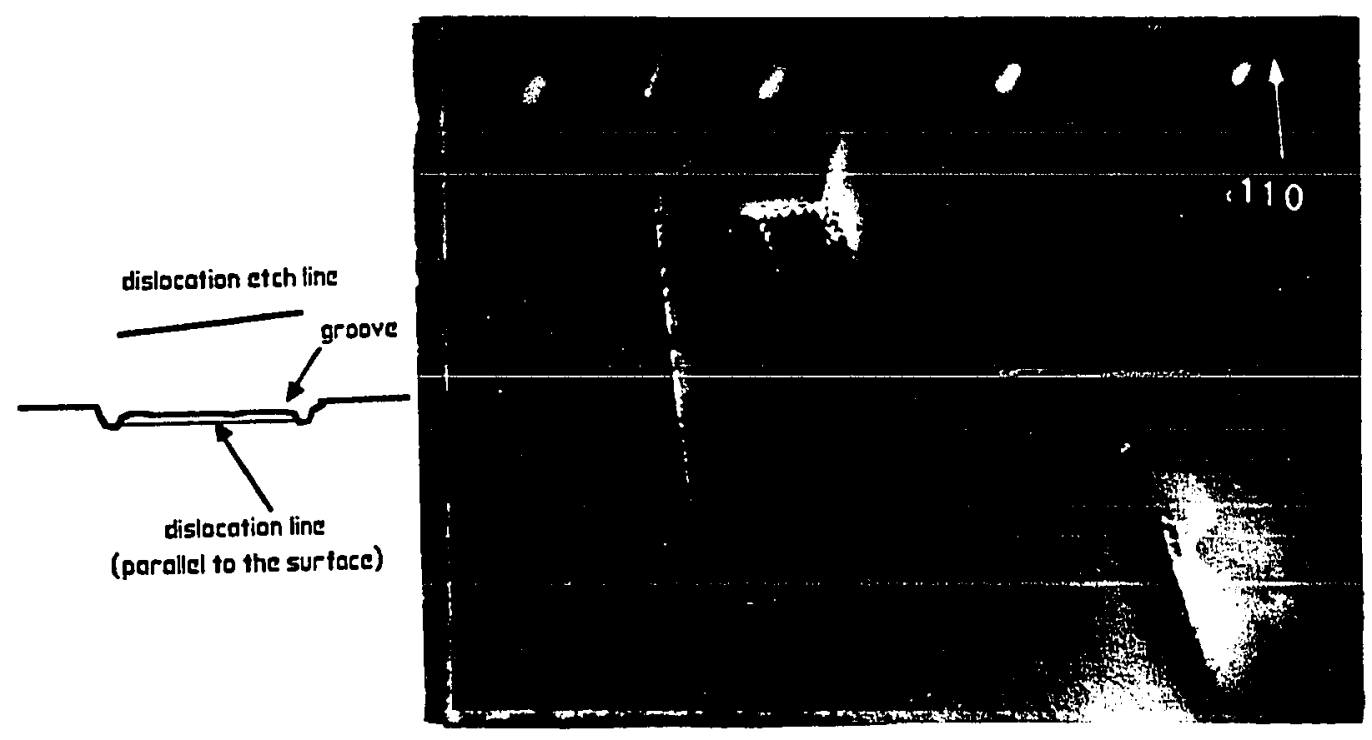

Figure 6. (b) 


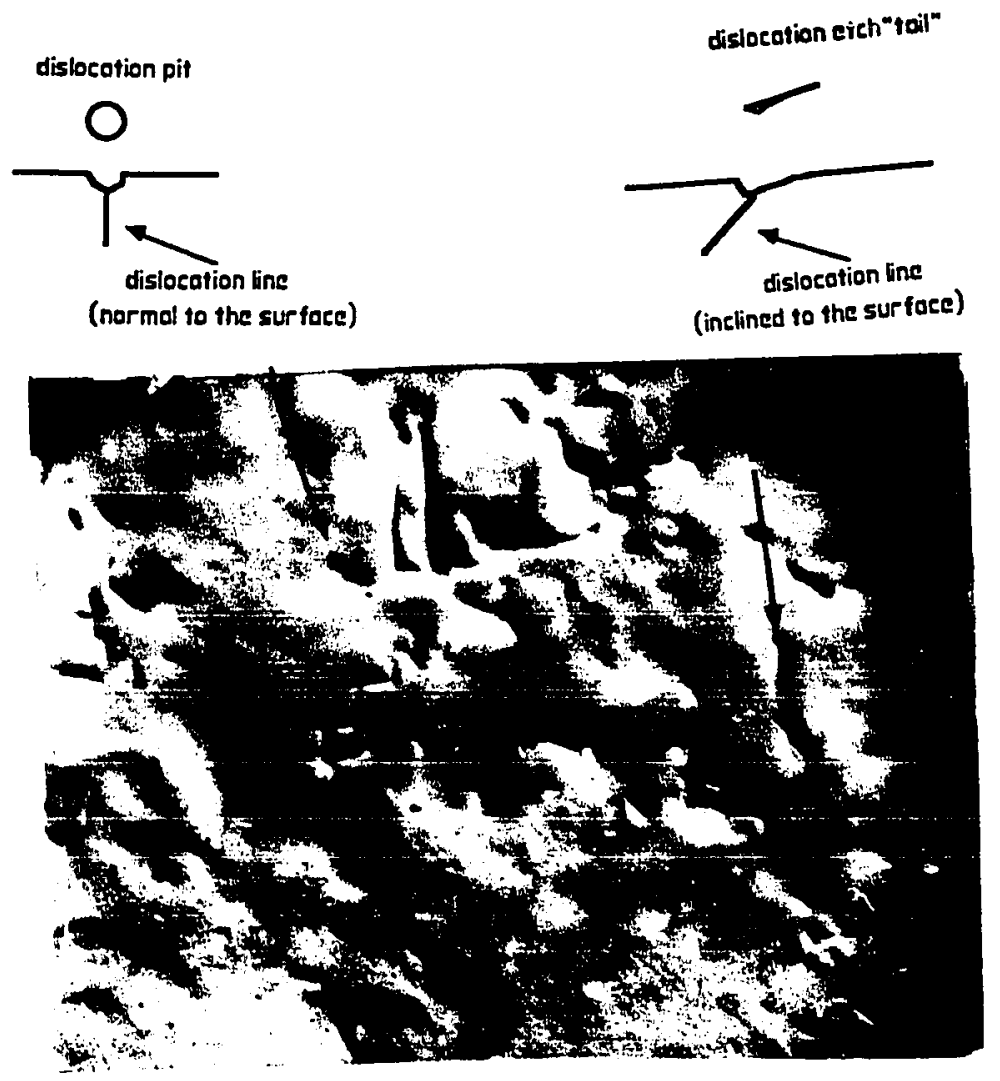

Figure 6. (c)

Figure 6. Typical microstructures on the $\{100\}$ surfaces by A/B elching. (a). Dislocations are nearly normal to $\{100\}$ surface (oval hillocks), Sidoped, 500X. (b). Dislocation lines decorated precipitates, Cr-doped, 100X. (c) Etched surfaces with different microstructures, undoped, 100X. 


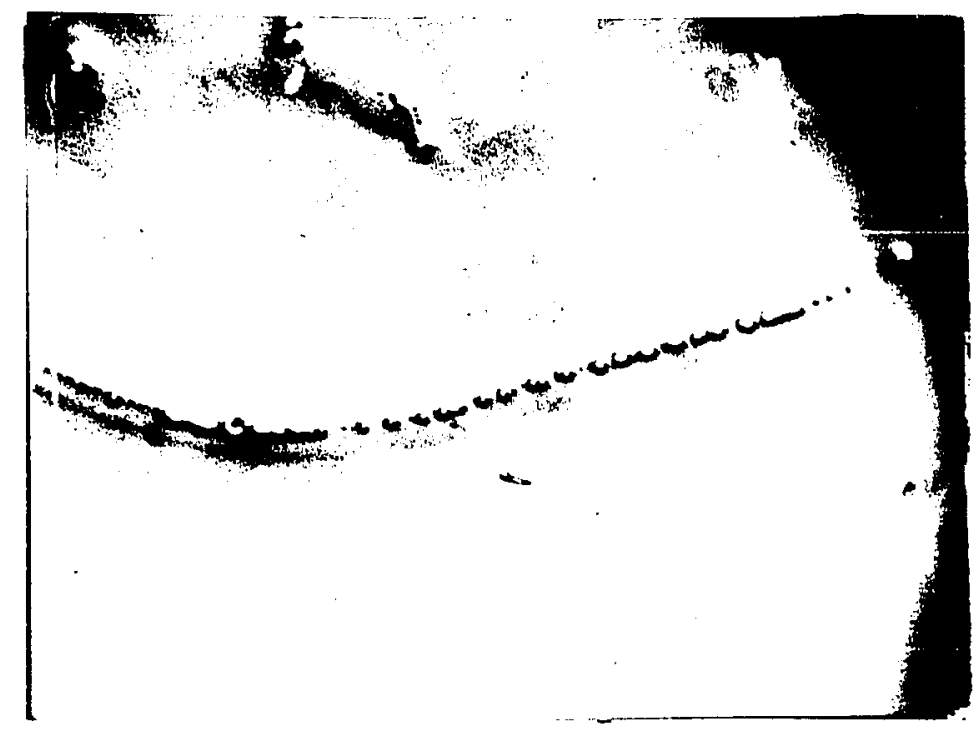

36

Figure 7. (a)

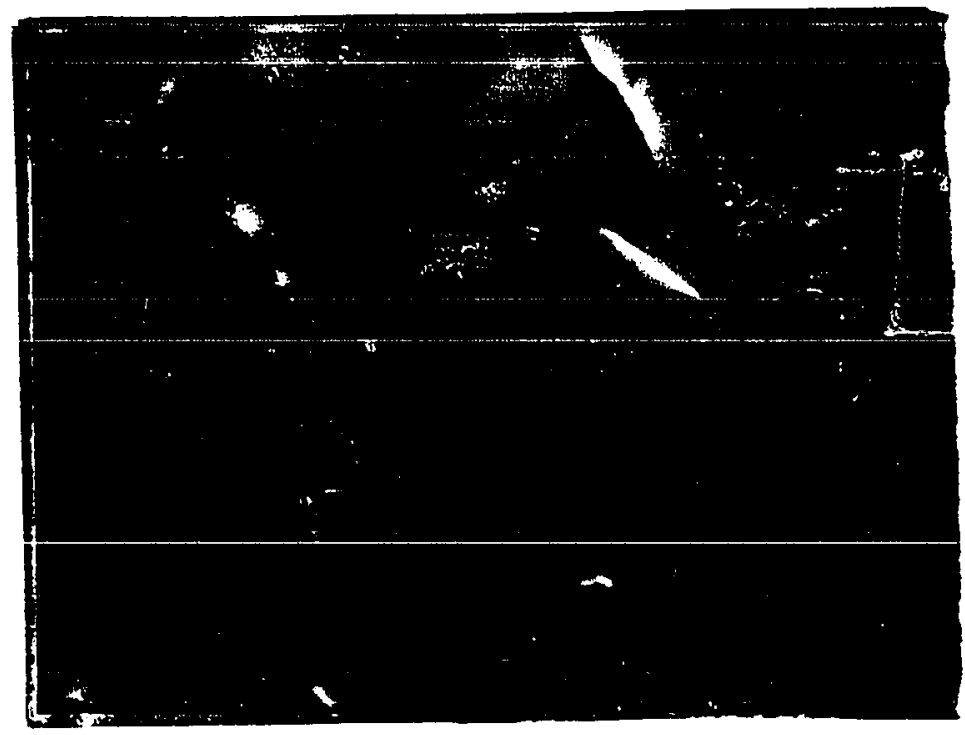

Figure 7. (b)

Figure 7. Dislocation etch structures due to dislocations parallel to or inclined to the surfaces. (a) A dislocation line due to dislocation parallel to the surface, Si-doped, 200X. (b). parallel and inclined dislocations, undoped, $200 \mathrm{X}$. 

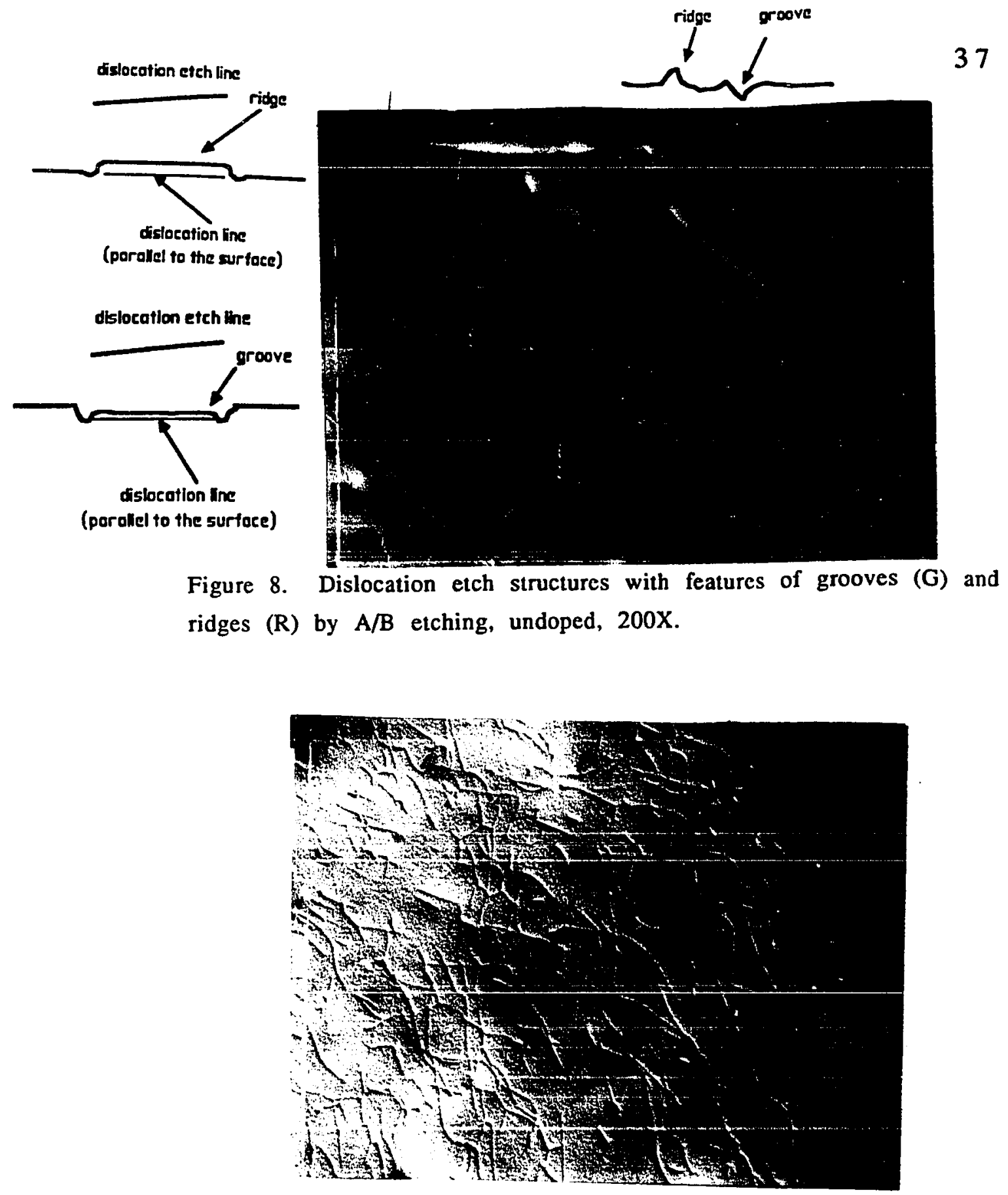

Figure 9. Polygonized dislocation arrays --- lineage by $A / B$ etching, Sidoped, $200 \mathrm{X}$. 
high etch rate. These areas of different etch rate are shown by scanning electron microscopy in the wavelength dispersive cathodoluminescence mode (SEM-WDCL) to correspond to areas with slightly different Fermi levels $\left(E_{f}\right)$ from average Fermi level of GaAs $\left(E_{f}-E_{v} \cong 1.0 \mathrm{eV}\right) .{ }^{(47)}$

Figure 8 shows Nomarski micrographs of typical groove features and typical ridge features. The grooves are decorated with small pits about $5 \mu \mathrm{m}$ apart, while the ridges are mostly undecorated. Noggle et al. used stereo transmission X-ray topography to establish the volumetric dislocation distribution. ${ }^{(48)}$ The Method was further used on the GaAs single crystals with $A / B$ etching; the results of experiments showed that the $\mathrm{A} / \mathrm{B}$ etchant was to produce ridges about $1-5 \mu \mathrm{m}$ high at dislocation lines (the ridges were seen as black/white lines on interference contrast micrographs). The etch ridges remained even after over $40 \mu \mathrm{m}$ of additional material had been etched away. ${ }^{(49)}$ Stirland and Ogden called this effect a dislocation "etch memory," because the ridges represented dislocation lines which no longer existed.

Dislocations in undoped and Cr-doped SI GaAs are often decorated with small As precipitates, ${ }^{(50),(51)}$ and these produce small etch pits on A/B etching ( Figs. 7,8). 
Figure 9 shows the polygonized dislocation arrays called "lineage" on the Si-doped $\left(n_{c} \cong 10^{17}\right)$ samples. The similar arrays are found in undoped and Cr-doped SI GaAs crystals.

\subsection{2. $\{110\}$. Surface}

Dislocations lying in the $\{110\}$ plane of undoped and $\mathrm{Cr}$-doped SI samples are shown in Fig.10. The features of etch structures are similar to those on the $\{100\}$ plane. The long dislocation lines are revealed when the dislocations lie parallel to the $\{110\}$ surface, while the conical etch pits or hillocks on the $\{110\}$ face indicate the dislocations are perpendicular to the surfaces. The etch pits with tails, which are due to inclined dislocations, have also been observed.

Figures 11 and 10 (a) show growth striation of Si-doped and undoped samples; the wide diffuse vertical bands are due to the impurity addition and are a record of the shape and progress of the freezing interface during crystal growth. Hurle ${ }^{(52)}$ has shown that when a melt is subjected to a temperature gradient, thermal oscillations are set up, and growth advances in a non-smooth fashion. The reason for this is that convection currents present in the melt bring alternatively cooler and hotter material to the interface. As a consequence, when each growth step is momentarily checked there is change in the amount of impurity or dopant incorporated in the 


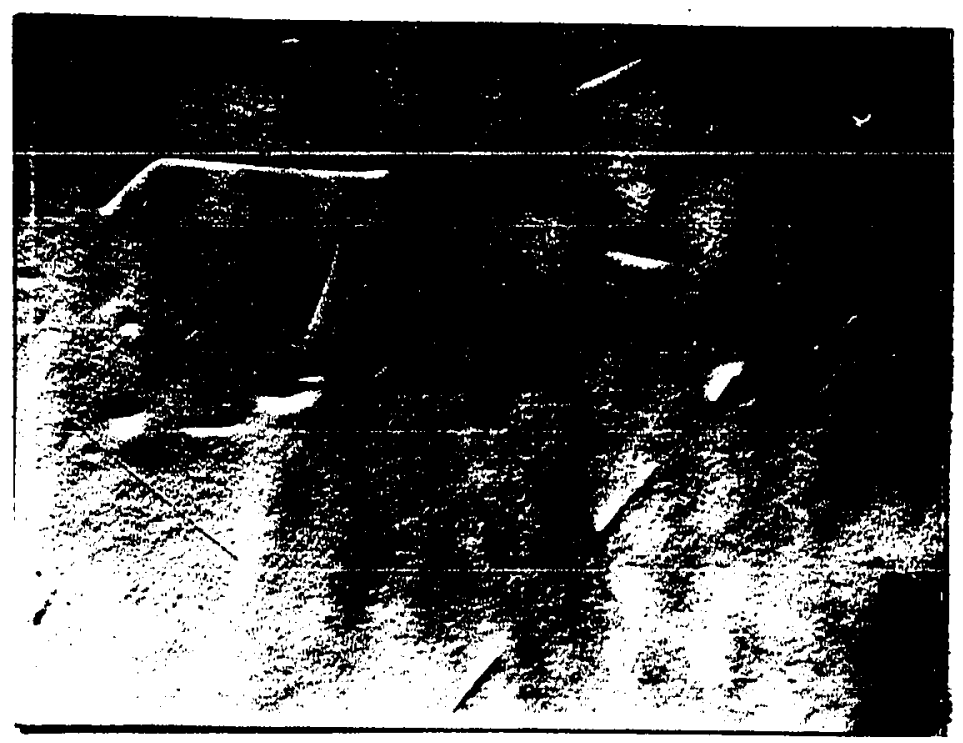

Figure 10. (a)

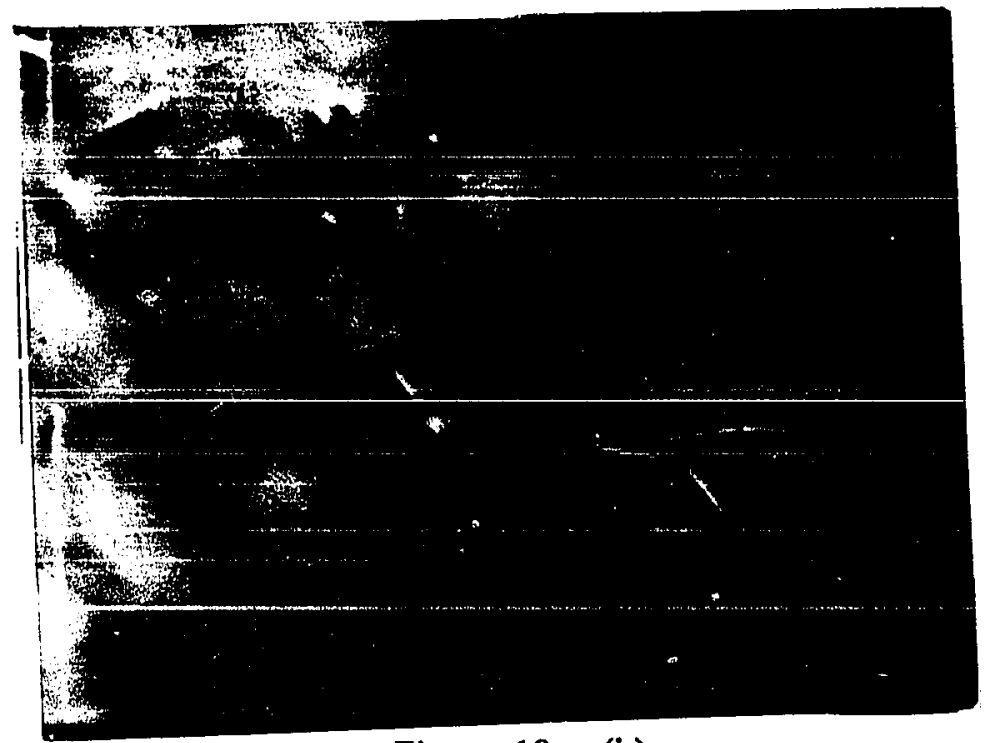

Figure 10. (b)

Figure 10. Typical etch structures on $\{110\}$ surfaces by $A / B$ etching. (a). undoped sample, 100X. (b). Cr-doped sample, 100X. 


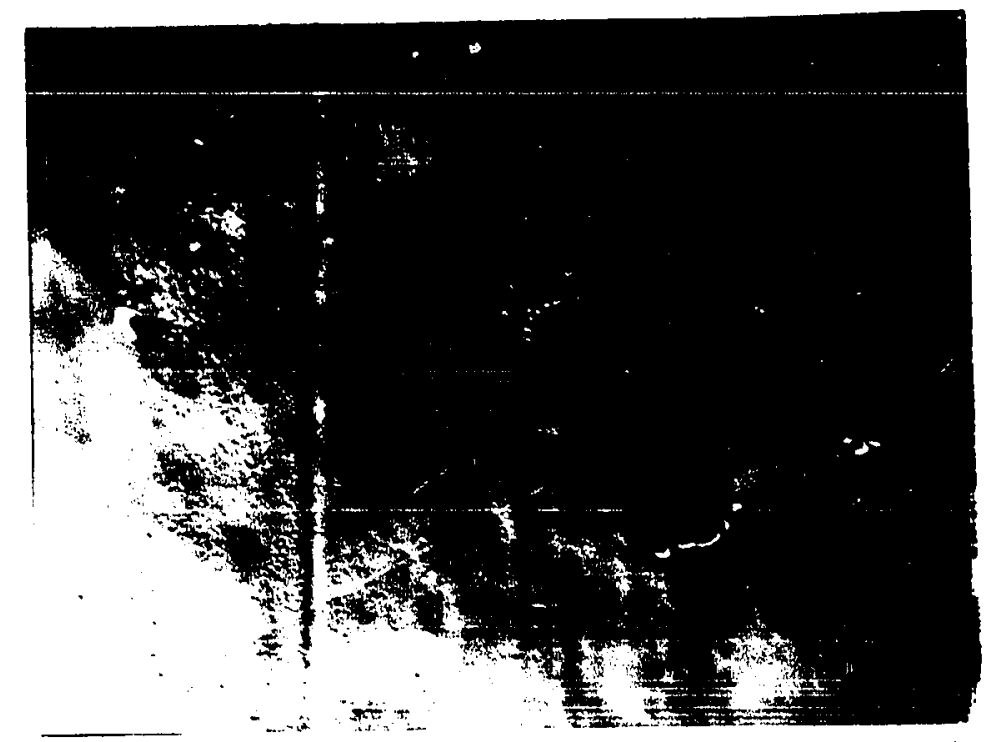

Figure 11. Growth striations on $\{110\}$ surfaces by A/B etching, Si-doped, $100 \mathrm{X}$.

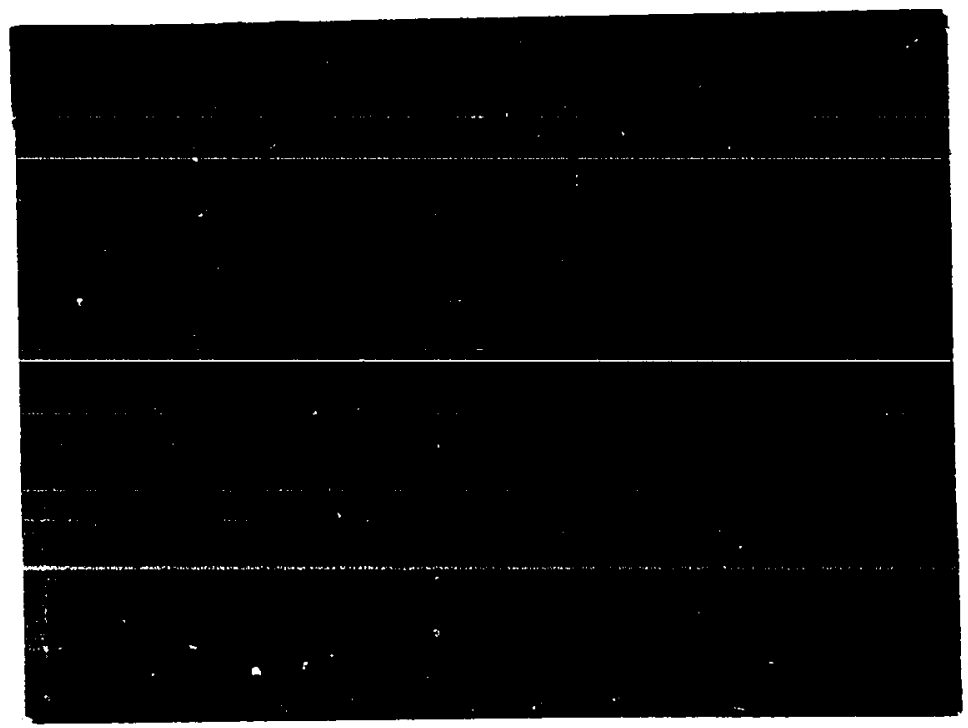

Figure 12. Decoration of a dislocation lying in the $\{110\}$ surface. Small As- precipitates can be observed, undoped, 500X. 
crystal at that instant. The Figs. 11 and 10 (a) also show that the impurity content of undoped GaAs is lower than the Si-doped GaAs; the striations are fewer on the former than on the latter.

Decoration of a dislocation lying in $\{110\}$ surface is shown in Fig.12. Small As precipitates with dimensions of micrometers, spacing about 2-4 $\mu \mathrm{m}$, are observed to decorate the dislocation. Cullis et al ${ }^{(50)}$ postulated that the segregation of Ga precipitates along dislocations occurs by condensation of As interstitials from the surrounding lattice.

\subsection{3. $\{111\} \mathrm{Ga}$ Surface}

The etch structures produced on the $\{111\} \mathrm{Ga}$ face have different shapes for differently doped GaAs materials as shown in Fig.13. On the Si-doped n-type sample (Fig.13 (a)), some etch pits have a long tiny tail, and others have no evident tails, which indicates some dislocations are inclined to the surface (with a long tail) and some are nearly normal to the surface. However, the $\mathrm{Zn}$ doped p-type sample has nearly triangular etch mounts (Fig.13 (b)). The etch mounts form a tiny head at the beginning and develop to a large triangular tail at the ends, which looks like a hot pepper inlaid 


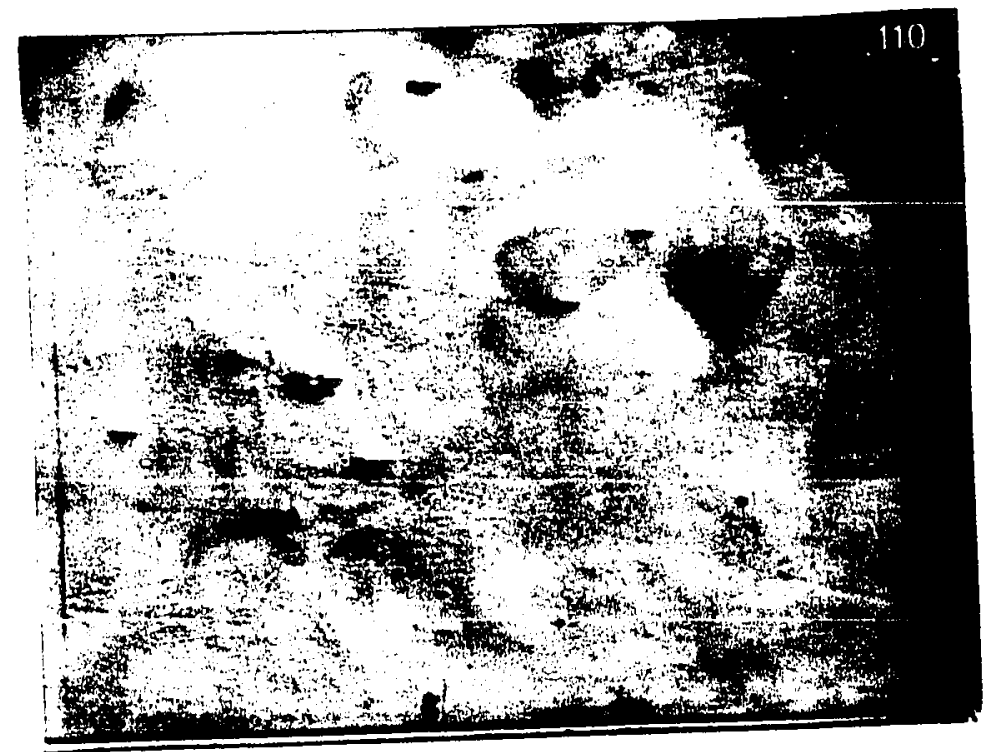

Figure 13. (a)

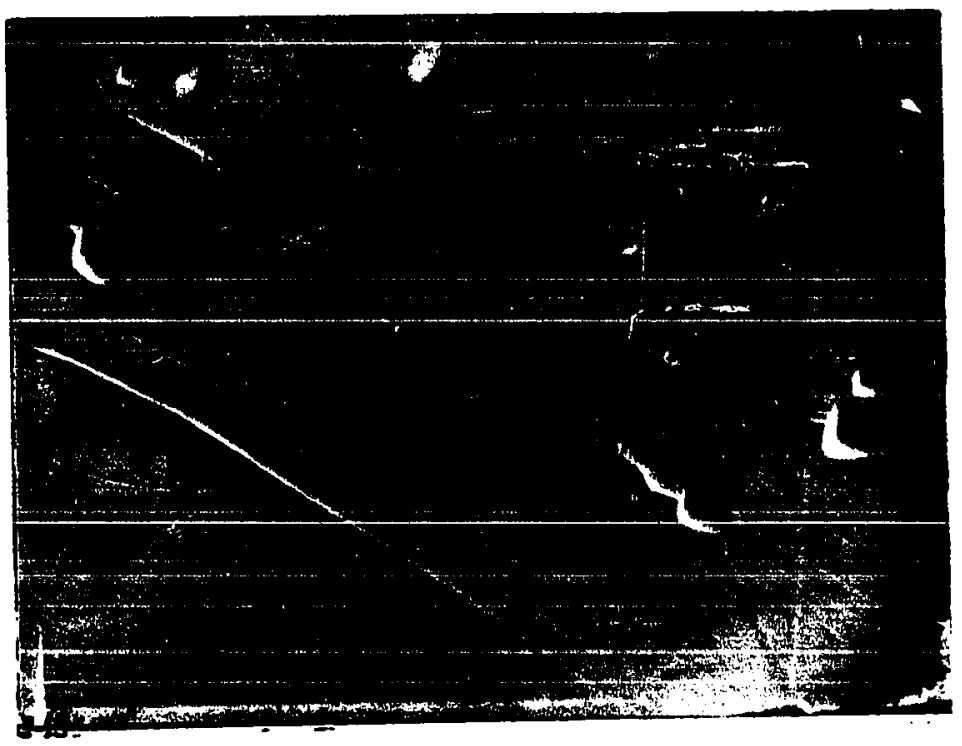

Figure 13. (b) 


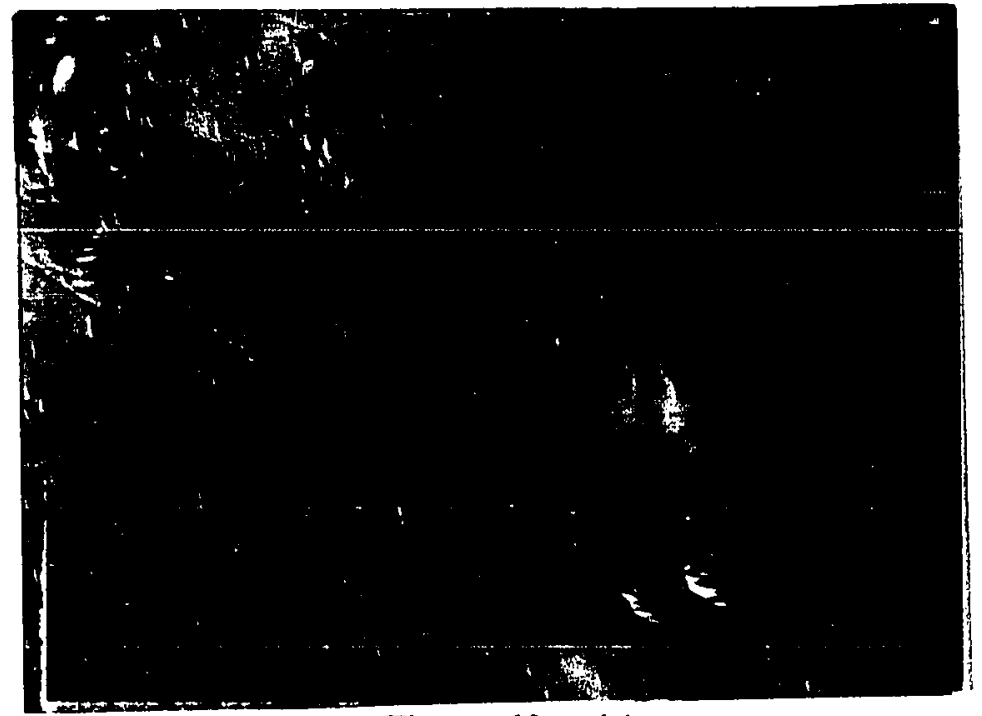

44

Figure 13. (c)

Figure 13. Typical etch structures on $\{111\} \mathrm{Ga}$ surfaces by $A / B$ etching. (a). Etch pits on Si-doped sample, with a long tiny tail, 100X. (b). Etch mounts on $\mathrm{Zn}$-doped sample, nearly triangular shape mounts, $200 \mathrm{X}$. (c). Etch pits on undoped sample, 200X.

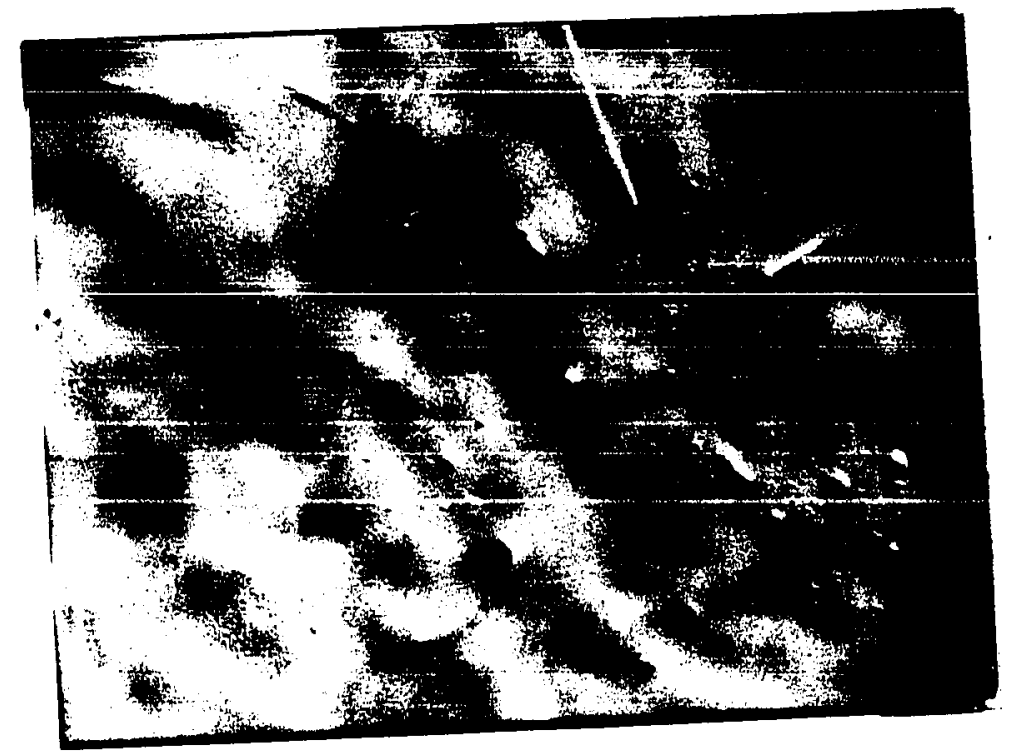

Figure 14. (a) 


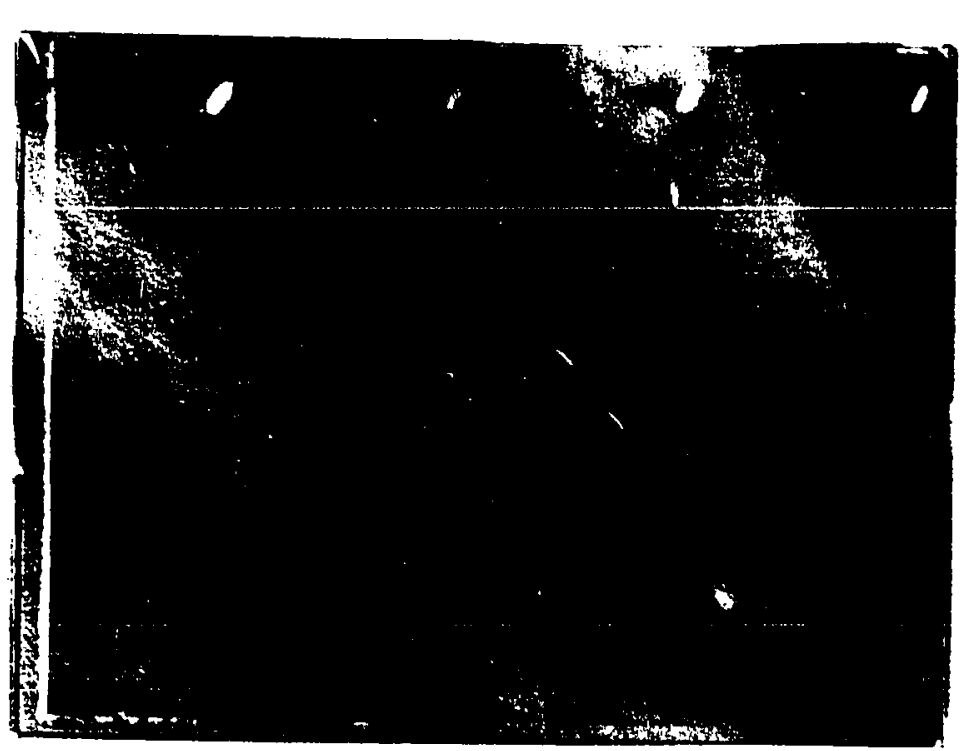

45

Figure 14. (b)

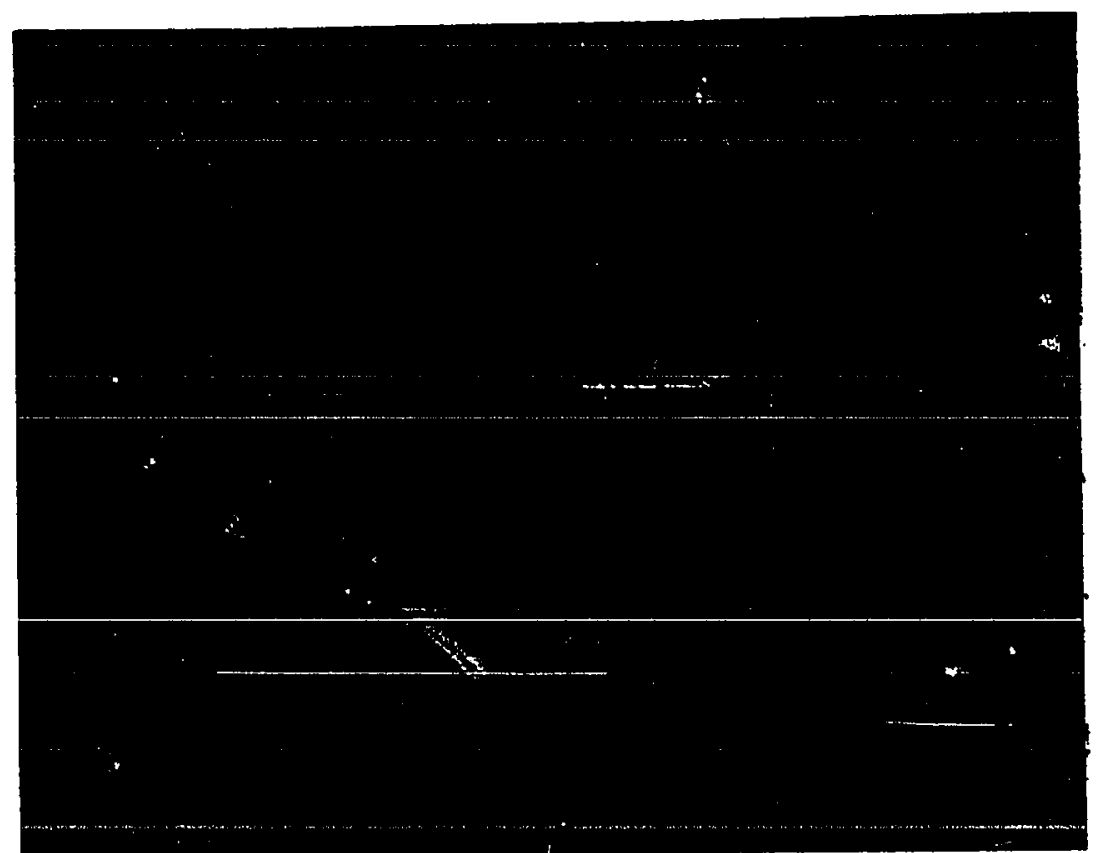

Figure 14. (c)

Figure 14. Typical etch structures on $\{111\}$ As surfaces by $A / B$ etching. (a). Si-doped sample, 100X. (b). Zn-doped sample, 100X. (c). Undoped sample, 100X. 


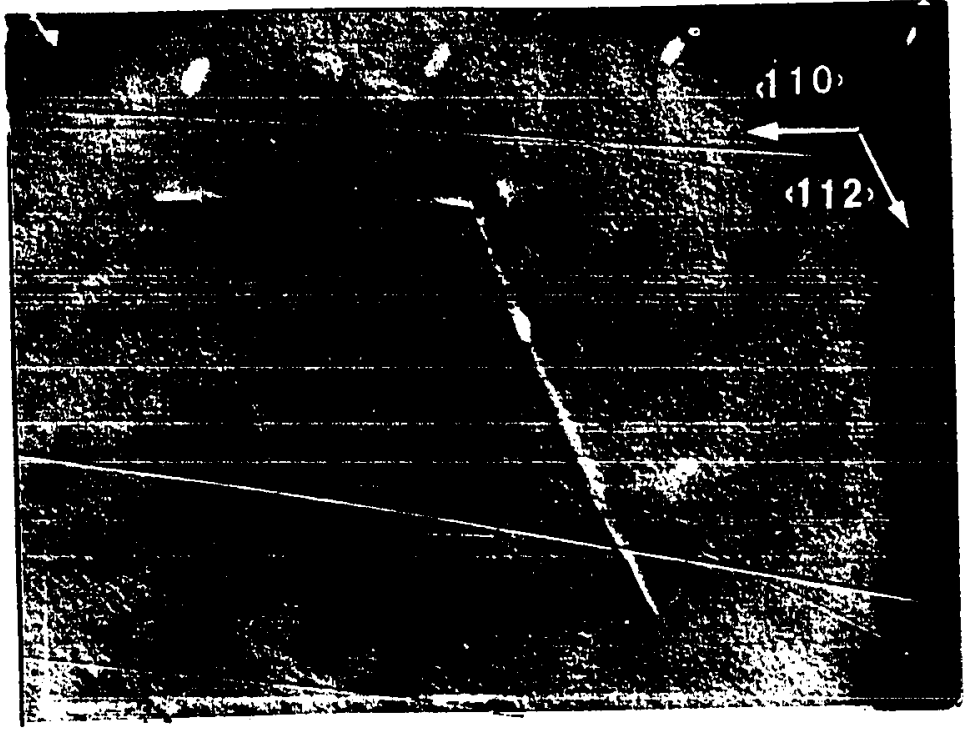

Figure 15. Straight dislocation lines lying in the $\{111\}$ As surface, along $<110\rangle$ and $<112>$ directions, Zn-doped, $200 \mathrm{X}$. 


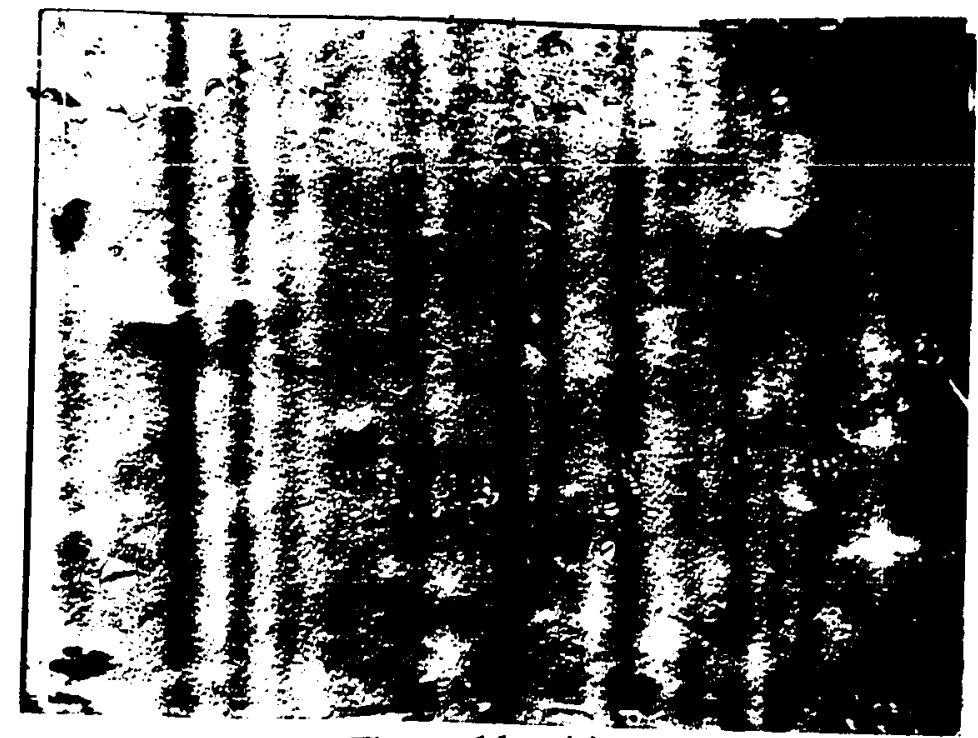

Figure 16. (a)

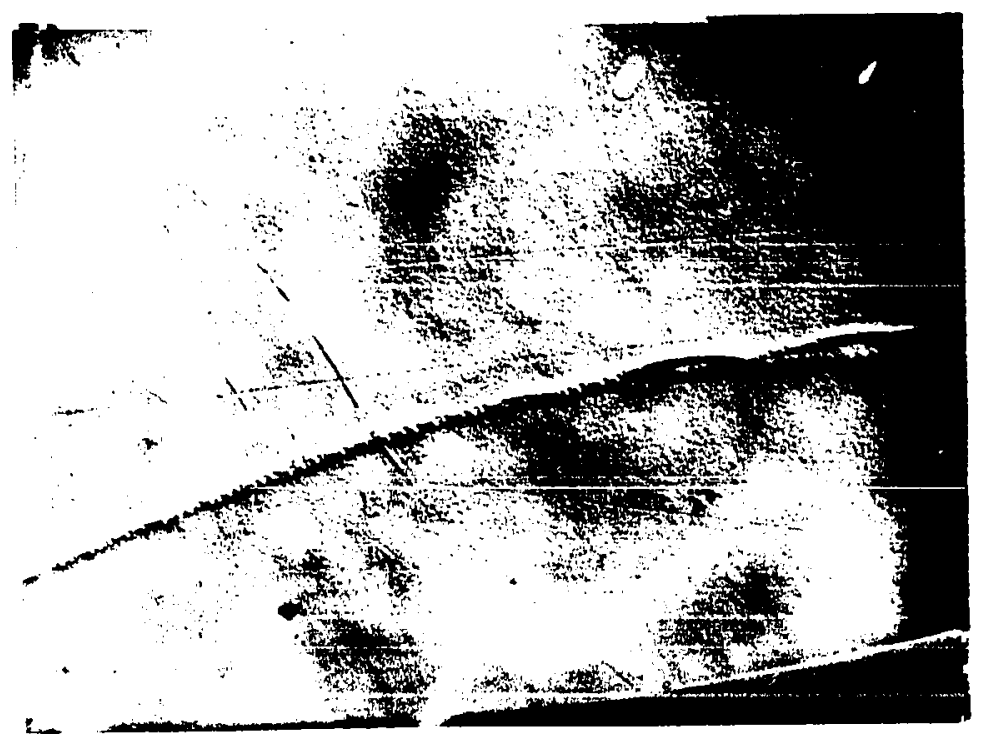

Figure 16. (b)

Figure 16. Growth striations and precipitates on the $\{111\}$ As surface by A/B etching. (a). Growth striations on a $\{111\}$ As surface, Si-doped, 100X. (b). Precipitates on a $\{111\}$ As surface, $\mathrm{Zn}$-doped, 100X. 
on the surface. The dimension of the etch pits is $30-40 \mu \mathrm{m}$. Figure 13 (c) shows an etch pit (P) of undoped SI sample. It is likely that originally the dislocation was nearly normal to the surface, but at some distance bent down and became inclined to the surface.

\subsection{4. $\{111\}$ As Surface}

The etching structures observed on the $\{111\}$ As faces are analogous to those on the $\{111\} \mathrm{Ga}$ faces with the exception that the etch structures have shapes similar to the $\{100\}$ faces as in Fig.14. In Fig.14 (c), dislocation pits marked A, B, and $\mathrm{C}$ are examples of dislocations lying normal, inclined, and parallel to the surface, respectively. Dislocations lying in the $\{111\}$ planes are often straight over appreciable distances (Figure 15); the angles between the sharply bent segments suggest the presence of both $60^{\circ}$ and edge dislocations lying in $\langle 110\rangle$ and $\langle 112\rangle$ directions, respectively.

Growth striations and precipitates are also found on the (111)As surface of GaAs materials (Fig.16). Otherwise, Fig.14 (c) shows that a lot of river-like ridge lines are observed; those lines array along the direction $\langle 110\rangle$, which suggests these lines may be the dislocation lines. 


\subsubsection{Summary}

The etched structures on $A / B$ etched GaAs substrates, described in this section, are summarized in Table 2.

Table 2. Summary of etched structures in GaAs single crystals by $A / B$ etching

\begin{tabular}{|c|c|c|c|c|}
\hline $\begin{array}{l}\text { Names of } \\
\text { etched } \\
\text { structures }\end{array}$ & $\begin{array}{l}\text { Shape } \\
\text { and } \\
\text { size }\end{array}$ & $\begin{array}{l}\text { (Probable) } \\
\text { Origin }\end{array}$ & $\begin{array}{l}\text { Revealed on } \\
\text { crystallographic } \\
\text { surfaces }\end{array}$ & Explanations \\
\hline $\begin{array}{l}\text { Conical } \\
\text { etch pit } \\
\text { or hillock }\end{array}$ & $\begin{array}{c}\mathcal{O} \\
2-8 \mu \mathrm{m}\end{array}$ & Dislocation & $\begin{array}{l}\{100\},\{110\}, \\
\{111\} \mathrm{Ga},\{111\} \mathrm{As}\end{array}$ & $\begin{array}{l}\text { Dislocation normal to the } \\
\text { surface }\end{array}$ \\
\hline $\begin{array}{l}\text { Line structure } \\
\text { (ridge and } \\
\text { groove) }\end{array}$ & & Dislocation & $\begin{array}{l}\{100\},\{110\}, \\
\{111\} \mathrm{Ga},\{111\} \mathrm{As}\end{array}$ & $\begin{array}{l}\text { Dislocation parallel to the } \\
\text { surface, dislocation axes } \\
\text { along some crystallograhpic } \\
\text { directions }\end{array}$ \\
\hline $\begin{array}{l}\text { Conical pit } \\
\text { with a long } \\
\text { tail }\end{array}$ & $<$ & Dislocation & $\begin{array}{l}\{100\},\{110\}, \\
\{111\} \mathrm{Ga},\{111\} \mathrm{As}\end{array}$ & $\begin{array}{l}\text { Dislocation inclined to the } \\
\text { surface }\end{array}$ \\
\hline $\begin{array}{r}\text { Triangular } \\
\text { etch mount }\end{array}$ & $30-40 \mu \mathrm{m}$ & Dislocation & $\mathrm{Zn}$-doped $\{111\} \mathrm{Ga}$ & $\begin{array}{l}\text { Dislocation inclined to the } \\
\text { surface }\end{array}$ \\
\hline $\begin{array}{c}\text { Particles } \\
\text { on dislocatior } \\
\text { line } \\
\end{array}$ & 2-4um apart & $\begin{array}{l}\text { Impurity } \\
\text { precipitates }\end{array}$ & $\begin{array}{l}\{100\},\{110\}, \\
\{111\} \mathrm{Ga},\{111\} \text { As }\end{array}$ & $\begin{array}{l}\text { Dislocation acting as sinks } \\
\text { for the impurities }\end{array}$ \\
\hline $\begin{array}{l}\text { Growth } \\
\text { striation }\end{array}$ & & $\begin{array}{l}\text { Impurity } \\
\text { aggregation }\end{array}$ & $\{110\},\{111\}$ As & $\begin{array}{l}\text { A record of the shape and } \\
\text { progress of the freezing } \\
\text { tterface during crystal growth. } \\
\text { Striations on undoped GaAs }\end{array}$ \\
\hline
\end{tabular}




\subsection{PHOTO-ETCHING}

The etchant which contained 3:1:1 $\mathrm{H}_{2} \mathrm{SO}_{4}: \mathrm{H}_{2} \mathrm{O}_{2}: \mathrm{H}_{2} \mathrm{O}$ can be used to reveal dislocations and striations with excellent resolution on $\{100\},\{110\},\{111\} \mathrm{Ga}$, and $\{111\}$ As surfaces.

\subsection{1. $\{100\}$ Surface}

Dislocation etch microstructures on the $\{100\}$ planes are nearly similar for different doped and undoped GaAs samples. They have a long hillock, with typical dimension about $30 \mu \mathrm{m}$ long and $10 \mu \mathrm{m}$ wide (Fig.17). No appearance features are observed for the dislocations with different orientations such as inclined, normal and parallel to the etched surfaces.

\subsection{2. $\{110\}$ Surface}

The etch structures on the $\{110\}$ faces have some different etching features from those on the $\{100\}$ faces; dislocations with different orientations can be revealed very clearly. Figure 18 shows the etch structures of dislocations normal to (A), parallel to (B) and inclined to (C) the surface for Si-doped SC GaAs samples; dislocations normal to the surface (A) have oval etch hillocks. Dislocations inclined to the surface (B) have the same etch hillocks but with a 
long tail, and dislocations parallel to the surface (C) have line-like etch structures with the appearance of a ridge. The Cr-doped and undoped SI etched samples not only have the same kinds of etch structures as Si-doped SC etched samples, but also have some particles which look like precipitates (Fig.19). Figure 19 (b) shows that some small particles (probably precipitates) are revealed on the dislocation lines. Two crossed dislocation lines on Fig.20 show the some angular relationship between them, which affirms that the dislocations have a $<112>$ axis.

Using 3:1:1 $\mathrm{H}_{2} \mathrm{SO}_{4}: \mathrm{H}_{2} \mathrm{O}_{2}: \mathrm{H}_{2} \mathrm{O}$ photo-etching can successfully reveal the growth striations on the $\{110\}$ surfaces. Preliminary investigations of impurity striation behavior in large diameter VGF GaAs crystals are illustrated in Fig.21; $\{110\}$ faces were etched in the 3:1:1 $\mathrm{H}_{2} \mathrm{SO}_{4}: \mathrm{H}_{2} \mathrm{O}_{2}: \mathrm{H}_{2} \mathrm{O}$ solution to reveal longitudinal striations under a Nomarski contrast microscope. These studies revealed longitudinal striations (presumably due to microscopic variation in resistivity) for undoped SI GaAs crystal (Fig.21 (a)) and low-resistivity n-type, Sidoped SC GaAs crystal (Fig.21 (b)). In the case of the SI GaAs crystal, the impurity content is low, suggesting that the observed striations correspond to microscopic variations in compensation and may arise from local fluctuations in stoichiometry. The closely spaced striations in the Si-doped SC material (Fig.21 (b)) result from variations in dopant incorporation due to fluctuations in microscopic 


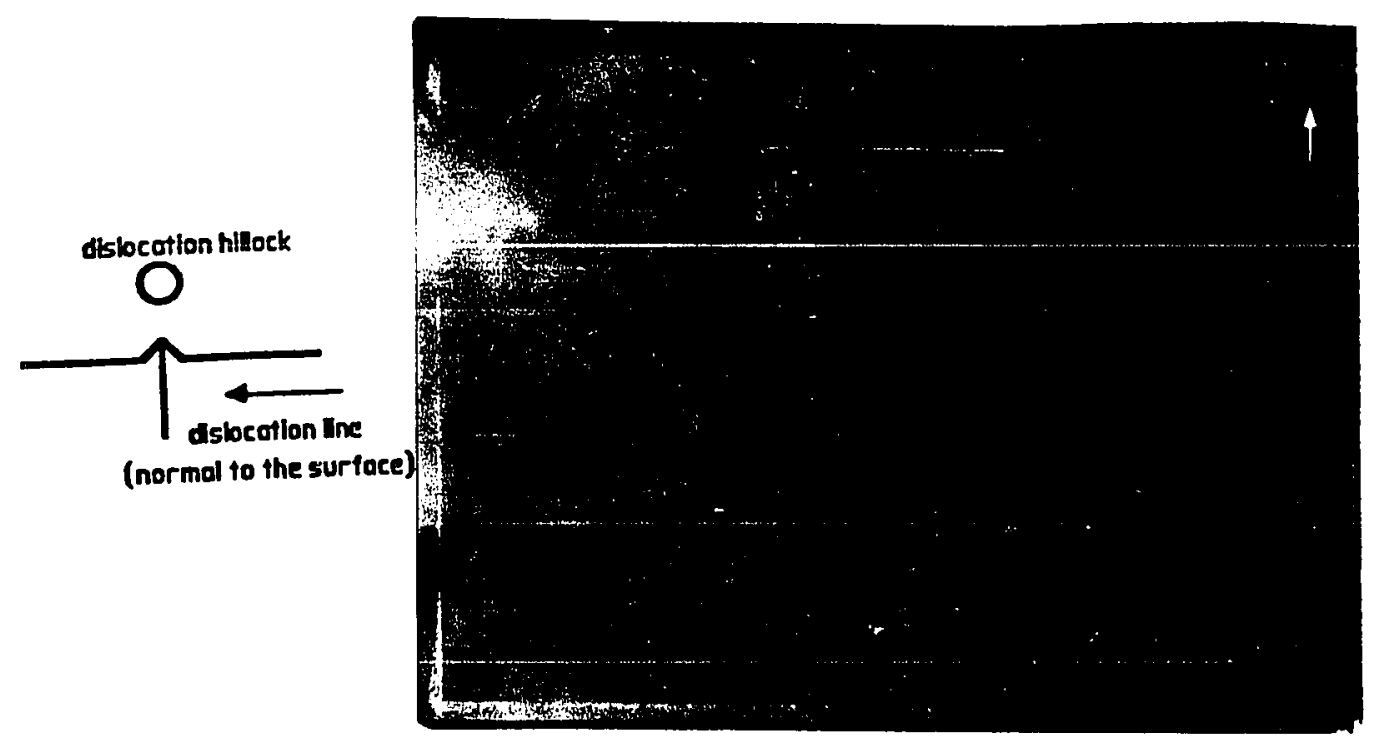

Figure 17. Typical etch structures on the $\{100\}$ surface by 311 photoetching, Si-doped, 200X.

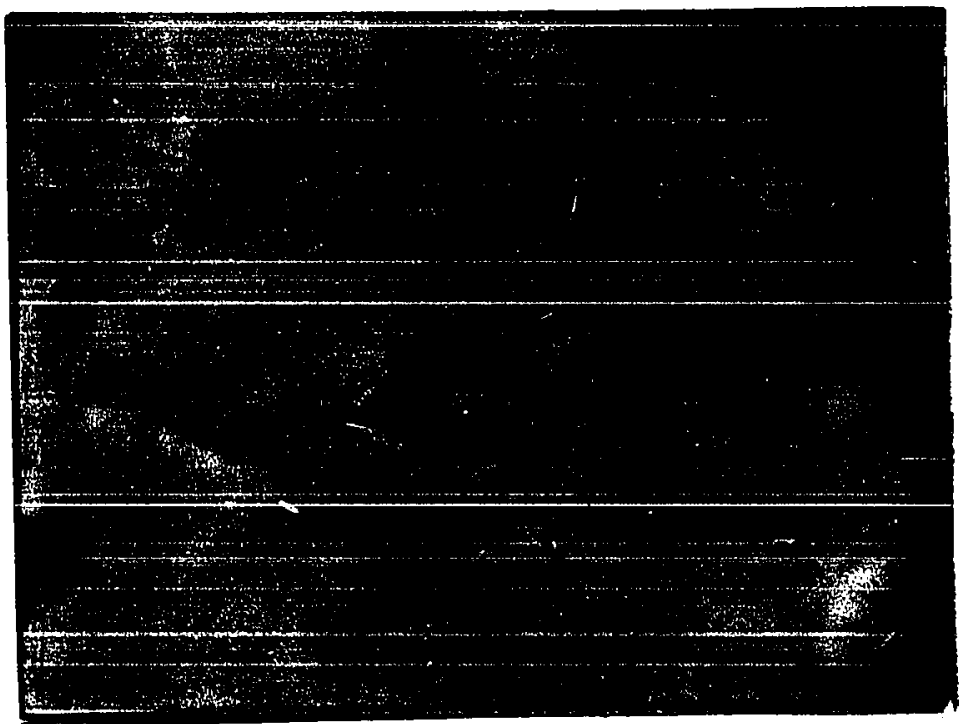

Figure 18. Etch structures on $\{110\}$ surfaces by 311 photo-etching. Dislocations normal (A), inclined (B), and parallel (C) to the surface can be observed, Si-doped, $200 \mathrm{X}$. 


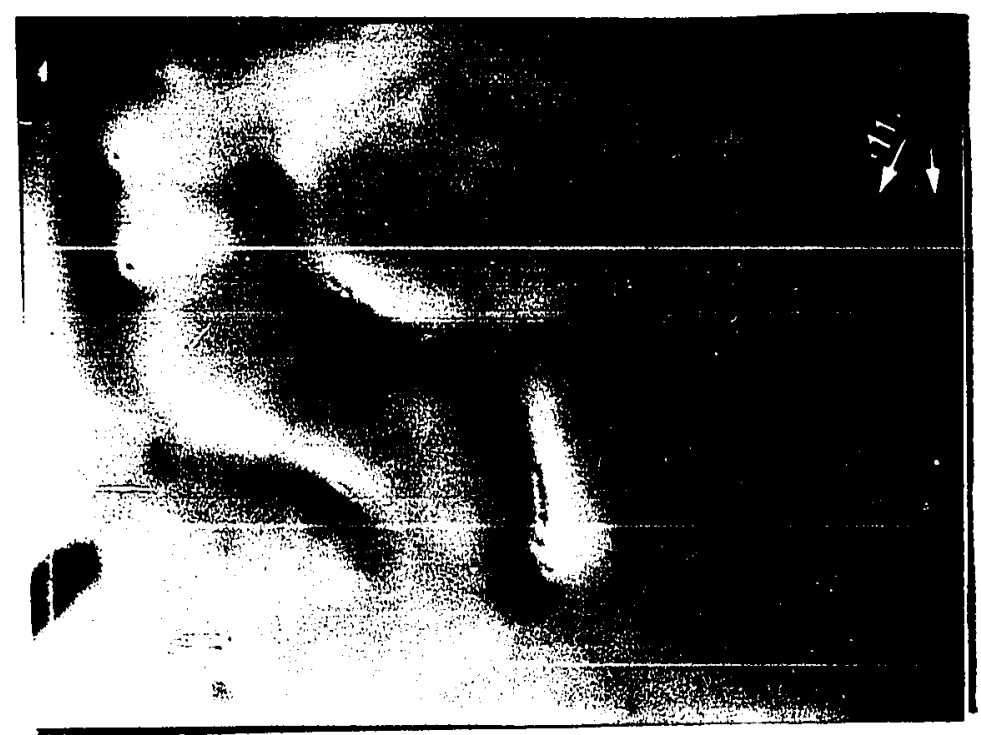

Figure 19. (a)

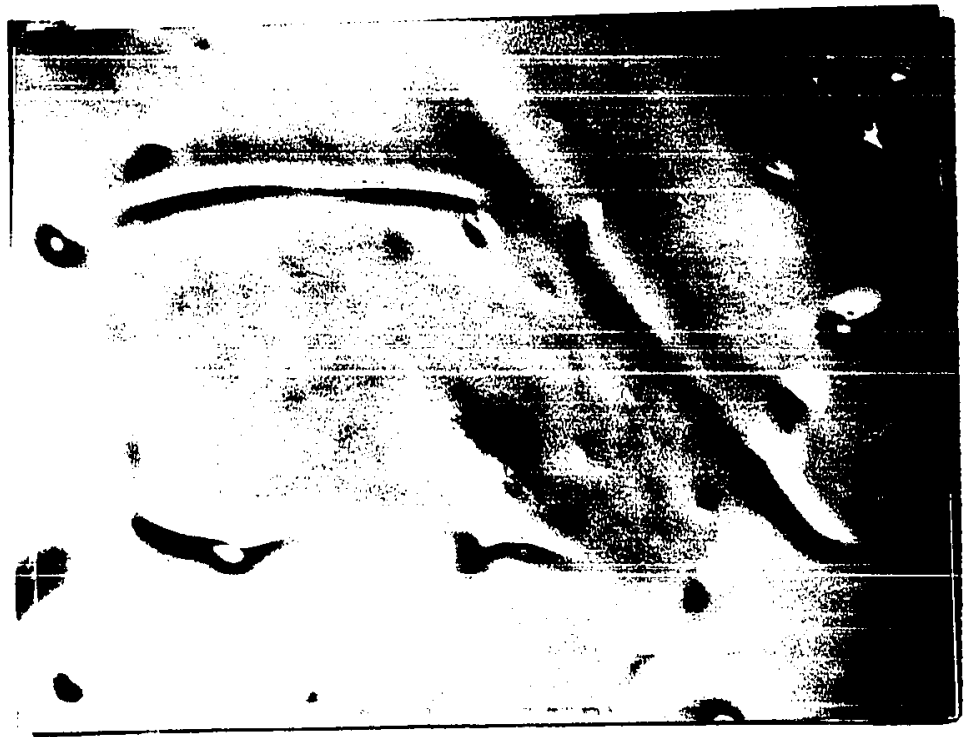

Figure 19. (b)

Figure 19. Etch structures on the undoped and Cr-doped [110\} surfaces by 311 photo-etching. Precipitates decorate the dislocation lines. (a). Cr-doped, 200X. (b) Undoped, 200X. 
Figure 20. Two crossed dislocation lines on a $\{110\}$ undoped GaAs sample. The dislocations have a $<112>$ axis, 500X.

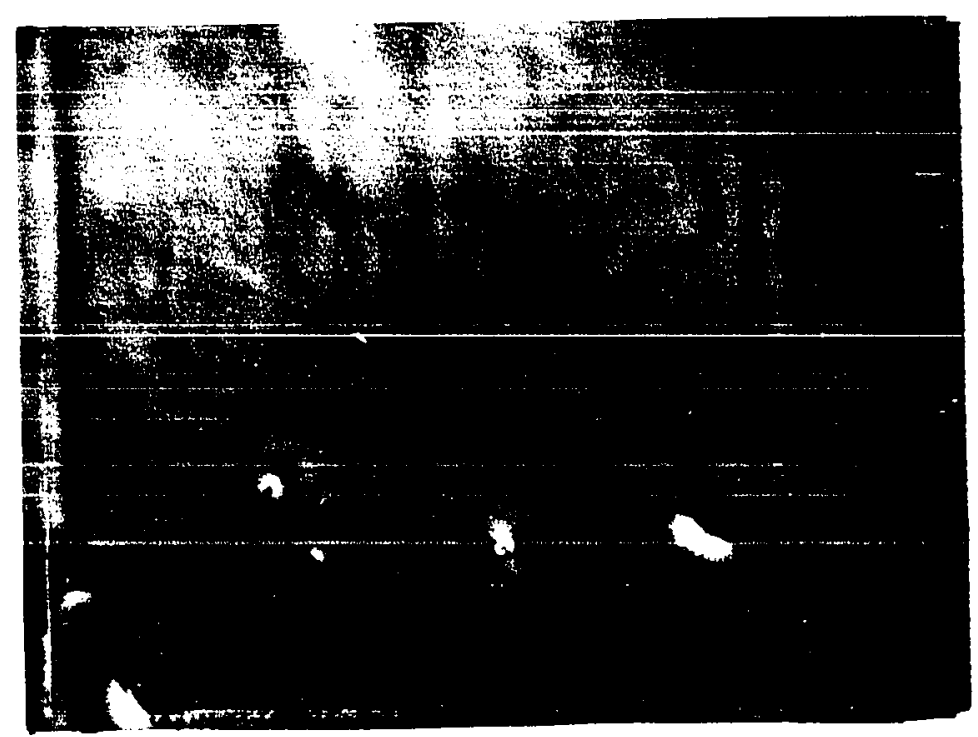

Figure 21. (a) 


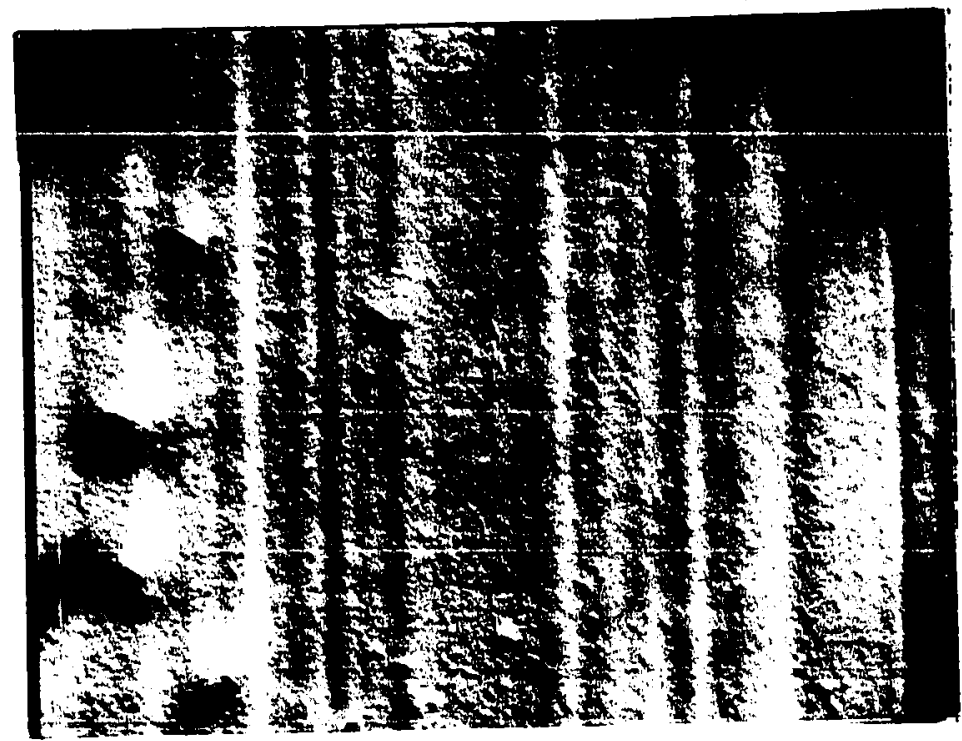

Figure 21. (b)

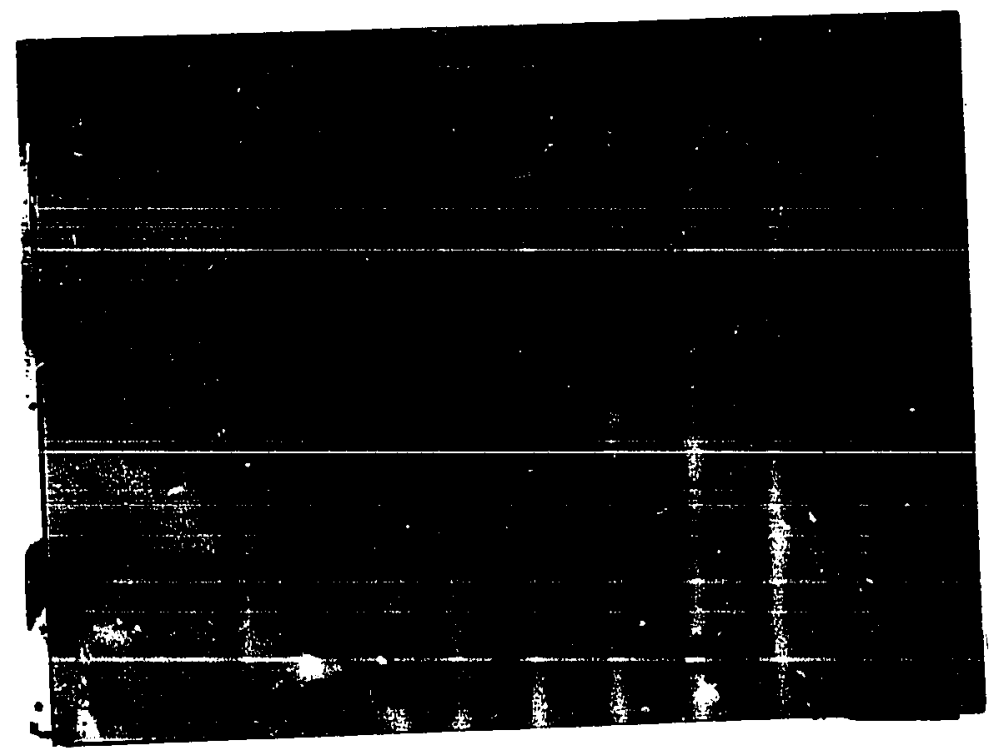

Figure 21. (c)

Figure 21. Growth striations on $\{110\}$ surfaces by 311 photo-etching. (a). Undoped, 100X. (b). Si-doped, 100X. (c). Cr-doped, 100X. 
growth rate. An even greater axially striated impurity distribution and greater microscopic inhomogeneity is expected in Cr-doped SI crystal because of the very low segregation coefficient of chromium (Fig.21 (c)) ${ }^{(53)}$

The dislocation etch pit features and growth striations on the $\{110\}$ surface by 311 photo-etching are very similar to those by $A / B$ etching. This situation was not found in the literature search, which means no published papers state this situation as far as the author knows.

\subsection{3. $\{111\} \mathrm{Ga}$ Surface}

Typical conical hillocks responding to the dislocation normal to surfaces and line ridges responding to the dislocation parallel to surface are revealed on $\{111\} \mathrm{Ga}$ faces for different types of etched samples. Figure 22 gives the dislocation etch structures of Si-doped SC material, Figure 23 (a) and (b) show the etch pits of $\mathrm{Zn}$-doped SC and undoped SI GaAs samples. Analysis of etch structures can follow a similar way as mentioned in former sections.

A dislocation line decorated the precipitates can be found on the $\mathrm{Zn}$-doped SC GaAs sample (Fig.23 (a)) and undoped SI material (Fig.23 (b)). The precipitates in Fig.23 (b) were proposed as As- 


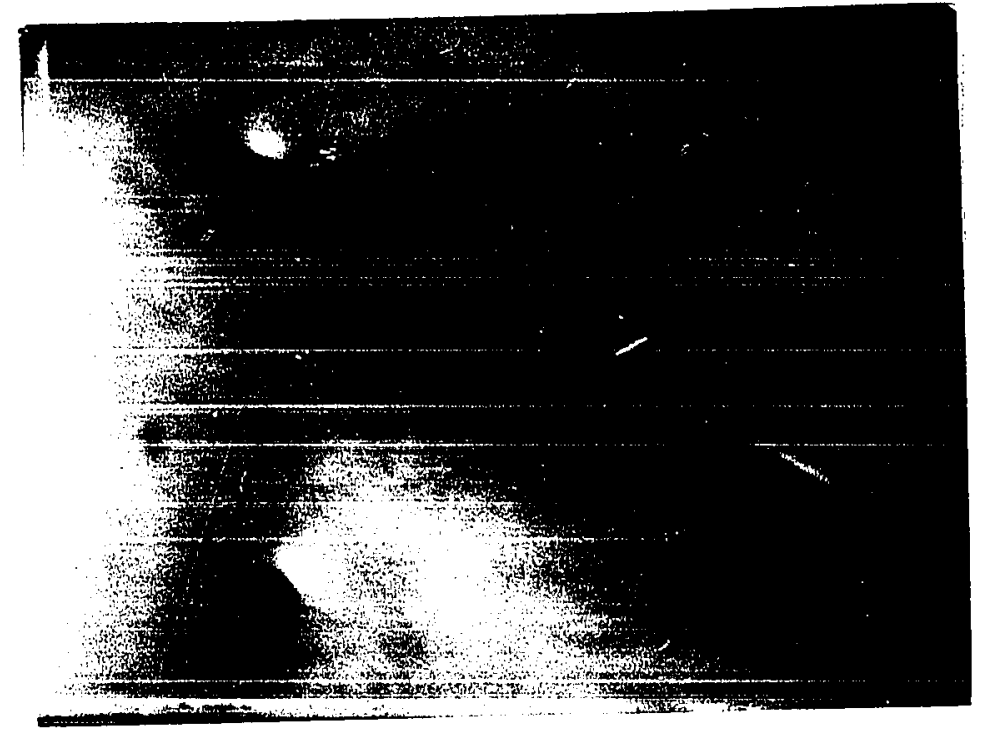

Figure 22. Typical etch structures on a $\{111\} \mathrm{Ga}$ surface by 311 photoetching, Si-doped, 200X. 


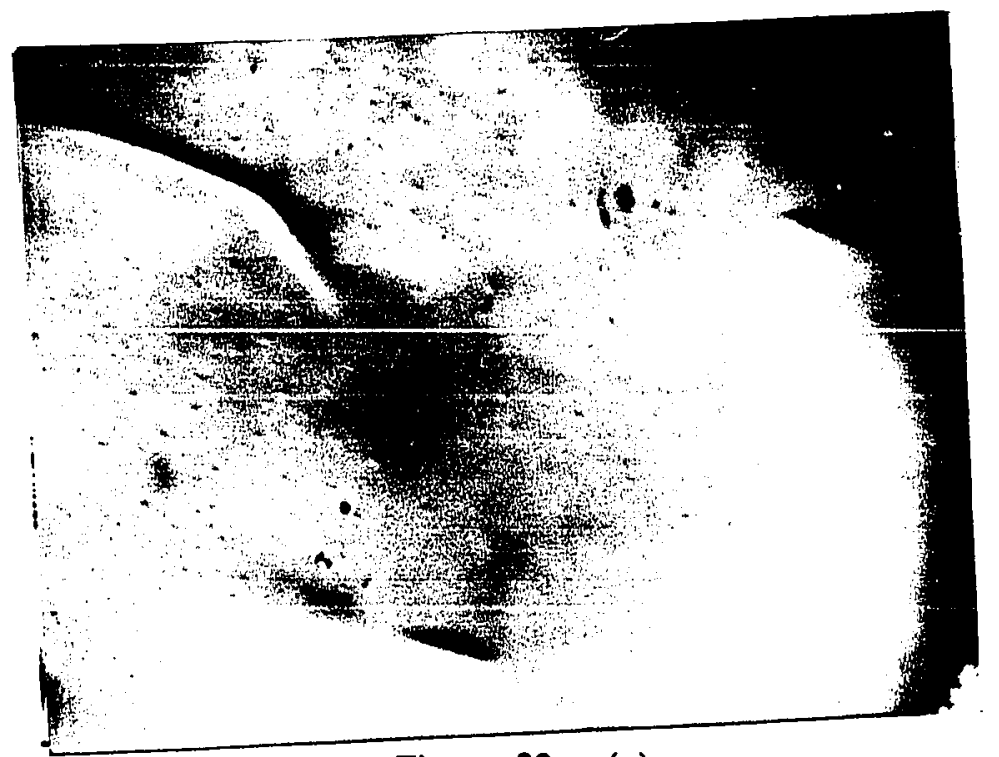

Figure 23. (a)

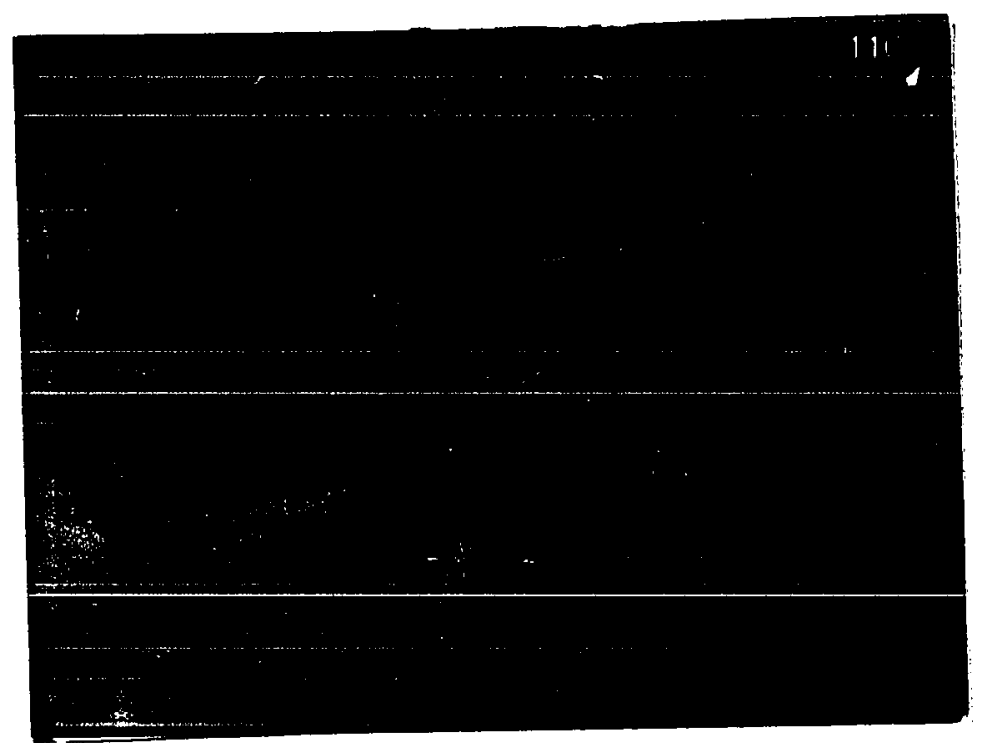

Figure 23. (b)

Figure 23. Etch structures on $\{111\} G$ a surfaces of the $\mathrm{Zn}$-doped and undoped GaAs materials by 311 photo-etching. (a). Zn-doped, dislocation lines with precipitates, 200X. (b). Undoped, dislocation lines with precipitates, $200 \mathrm{X}$. 


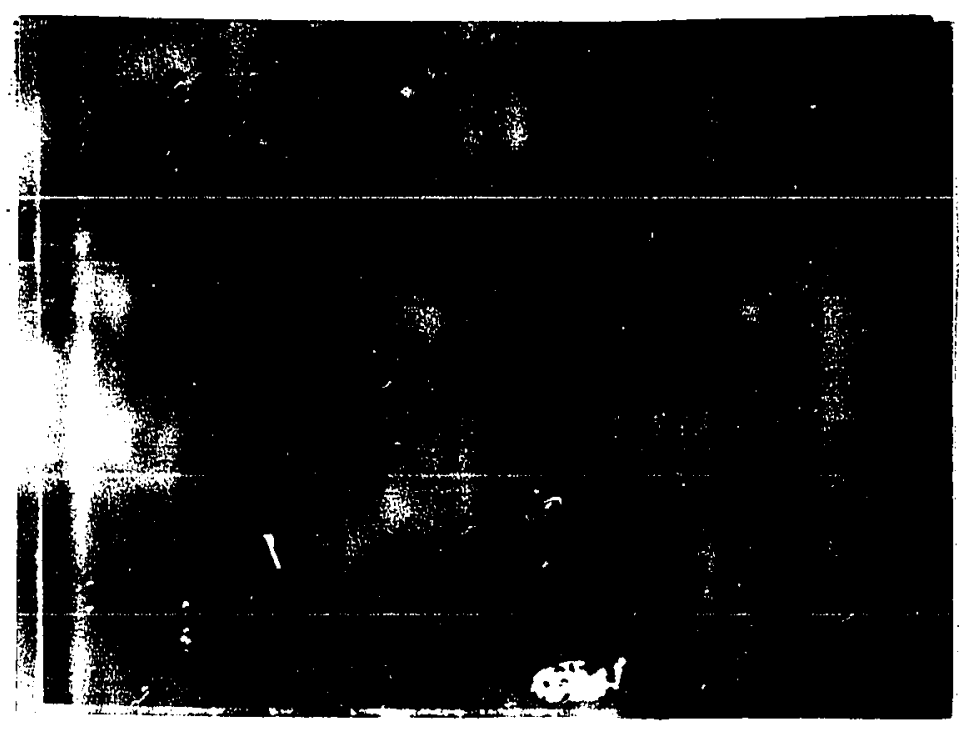

Figure 24. (a)

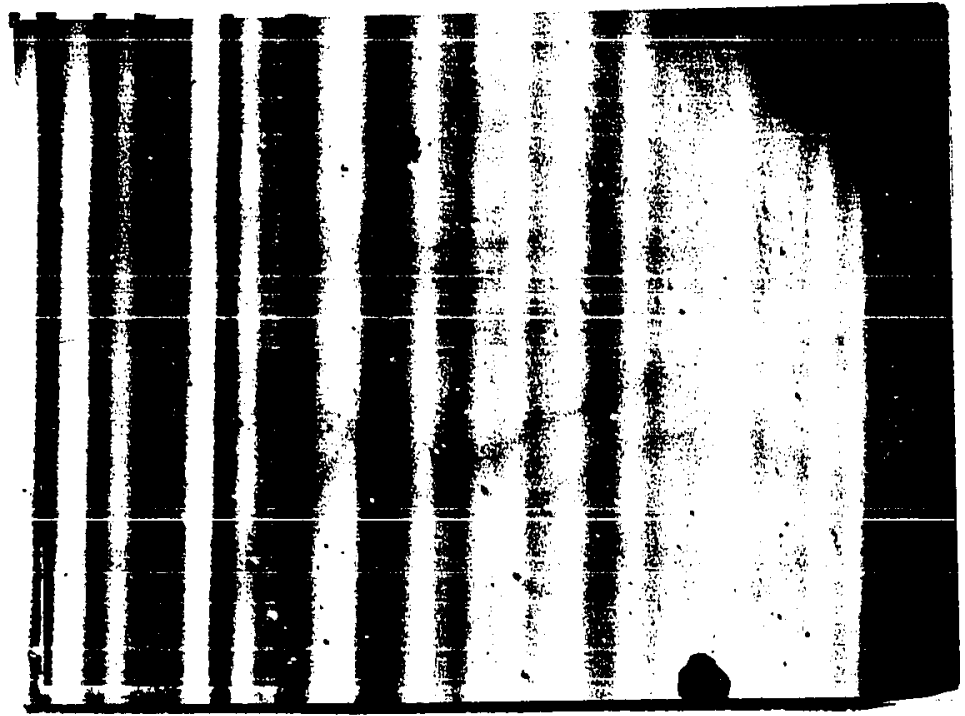

Figure 24. (b)

Figure 24. Growth striations on $\{111\} \mathrm{Ga}$ and $\{111\}$ As surfaces by 311 photo-etching. (a). \{111\}Ga surface, Si-doped, 100X. (b). \{111\}As surface, Si-doped, 100X. 
precipitates because the crystals were grown in an As-atmosphere; but the precipitates in Fig.23 (a) cannot be definite. One possibility is that $\mathrm{Zn}$ dopant precipitates along the length of dislocations with $<110>$ directions. Abrahams and Buiocchi ${ }^{(54)}$ and Abrahams and Pankove ${ }^{(55)}$ have interpreted etching observations on misfit dislocations in a p-n junction regions, where the p-type dopant was $\mathrm{Zn}$ (about $2 \times 10^{19} \mathrm{~cm}^{-3}$ ). It was proposed that the misfit dislocations, which lay in orthogonal $\langle 110\rangle$ directions, were pure edge dislocations on (001) with Burger vectors of $1 / 2 a_{0}[110]$ and $1 / 2 a_{0}[1 \overline{1} 0]$. One set of dislocations, along [110], etched unevenly and showed discrete particles along the lengths of the dislocations, whereas the [110] set did not. The authors suggested that the [110] set showed enhanced etching compared to the [110] set due to greater impurity segregation of the zinc dopant. They also suggested this because $\mathrm{Zn}$ will normally substitute for $\mathrm{Ga}$ atoms in $\mathrm{GaAs}$ rather than a $\mathrm{Zn}$ atom would be attracted to the site between the two incompletely bonded As atoms.

Growth striations can also be revealed on the $\{111\} \mathrm{Ga}$ surfaces by $3: 1: 1 \mathrm{H}_{2} \mathrm{SO}_{4}: \mathrm{H}_{2} \mathrm{O}_{2}: \mathrm{H}_{2} \mathrm{O}$ photo-etching. 


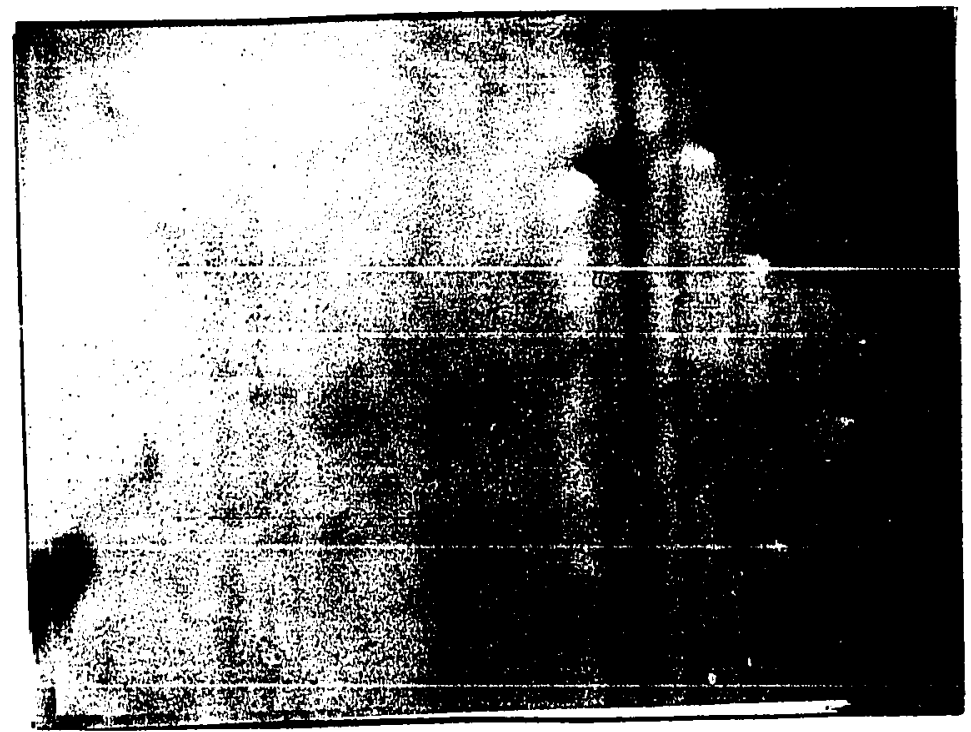

61

Figure 25. (a)

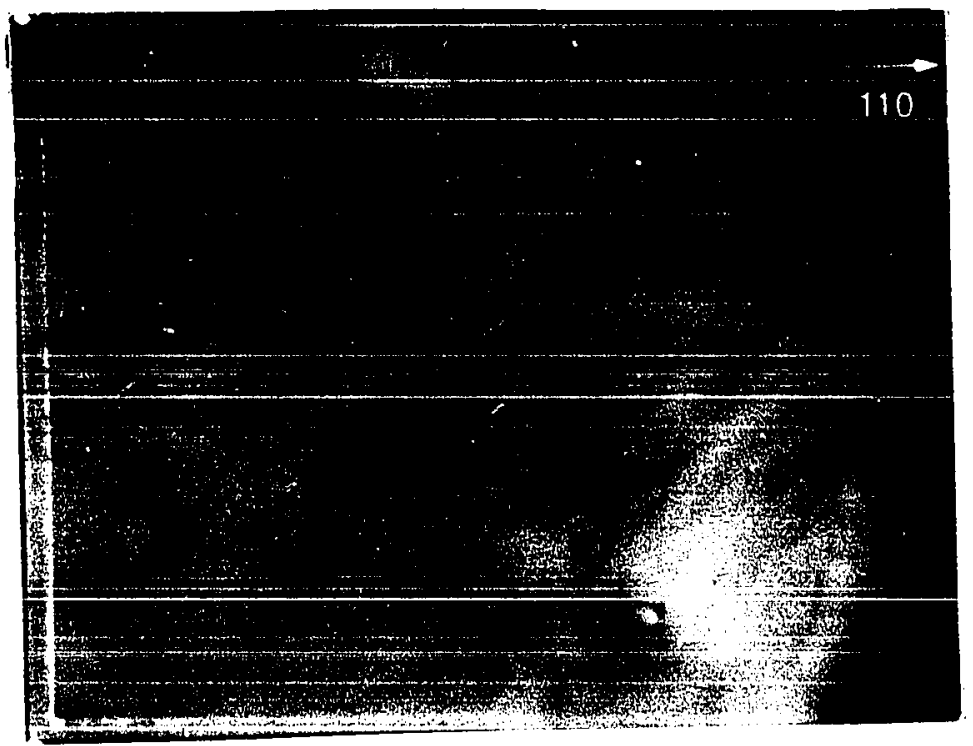

Figure 25. (b)

Figure 25. Typical etch structures on 1111 ) As surfaces by 311 photoetching. (a). Dislocation hillocks and growth striations of a Si-doped sample, 100X. (b). Dislocation hillocks, Si-doped, 500X. 


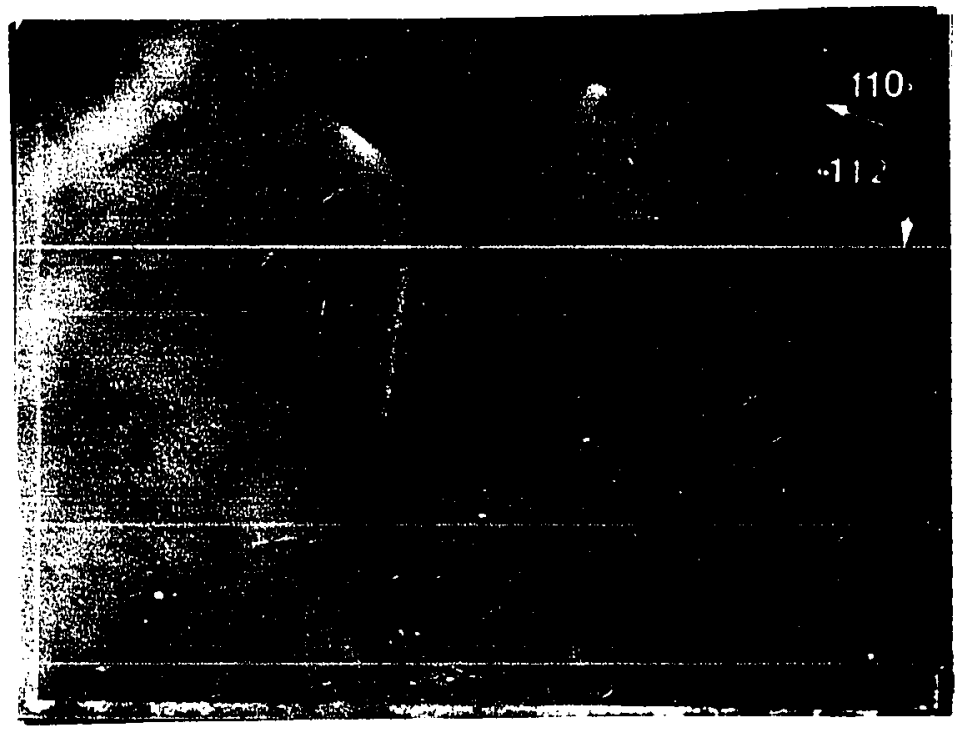

Figure 26. (a)

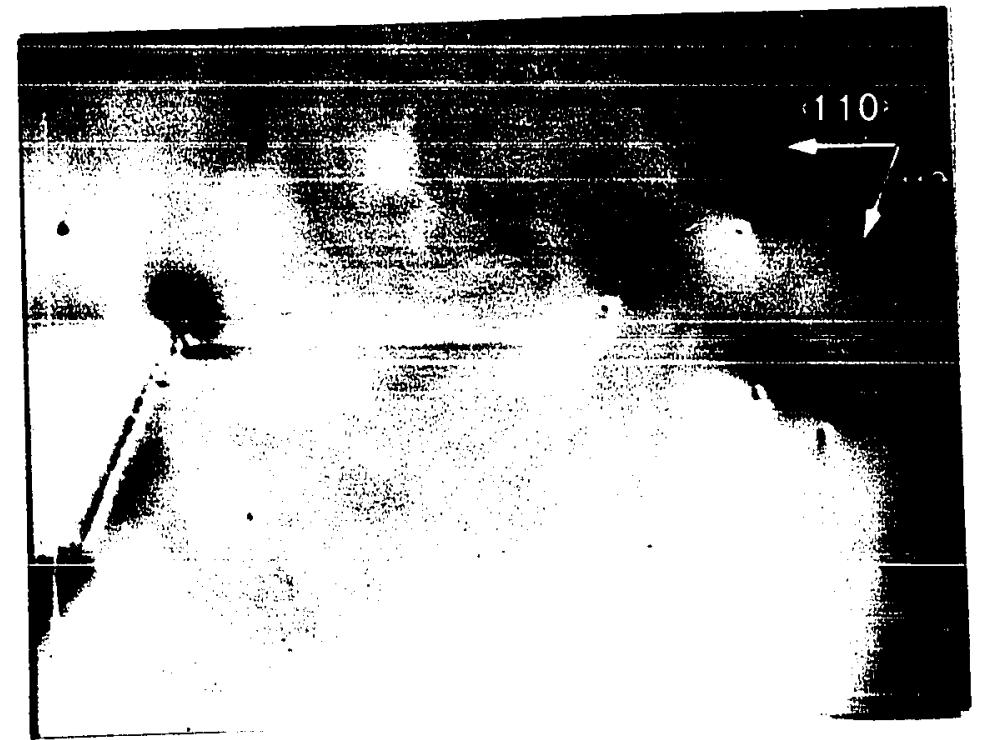

Figure 26. (b)

Figure 26. Etch structures on [111\}As surfaces by 311 photo-etching. The precipitates can be revealed on dislocation lines. (a). $\mathrm{Zn}$-doped, 200X. (b) Undoped, there exists an angular relationship between the dislocation lines, 200X. 


\subsection{4. $\{111\}$ As Surface}

The etch structures on the $\{111\}$ As faces have no apparent difference compared with those on the $\{111\} \mathrm{Ga}$ faces. Figure 25 shows the dislocation hillocks and growth striation of a Si-doped SC $\{111\}$ As sample. Compared with dislocation hillocks of a $\{111\} \mathrm{Ga}$ sample (Fig.22), the hillocks of the $\{111\}$ As face appear to have the same conical hillock shape. But a small circular pit exists on the top of the conical hillocks, so that the whole etch pit has a hollow shape.

Figure 26 shows the etch structures on the $\mathrm{Zn}$-doped SC \{111\}As face and undoped SI $\{111\}$ As face. Similar to $\{111\} \mathrm{Ga}$ samples, precipitates were also revealed on the dislocation lines for the $\{111\}$ As faces. Meanwhile, the dislocations along $\langle 110\rangle$ and $\langle 112\rangle$ directions were seen on undoped SI $\{111\}$ As surfaces (Fig.26 (b)).

In Fig.24, the growth striations on the two opposite sites ( $\{111\} \mathrm{Ga}$ and $\{111\} \mathrm{As})$ of the same sample show that the striation densities are almost equal for both sites of the sample. This again proves that the growth striations are only concerned with the impurity addition, not with other factors such as crystallographic orientation and etching conditions. 


\subsubsection{Summary}

Table 3 summarizes the etched structures on GaAs crystals by 3:1:1 $\mathrm{H}_{2} \mathrm{SO}_{4}: \mathrm{H}_{2} \mathrm{O}_{2}: \mathrm{H}_{2} \mathrm{O}$ photo-etching.

Table 3. Summary of etched structures in GaAs single crystals by 311 photo- etching

\begin{tabular}{|c|c|c|c|c|}
\hline $\begin{array}{l}\text { Names of } \\
\text { etched } \\
\text { structures }\end{array}$ & $\begin{array}{l}\text { Shape } \\
\text { and } \\
\text { size }\end{array}$ & $\begin{array}{c}\text { (Probable) } \\
\text { Origin }\end{array}$ & $\begin{array}{l}\text { Revealed on } \\
\text { crystallographic } \\
\text { surfaces }\end{array}$ & Explanations \\
\hline $\begin{array}{l}\text { Long etch } \\
\text { hillock }\end{array}$ & $\begin{array}{c}\odot \\
30 \mu \mathrm{m} \text { long } \\
\end{array}$ & Dislocation & $\{100\}$ & $\begin{array}{l}\text { Dislocation normal to the } \\
\text { surface }\end{array}$ \\
\hline $\begin{array}{l}\text { Line } \\
\text { structure }\end{array}$ & & Dislocation & $\begin{array}{r}\{110\},\{111\} \mathrm{Ga}, \\
\{111\} \mathrm{As}\end{array}$ & $\begin{array}{l}\text { Dislocation parallel to the } \\
\text { surface, some angular } \\
\text { relationship between disloca- } \\
\text { tion lines }\end{array}$ \\
\hline $\begin{array}{l}\text { Round hillocl } \\
\text { with a tail }\end{array}$ & - & Dislocation & $\begin{array}{l}\{110\},\{111\} \mathrm{Ga}, \\
\{111\} \mathrm{As}\end{array}$ & $\begin{array}{l}\text { Dislocation inclined to the } \\
\text { surface }\end{array}$ \\
\hline $\begin{array}{l}\text { Particles } \\
\text { on dislocatior } \\
\text { line pit }\end{array}$ & 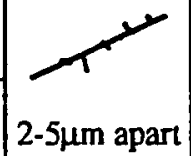 & $\begin{array}{l}\text { Impurity } \\
\text { precipitates }\end{array}$ & $\begin{array}{l}\{110\},\{111\} \mathrm{Ga}, \\
\{111\} \mathrm{As}\end{array}$ & $\begin{array}{l}\text { Dislocation acting as sinks } \\
\text { for the impurities }\end{array}$ \\
\hline $\begin{array}{l}\text { Growth } \\
\text { striation }\end{array}$ & & $\begin{array}{c}\text { Impurity } \\
\text { aggregation }\end{array}$ & $\begin{array}{l}\{110\},\{111\} \mathrm{Ga}, \\
\{111\} \mathrm{As}\end{array}$ & $\begin{array}{l}\text { A record of the shape and } \\
\text { progress of the freezing } \\
\text { interface during crystal growth. } \\
\text { Striations on undoped GaAs }\end{array}$ \\
\hline
\end{tabular}




\subsection{KOH ETCHING}

Etching in molten $\mathrm{KOH}$ is routinely done to delineate dislocations in GaAs single substrates. The dislocation etch pits on the $\{100\},\{110\},\{111\} \mathrm{Ga}$ and $\{111\}$ As samples were successfully revealed by $\mathrm{KOH}$ etchant.

\subsection{1. $\{100\}$ Surface}

Typical hexagonal pyramid pits appear on all the GaAs $\{100\}$ surfaces after $\mathrm{KOH}$ etching; these characteristically-shaped six-sided pits are elongated along one of the $\langle 110\rangle$ directions in the $\{100\}$ surface (Fig.27). Average etch pit sizes are about $40 \mu \mathrm{m}$. The surfaces of the etch pits consist of planes defined by the differential in vertical etch rate and directions of minimum etch rate in the horizontal plane. ${ }^{(56)}$

There exist two kinds of etch pits on the sample, which are dislocation etch pits (line defects) and surface damage etch pits (localized defects). Dislocation etch pits will simply continue to grow without changing shape and maintain a pointed morphology (see pits $A$ in Fig.27). If the dislocation is not normal to the surface, the pits will be distorted, such as $A_{1}$ and $A 2$ in Fig.27, which are inclined a few degrees in roughly opposite directions. For surface damage etch 
pits (B in Fig.27), damage areas such as scratches will be etched faster and grooves or pits will form which will remain after the initially strained material is etched away. Therefore, both line and localized defect etch pits can initially have the same morphology. But upon continued etching, the localized defect pits become flatter round bottom (B in Fig.27), while the dislocation pits will continue to deepen to sharp bottom (A in Fig.27).

Experimental results of $\{100\}$ face $\mathrm{KOH}$ etching also show that the increased time has only increased the pit size; the distribution and the shape of pits has remained the same. The shapes of the pits on the two opposite faces of a wafer are rotated by $90^{\circ}$ because of the polar axis of the GaAs lattice.

$\mathrm{KOH}$ etching can be used to analyze the dislocation distribution on a whole GaAs wafer. Etch pit density (EPD) on the $\{100\}$ surface basically corresponds the dislocation density on the substrate surface; there is a one-to-one correspondence between the pits and the dislocations. ${ }^{(45)}$ There exists a radial dislocation distribution on (100) VGF GaAs wafers after $\mathrm{KOH}$ etching. Figure 28 shows that undoped SI GaAs materials have a radial dislocation distribution on $\{100\}$ surfaces, which actually are suitable for almost all other kinds of GaAs materials including Si-doped and $\mathrm{Zn}$-doped SC GaAs wafers, as well as Cr-doped SI GaAs samples. Otherwise, the radial 


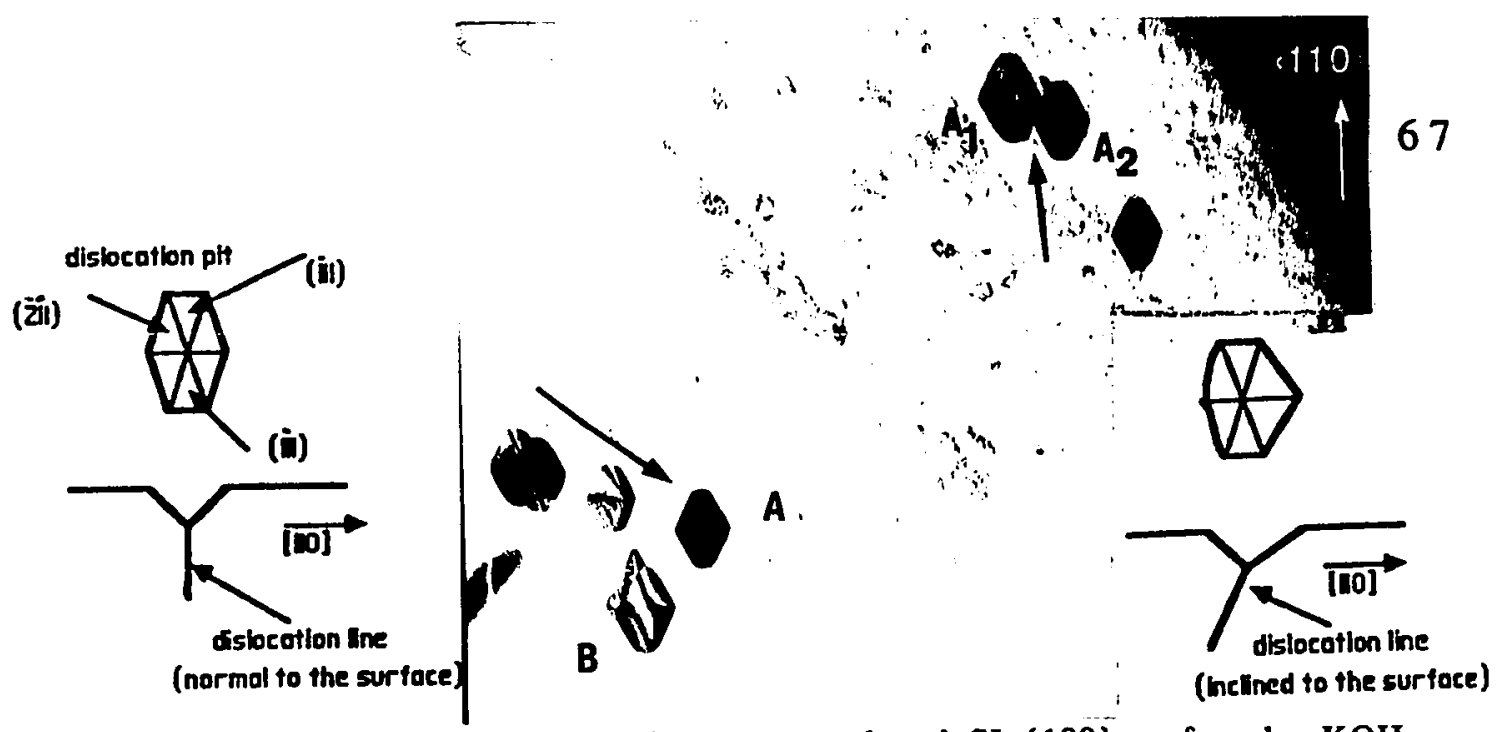

Figure 27. Typical etch pits on an undoped SI $\{100\}$ surface by $\mathrm{KOH}$ etching. A-type pits are due to dislocations, and type $B$ to localized defects. $A_{1}$ and $A_{2}$ are due to dislocation slightly inclined to the surface, $200 \mathrm{X}$

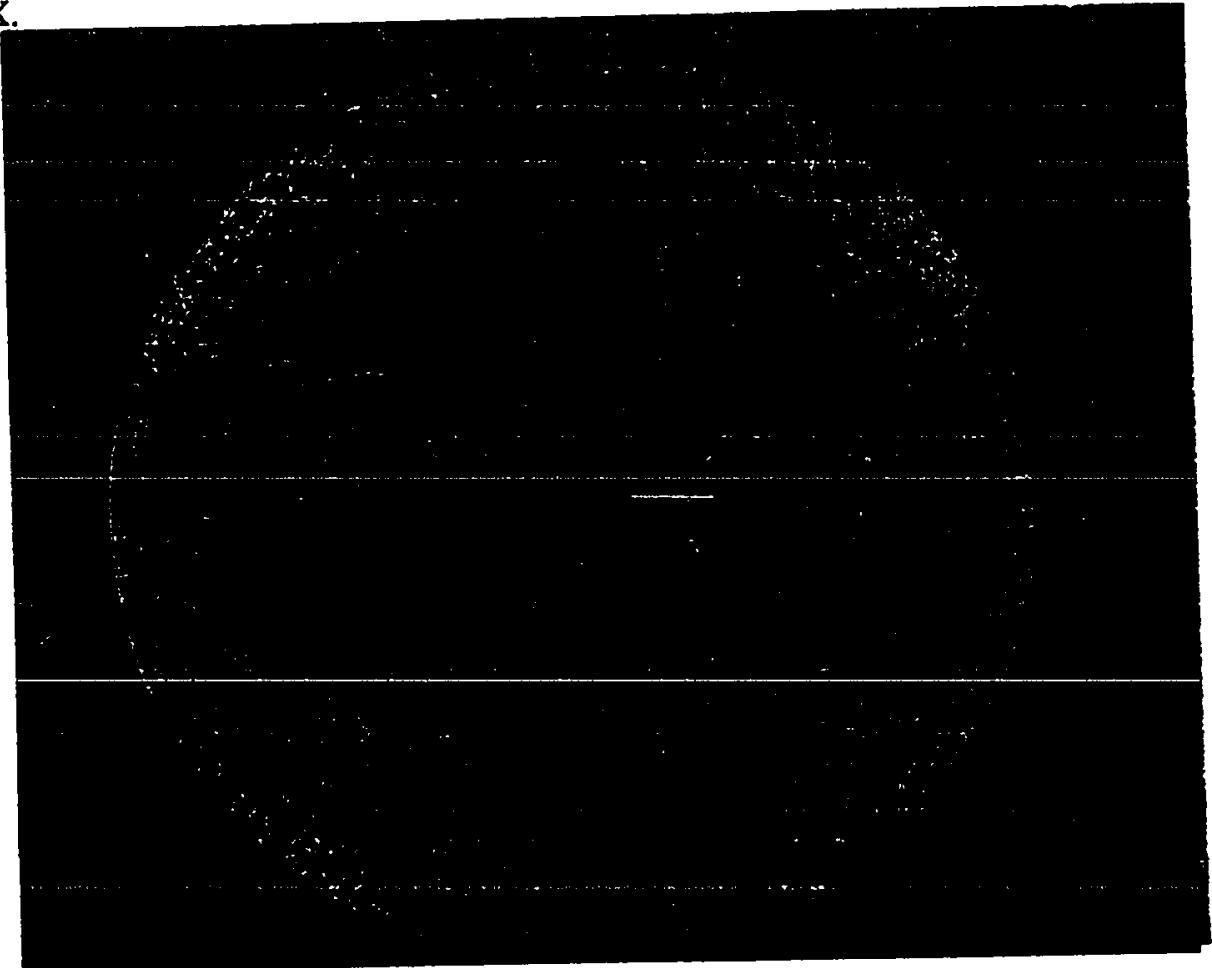

Figure 28. Dislocation distribution on the $\{100\}$ surface of undoped SI GaAs material by $\mathrm{KOH}$ etching. There exist a radial, four-fold symmetrical dislocation. 


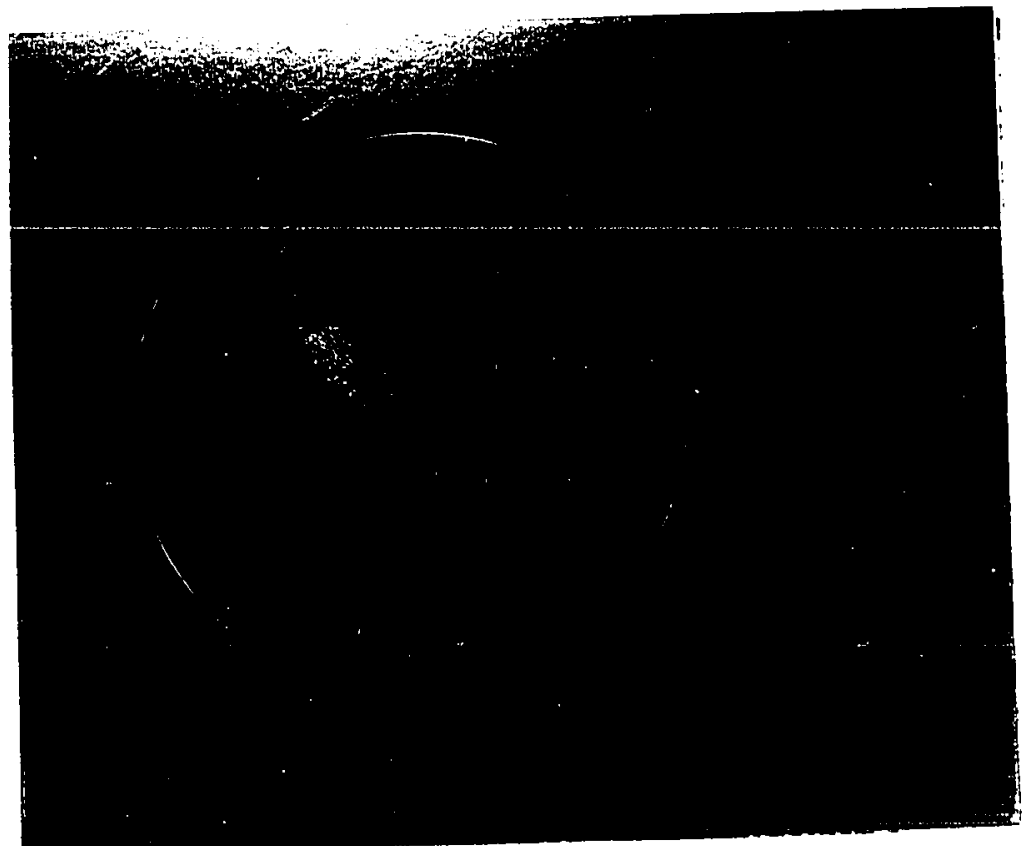

Figure 29. (a)

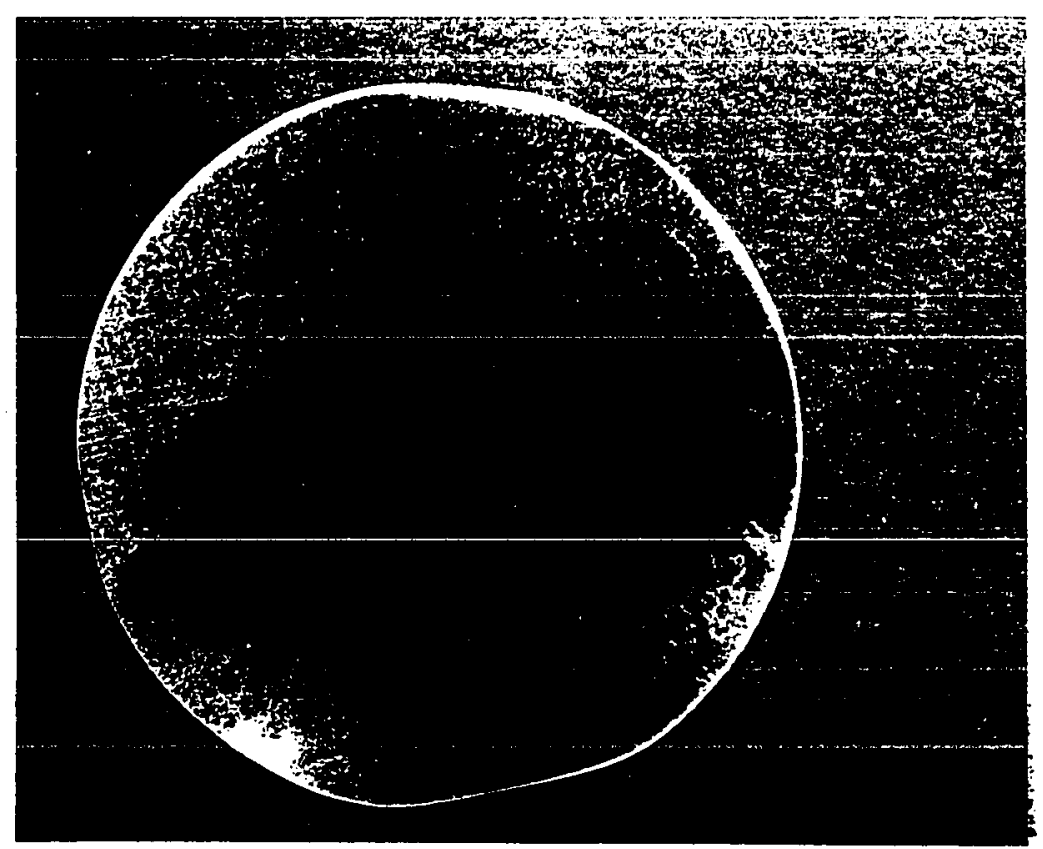

Figure 29. (b)

Figure 29. Etch Pit Density (EPD) maps of Si-doped SC GaAs materials. (a) high Si-doped $\left(n_{c}>10^{18}\right)$ sample, (b). low Si-doped $\left(n_{c} \equiv 10^{17}\right)$ sample. 
dislocation distribution across wafers also exhibits four-fold symmetry indicative of the (100) crystallographic orientation. Generally, different features appear for the GaAs ingots with different dopants.

On Si-doped GaAs wafers, the EPD map shows an un-uniform distribution on the wafer for a high dopant level (carrier concentration $c_{n}>10^{18}$ ) (Fig.29 (a)) and a generally uniform distribution for a lower dopant level $\left(\mathfrak{c}_{n}<10^{17}\right.$ ) (Fig.29 (b)). The dislocation density decreases with n-type (Si) doping. For a higher Si-doped sample, maximum EPD occurs at the edge along $<100>$ crystallographic directions, and in the center area; the EPD pattern looks like a butterfly. For a lower Si-doped sample, the maximum EPD also is at the edge; the minimum EPD occurs over an annulus between the center and edge; intermediate EPD occurs in the center. Otherwise, Fig.30 shows that a dislocation-free crystal of GaAs can be obtained from high Si-doping $\left(c_{n}>10^{18} \mathrm{~cm}^{-3}\right)$. Bourret et al. ${ }^{(57)}$ suggested that dislocations in GaAs originate from crystallographic glide induced by excessive thermal stress associated with crystal growth and dislocation motion. Multiplication occurs through glide or climb by nucleation and growth of jogs which must depend on the presence of point defects. ${ }^{(57)}$ Parsey et al. also found that doping with $\mathrm{Si}$ removed the arsenic pressure dependence of the dislocation density. ${ }^{(58)}$ Dislocation formation is closely related to the 
concentration of intrinsic point defects. The results obtained with Sidoped strongly suggest that charged gallium vacancies are the main native defects responsible for dislocation formation and climb in GaAs. ${ }^{(59)}$

The dislocation density is assumed to be proportional to the total stress within an additive constant. The relatively high EPD measured along $\langle 100\rangle$ compared to along $\langle 110\rangle$ is explained in terms of the theory by the fact that more slip systems contribute to the total stress along $<100>$.

Zn-doped, p-type SC GaAs has a uniform EPD distribution (Fig.31); cellular dislocation distribution was obtained on the whole wafer. Opposite to Si-doped, n-type GaAs, dislocation density of ptype materials increases with p-type $(\mathrm{Zn})$ doping. ${ }^{(60)}$

For $\mathrm{Cr}$-doped and undoped SI GaAs wafers, EPD distributions are similar to $\mathrm{Zn}$-doped wafers; uniform, cellular dislocation distributions were observed on the whole etched wafers (Fig.32). Generally, the EPD on the edges is higher than that in the center, which is different from a LEC-grown GaAs crystal. When the EPD maps of this work were compared with those of published references, the dislocation density of a VGF crystal was found to be much fewer than that of LEC crystal. 


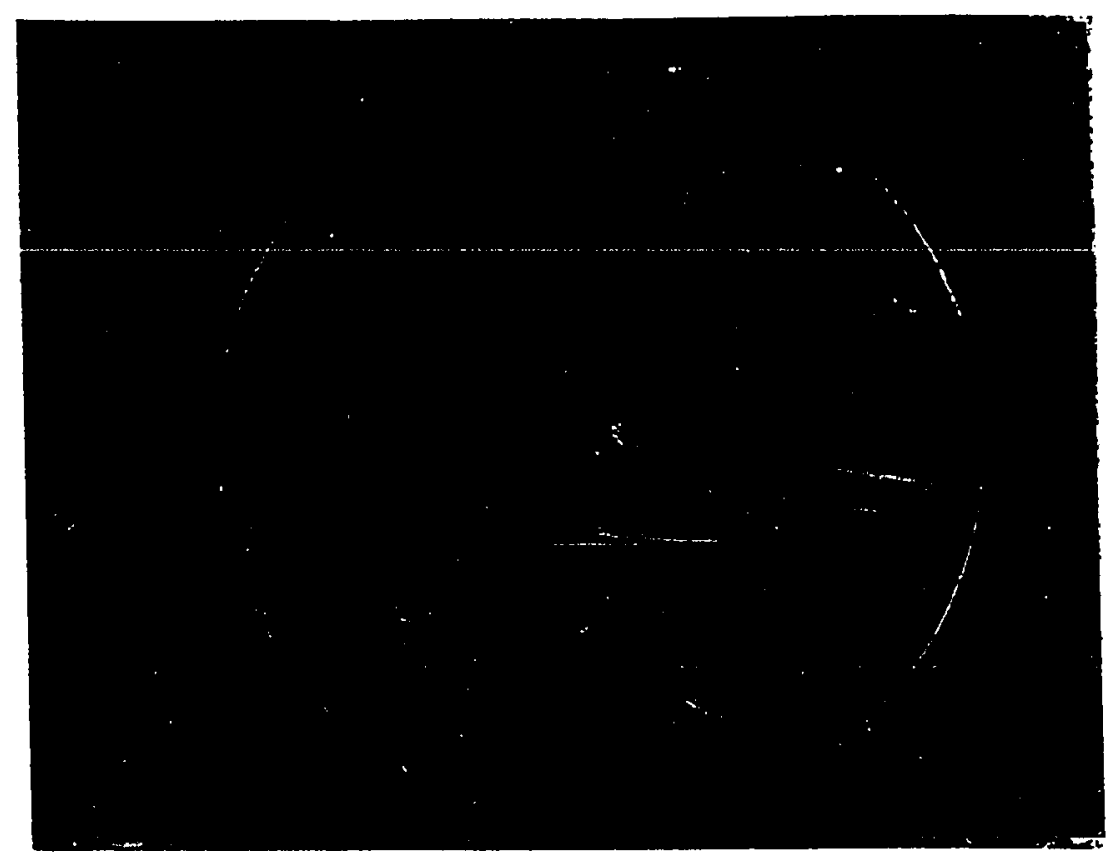

Figure 30. Dislocation-free crystal obtained from high $\mathrm{Si}$-doped $\left(n_{c}>10^{18}\right)$ SC GaAs material by $\mathrm{KOH}$ etching.

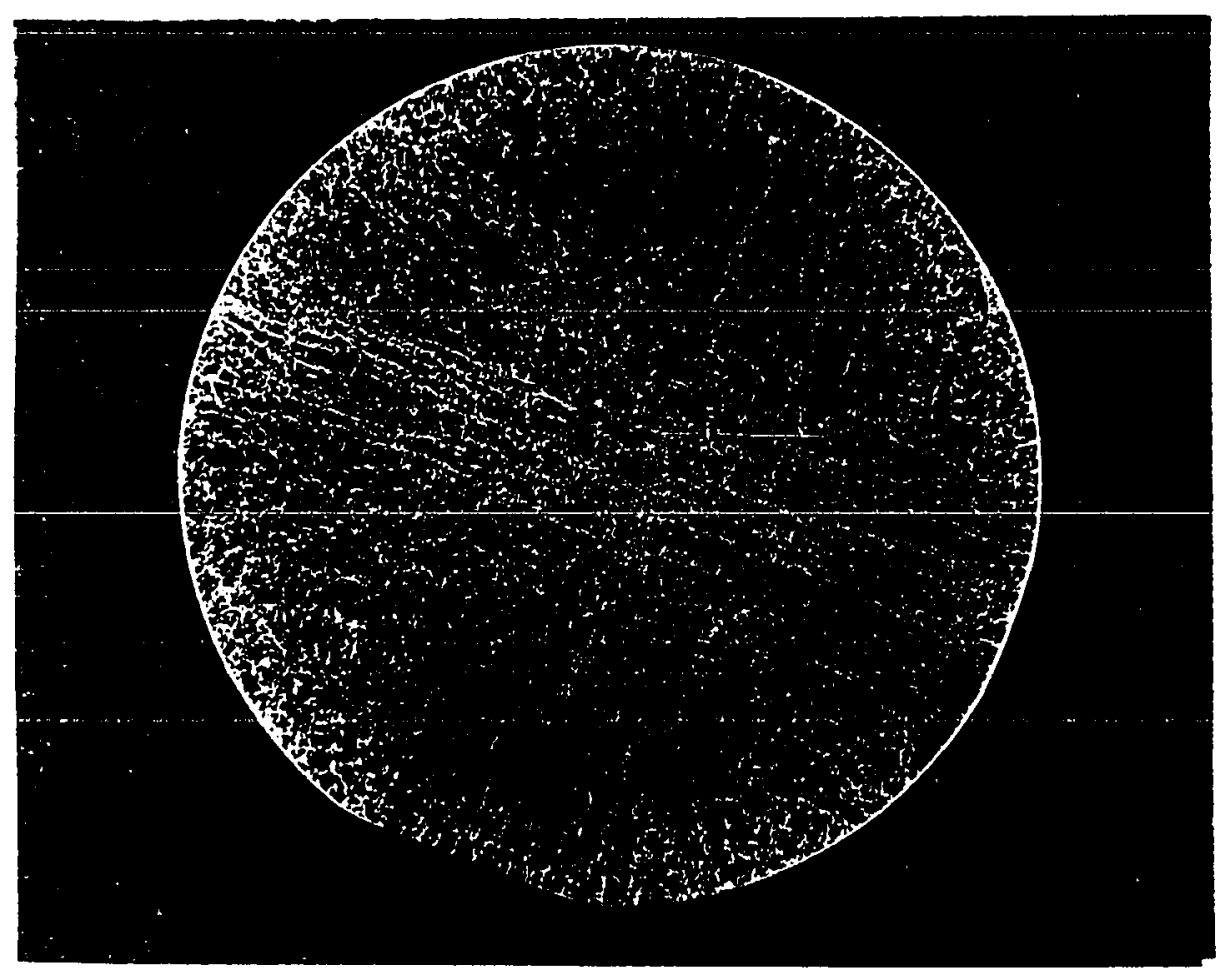

Figure 31. EPD map of $\mathrm{Zn}$-doped $\{100\}$ surface. 


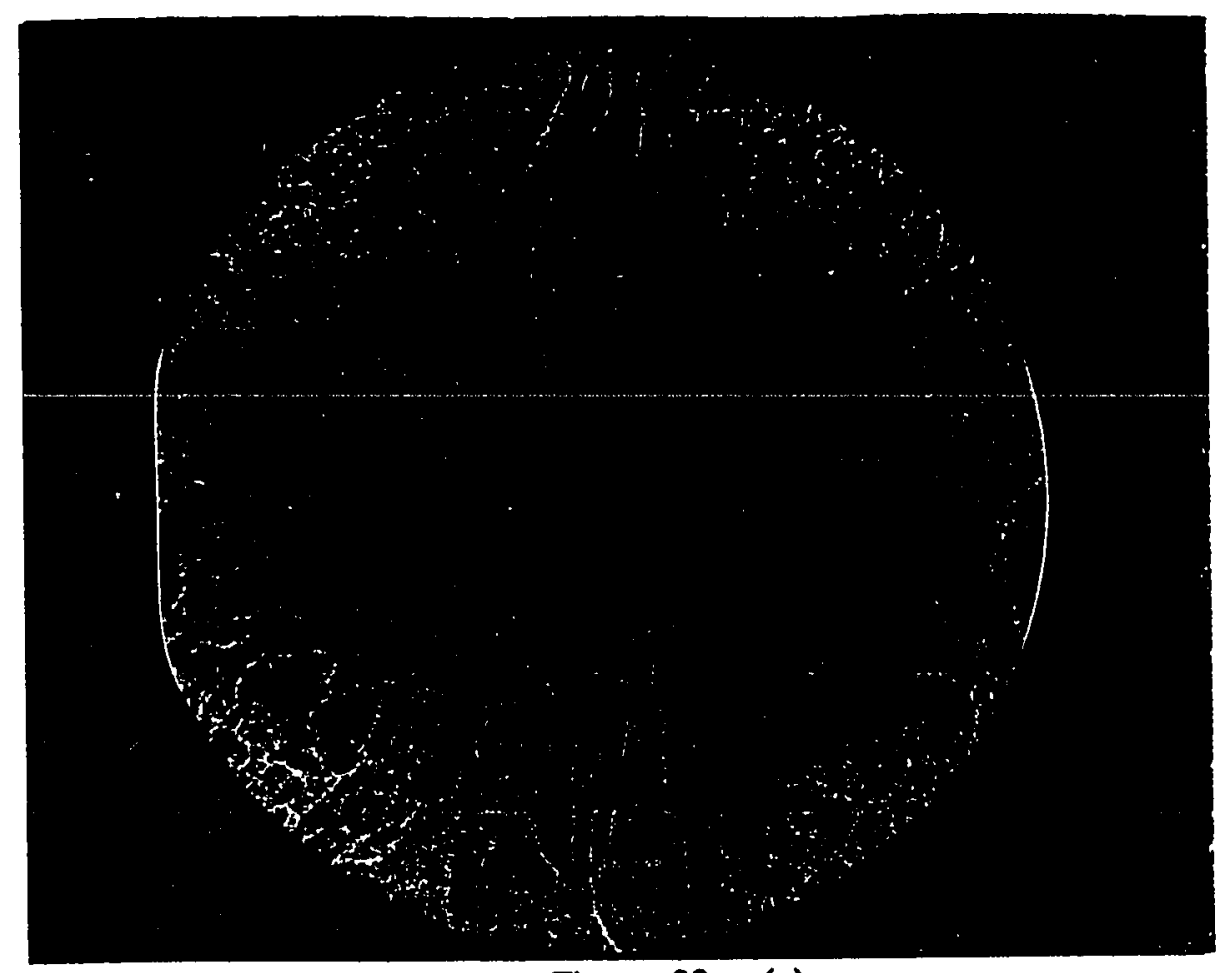

Figure 32. (a)

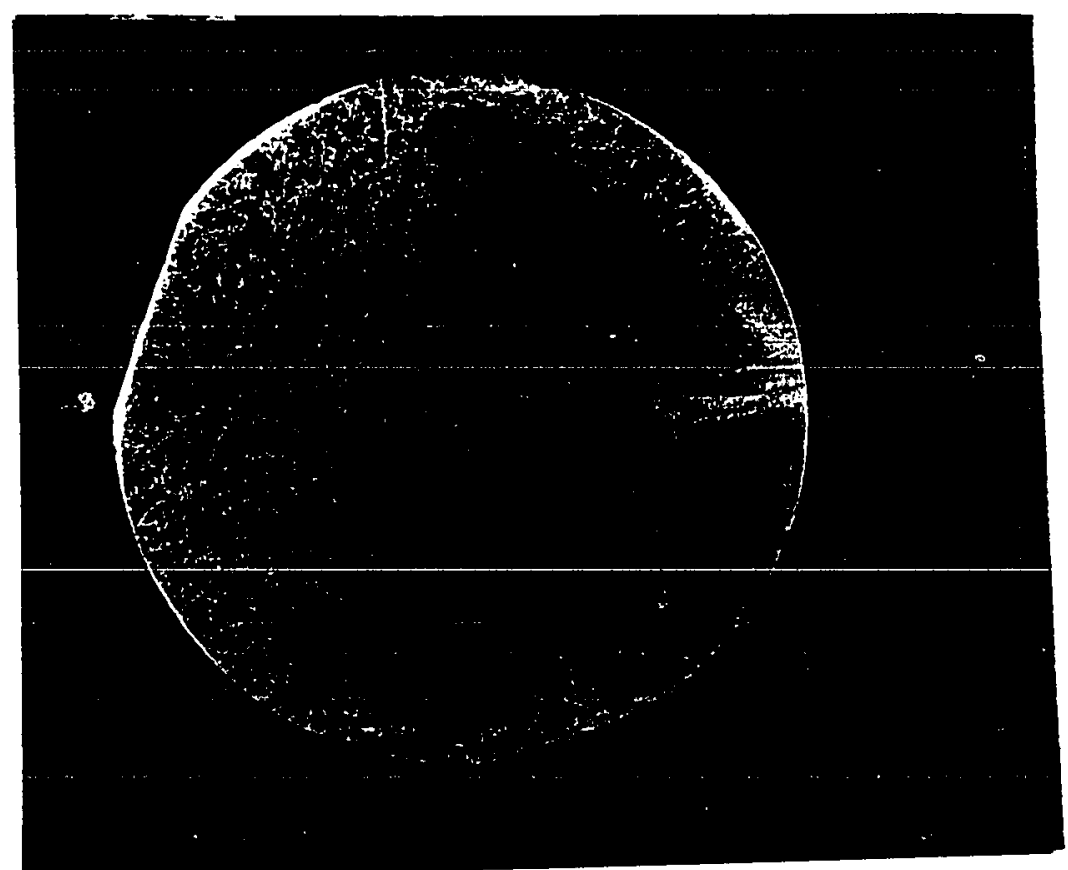

Figure 32. (b)

Figure 32. EPD distribution of $\mathrm{Cr}$-doped and undoped SI GaAs material, (100\} surface. (a). undoped, (b). Cr-doped. 


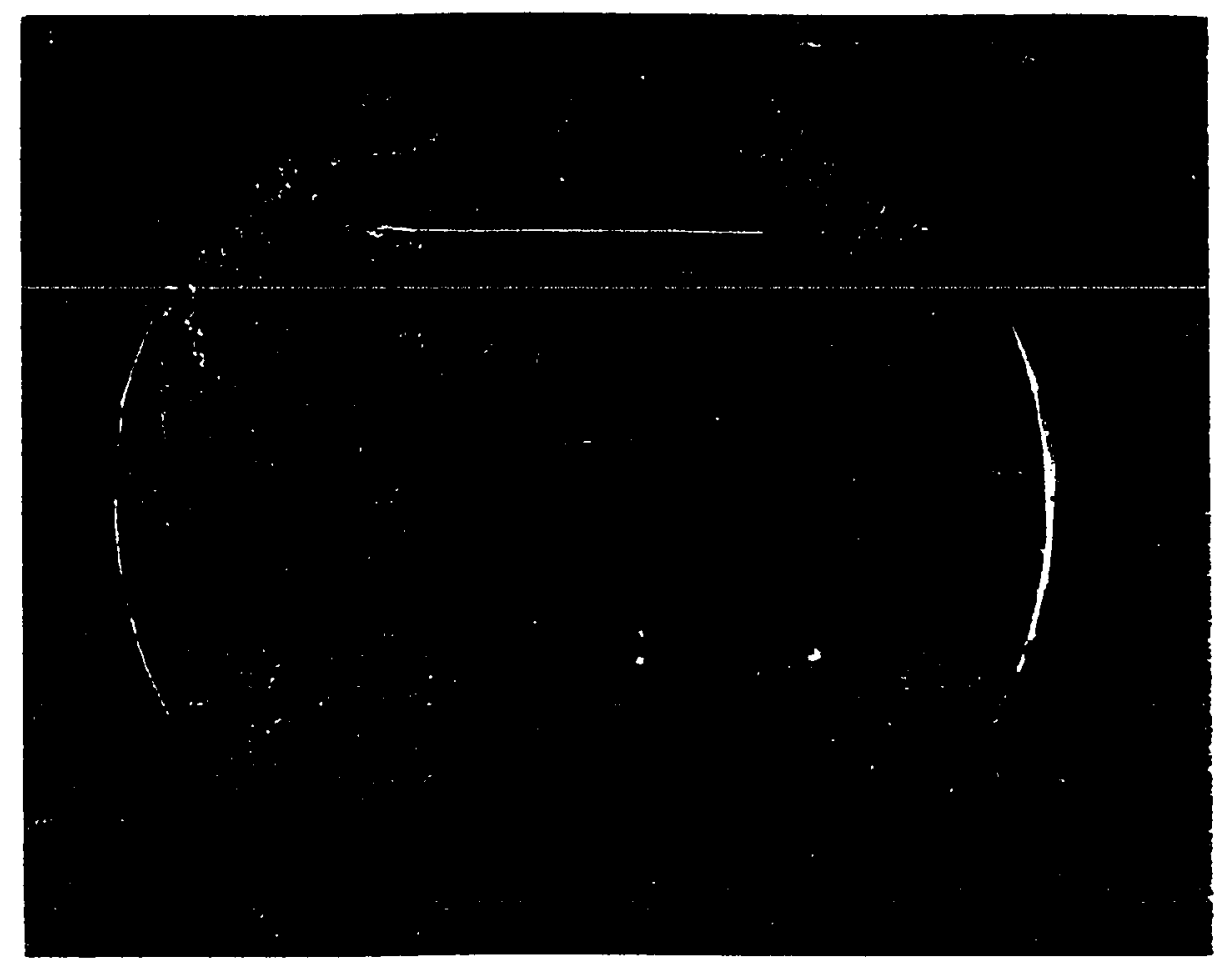

Figure 33. (a)

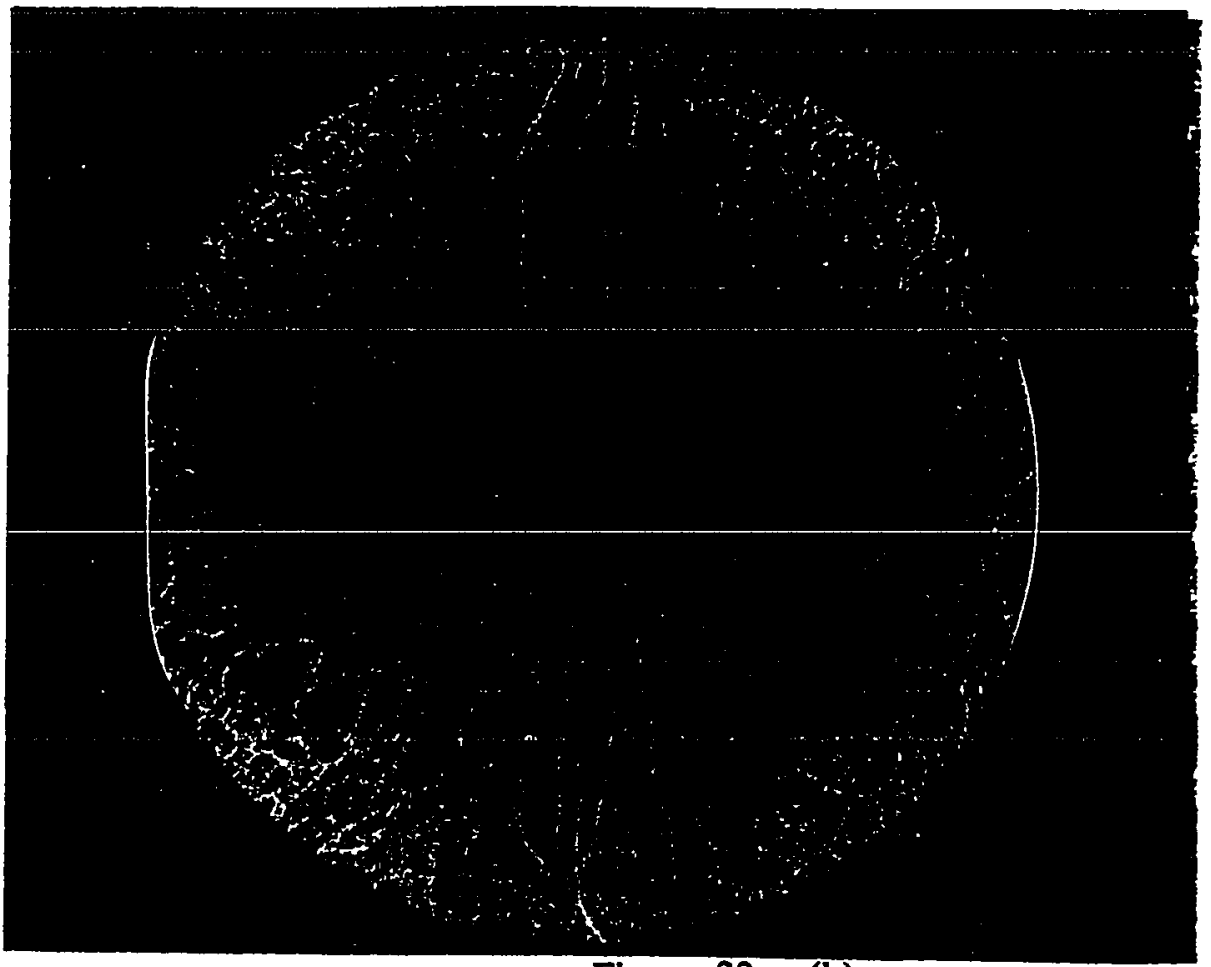

Figure 33 . (b) 


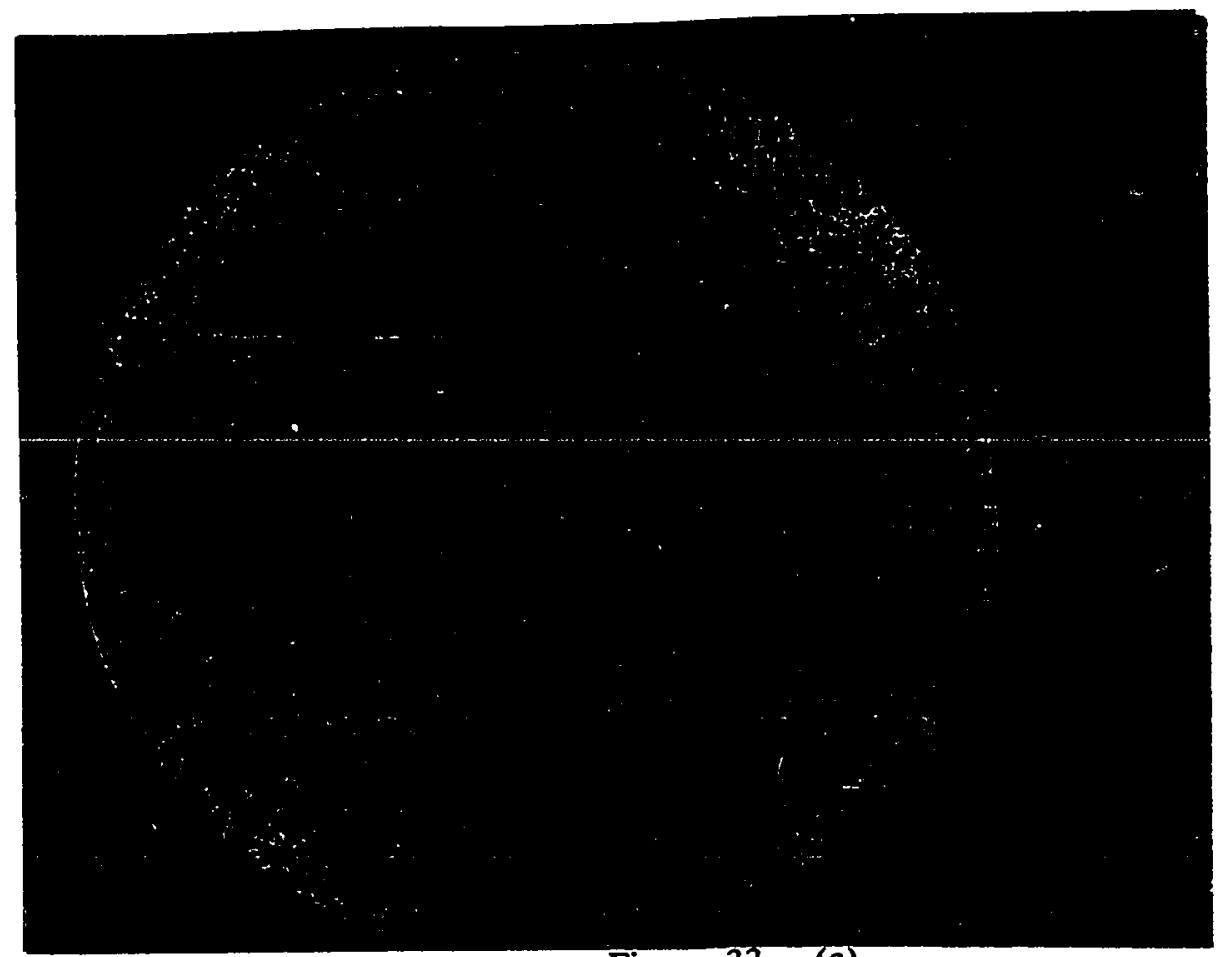

Figure 33. The longitudinal variation (along the growth direction) of the dislocation density by KOH etching, undoped. (a). EPD at the head of crystal, (b). EPD at the middle of crystal, (c). EPD at the tail of crystal.

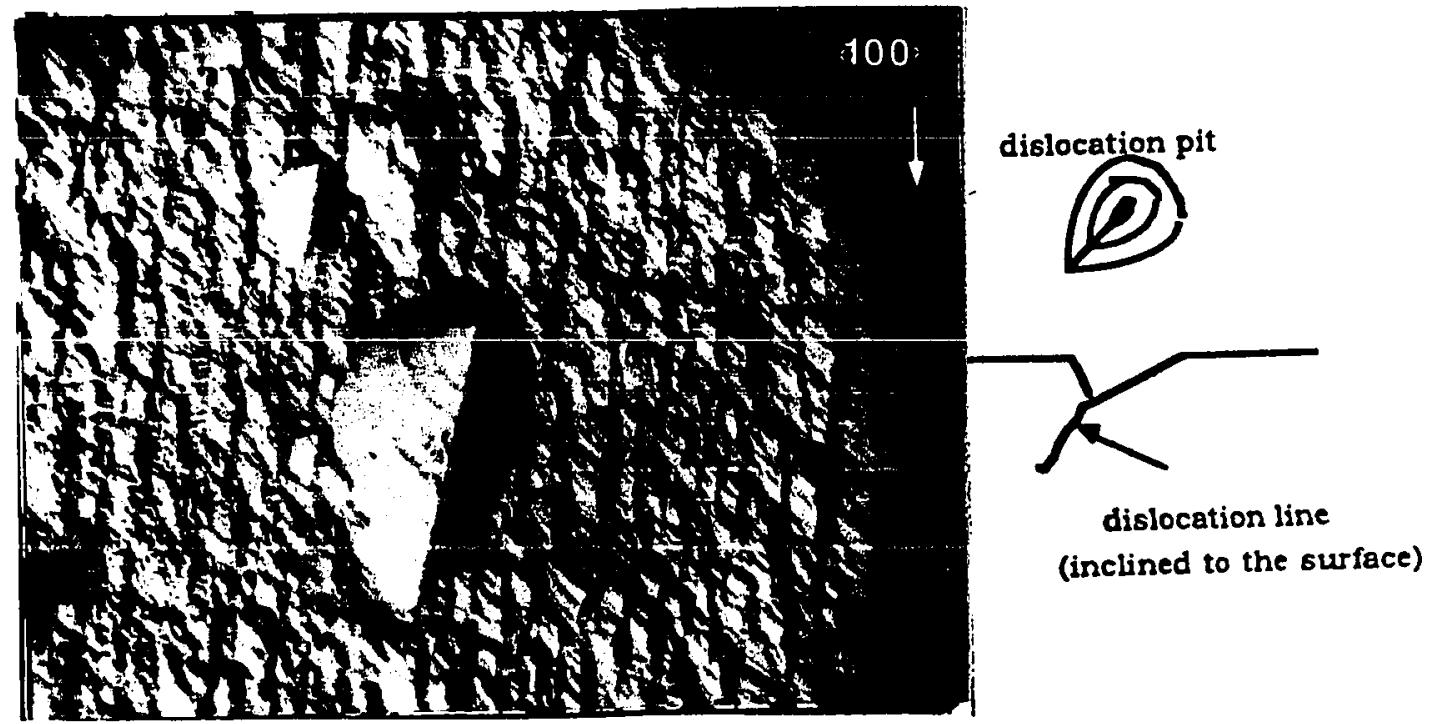

Figure 34. Dislocation etch pits on the $\{110\}$ surface by $\mathrm{KOH}$ etching, $200 X$. 
The longitudinal variation (along the growth direction) of the dislocation density was obtained by $\mathrm{KOH}$ etching the GaAs wafers obtained from the front, middle, and tail of a undoped VGF crystal ingot, as shown in Fig.33. The EPD is lowest at the front and highest at the tail.

\subsection{2. $\{110\}$ Surface}

The etch pit on all the $\{110\}$ samples looks like a clam shell, which is elongated along one of the $\langle 100\rangle$ directions (Fig.34). The reason that the shape of the pit on the $\{110\}$ faces is different from that on the $\{100\}$ faces is due to dislocations inclined to the surface for $\{110\}$ faces, and dislocations normal to the surface for $\{100\}$ faces. The typical dimension of etch pits is about 50-150 $\mu \mathrm{m}$ long.

The surfaces are rough on all the samples after $\mathrm{KOH}$ etching. Especially mentioned here, a raised polygon structure was found on the Cr-doped $\{110\}$ sample (Fig.35), which was not found in other published literature. No explanation is given for this phenomenon. The author guesses it probably is a kind of reaction product adhering to the etched surfaces. 


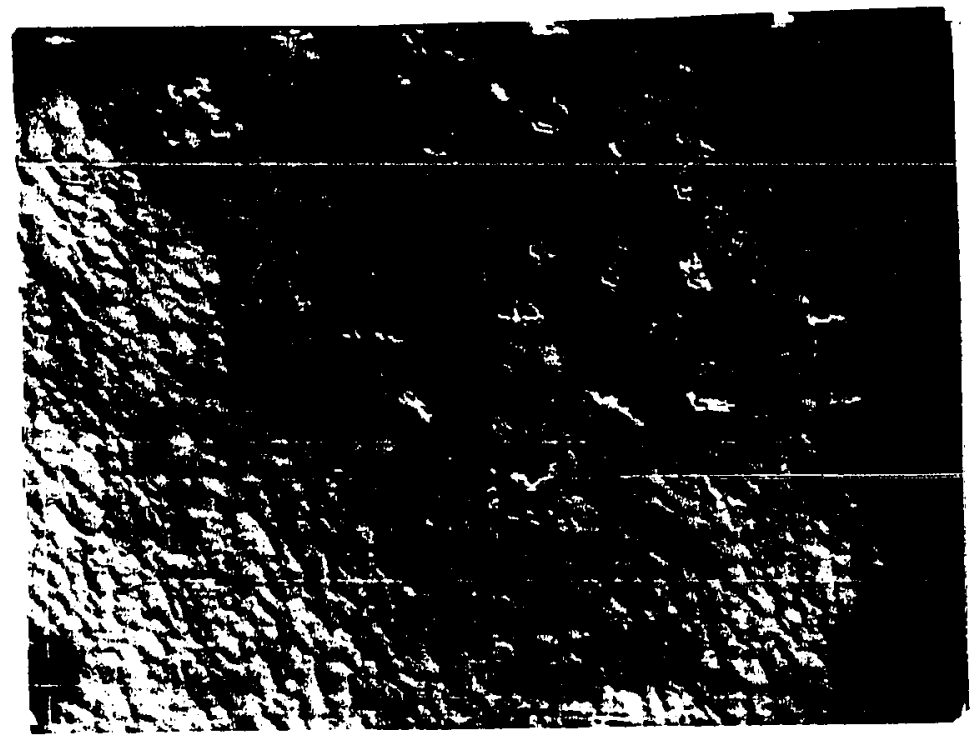

Figure 35. Special raised polygonal structures on a $\mathrm{Cr}$-doped $\{110\}$ surface by $\mathrm{KOH}$ etching, $200 \mathrm{X}$.

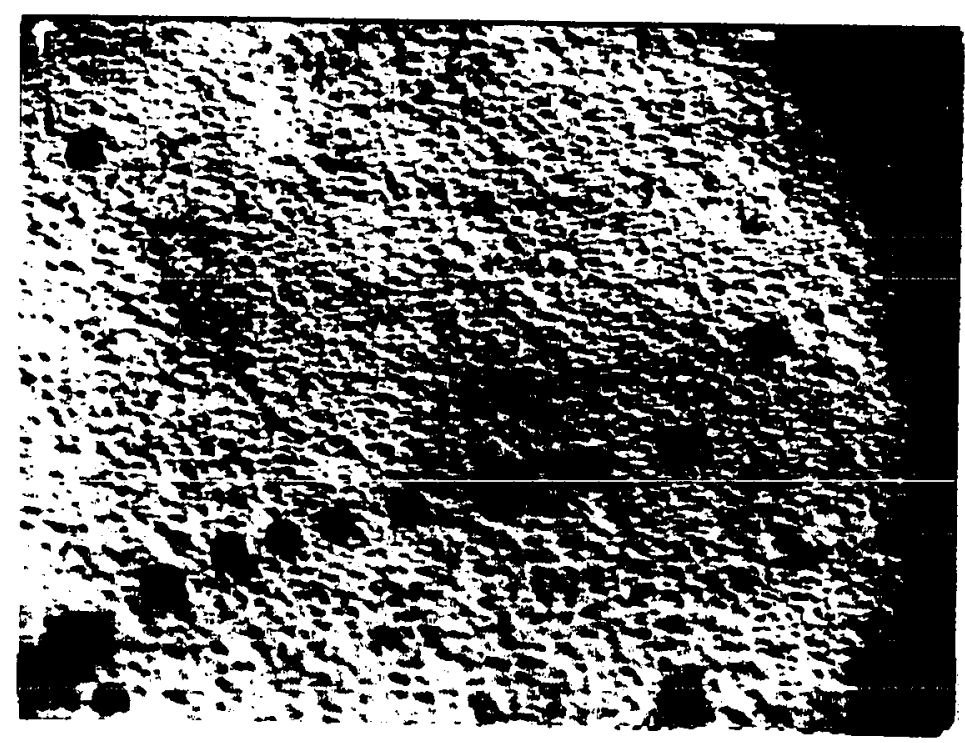

Figure 36. (a) 


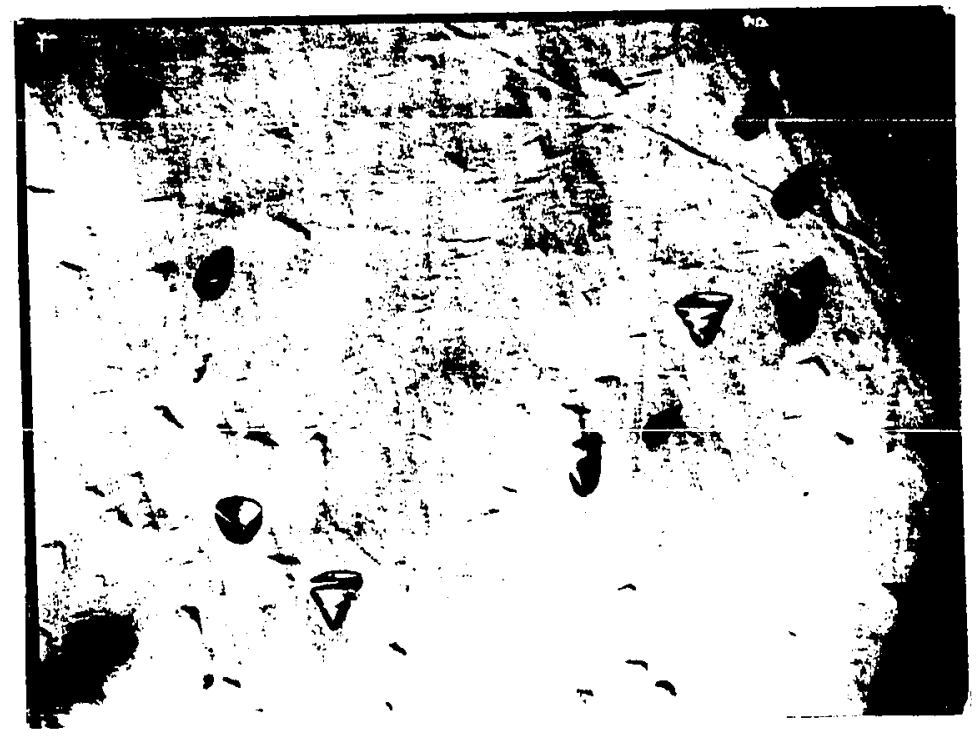

Figure 36. (b)

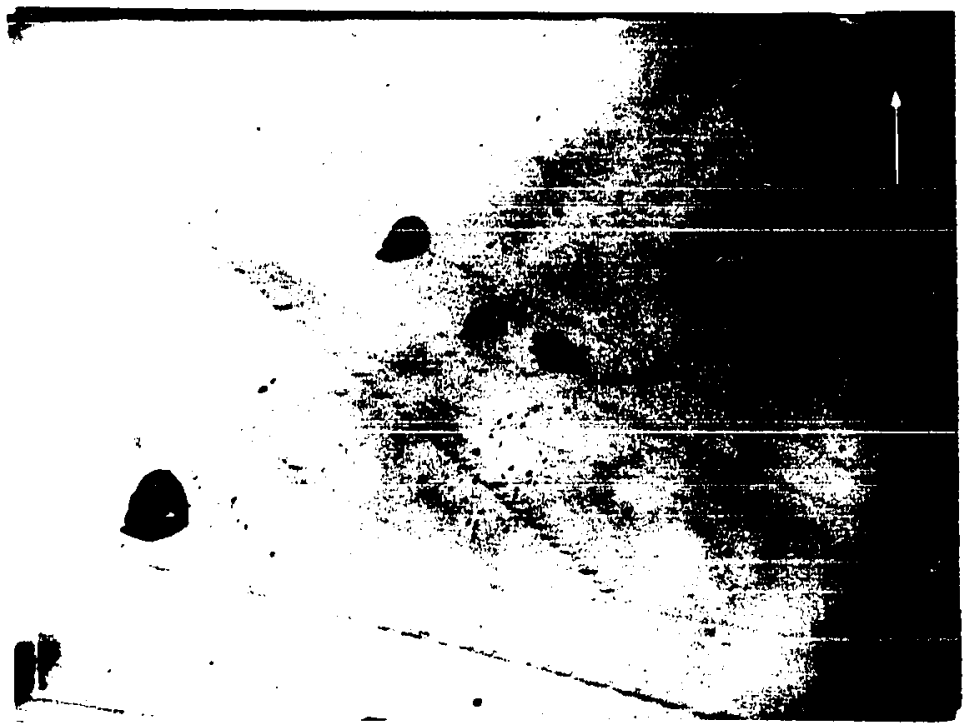

Figure $36 . \quad$ (c)

Figure 36. Typical etch pits on the $\{111\} \mathrm{Ga}$ surface by $\mathrm{KOH}$ etching. (a). Si-doped, 200X. (b). Zn-doped, 200X. (c). undoped, 200X. 


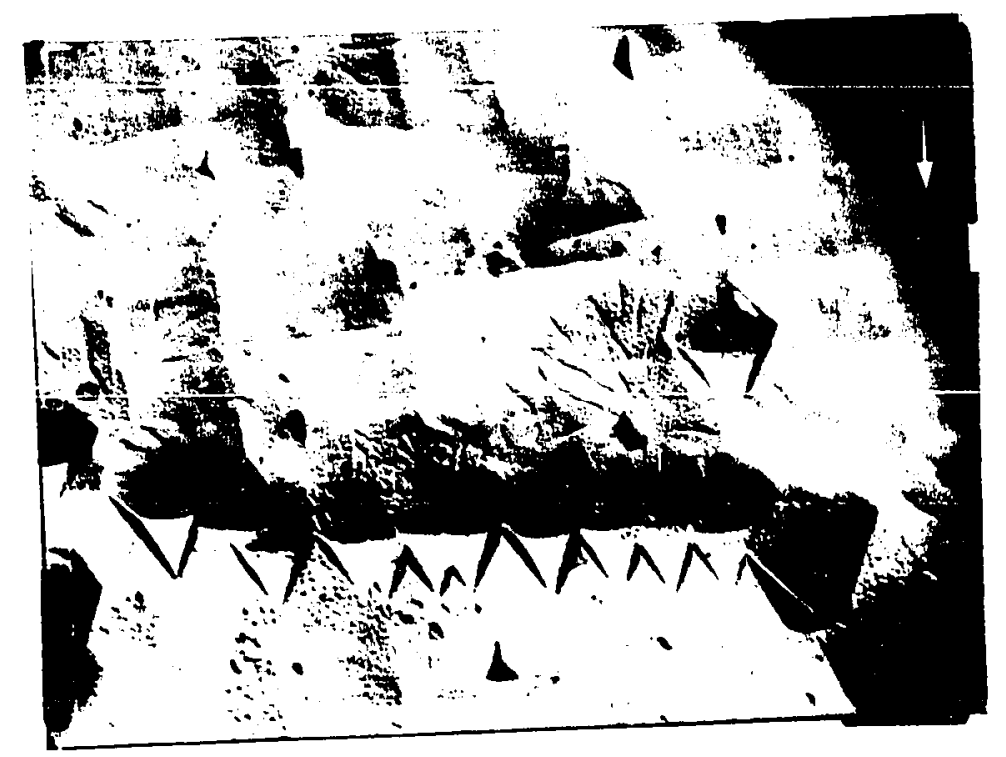

Figure 37. Triangular mounts and flower-like structures on the (111)As surface by $\mathrm{KOH}$ etching, Si-doped, $200 \mathrm{X}$.

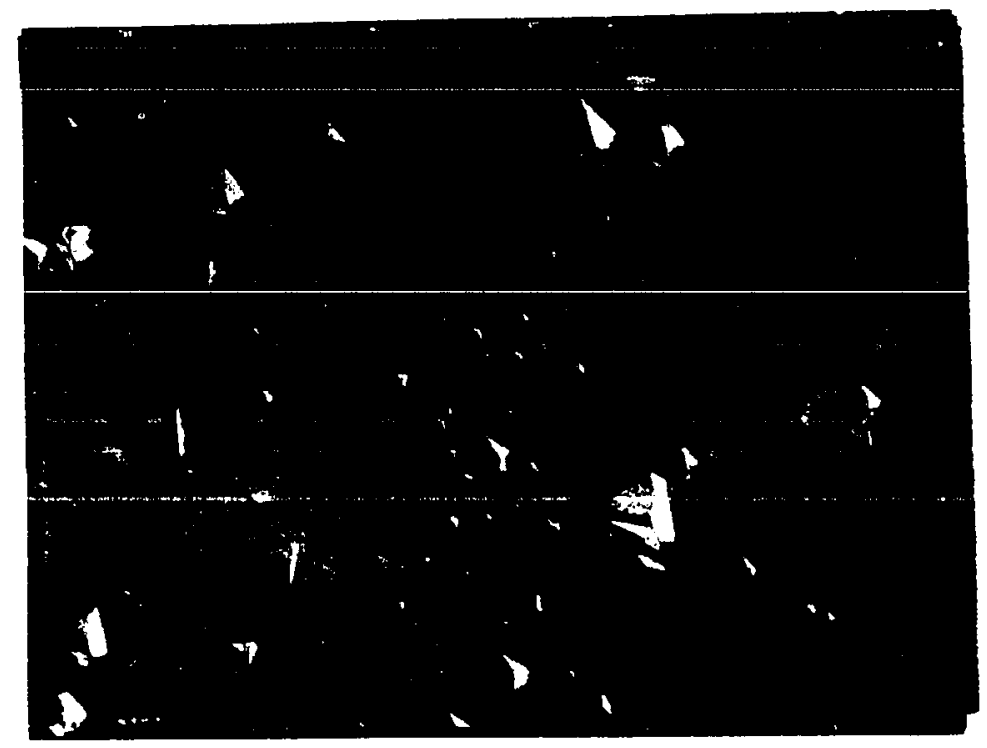

Figure 38. Polygonal pits on $\{111\}$ As by $\mathrm{KOH}$ etching, Zn-doped, $200 \mathrm{X}$. 


\subsection{3. $\{111\} \mathrm{Ga}$ Surface}

Figure 36 shows the etch pits (dislocation pits) of Si-doped, Zndoped and undoped $\{111\} \mathrm{Ga}$ VGF crystals by $\mathrm{KOH}$ etching, which have almost the same shapes and features. The pits thread their ways from the surface into the bulk, and follow the dislocation line down and in a specific direction. The shape of pits has a nearly triangular pyramid appearance, and a dimension of 25-30 $\mu \mathrm{m}$. The pits are crystallographic with the intercepts of pit edges aligned parallel to one of the $\langle 110\rangle$ directions.

Another feature is that the surface of the Si-doped sample is rougher than those of $\mathrm{Zn}$-doped and undoped samples (Fig.36). The same phenomenon also occurs at $\{111\}$ As faces.

\subsection{4. $\{111\}$ As Surface}

On the contrary to $\{111\} \mathrm{Ga}$ faces, the etch structures (dislocations) of $\{111\}$ As faces are the triangular mounts, which have bigger dimensions than those of the $\{111\} \mathrm{Ga}$ sample $(25-70 \mu \mathrm{m})$ (Fig.37). The pits also are crystallographic with intercepts of mount edges aligned parallel to one of the $\langle 110\rangle$ directions. Some random polygonal pits are found in Zn-doped SC GaAs crystal (Fig.38), as well as in Si-doped and undoped GaAs crystals. 
An interesting flower-like structure is found on the Si-doped \{111\}As surface (Fig.37). No regularity can be found for this structure. One possibility is that the structure may be the reaction products adhering the etched surface.

\subsubsection{Summary}

To conclude this section, a summary of etched structures on the GaAs substrates by $\mathrm{KOH}$ etching can be obtained, The results are in Table 4. 
Table 4. Summary of etched structures in GaAs single crystals by $\mathrm{KOH}$ etching

\begin{tabular}{|c|c|c|c|c|}
\hline $\begin{array}{l}\text { Names of } \\
\text { etched } \\
\text { structures }\end{array}$ & $\begin{array}{l}\text { Shape } \\
\text { and } \\
\text { size }\end{array}$ & $\begin{array}{l}\text { (Probable) } \\
\text { Origin }\end{array}$ & $\begin{array}{l}\text { Revealed on } \\
\text { crystallographic } \\
\text { surfaces }\end{array}$ & Explanations \\
\hline $\begin{array}{l}\text { Hexagonal } \\
\text { etch pit }\end{array}$ & $\begin{array}{l}<110> \\
40 \mu \mathrm{m} \\
\text { long }\end{array}$ & Dislocation & $\{100\}$ & $\begin{array}{l}\text { Dislocation normal to the } \\
\text { surface, Increasing etching } \\
\text { time only influences the pit } \\
\text { size, but not the distribution } \\
\text { and the shape if pits. }\end{array}$ \\
\hline $\begin{array}{l}\text { Shell shaped } \\
\text { pit }\end{array}$ & $\underset{50-150 \mu \mathrm{m}}{2}$ & Dislocation & $\{110\}$ & $\begin{array}{l}\text { Dislocation inclined to the } \\
\text { surface }\end{array}$ \\
\hline $\begin{array}{l}\text { Triangular } \\
\text { etch mount }\end{array}$ & $\begin{array}{c}\nabla \\
20-70 \mu \mathrm{m}\end{array}$ & Dislocation & $\{111\}$ As & $\begin{array}{l}\text { Dislocation inclined to the } \\
\text { surface }\end{array}$ \\
\hline \begin{tabular}{|l|}
$\begin{array}{l}\text { Triangular } \\
\text { pyramid } \\
\text { pit }\end{array}$ \\
\end{tabular} & $\otimes_{25-30 \mu \mathrm{m}}$ & Dislocation & $\{111\} \mathrm{Ga}$ & $\begin{array}{l}\text { Dislocation inclined to the } \\
\text { surface }\end{array}$ \\
\hline $\begin{array}{l}\text { Hexagonal } \\
\text { flat pit }\end{array}$ & $40 \mu \mathrm{m}$ & Surface damage & $\{100\}$ & Localized defects \\
\hline $\begin{array}{l}\text { Polygonal } \\
\text { pit }\end{array}$ & $\Delta$ & As-sites? & $\{111\}$ As & $\begin{array}{l}\text { Especial phenomenon in } \\
\text { \{111\}As surface, It may be } \\
\text { concerned with Ga sites in } \\
111 \text { As surfacelsee Section } 4 .\end{array}$ \\
\hline $\begin{array}{l}\text { Polygonal } \\
\text { raise } \\
\text { structure }\end{array}$ & $\square_{10-25 \mu \mathrm{m}}$ & $\begin{array}{l}\text { reaction } \\
\text { products }\end{array}$ & Cr-doped $\{110\}$ & Not identified \\
\hline
\end{tabular}




\subsection{EUTECTIC ETCHING}

The hydroxide eutectic etchant $(\mathrm{KOH}+\mathrm{NaOH})$ was used to reveal defects in GaAs crystals for evaluating the wafer quality, and was especially used for observing microscopic defects in dislocationfree GaAs crystals. ${ }^{(40)}$ The eutectic etchant, which consists of 50 mole percent $\mathrm{KOH}$ and 50 mole percent $\mathrm{NaOH}$, has a lower melting point $\left(170^{\circ} \mathrm{c}\right)$ compared with $\mathrm{KOH}$ etchant ( The melting point of $\mathrm{KOH}$ etchant is $360^{\circ} \mathrm{c}$ ). The eutectic etchant, therefore, is useful for both GaAs bulk crystals and thin epitaxial layers because the use of $\mathrm{KOH}$ to determine dislocations in thin epitaxial layers is difficult due to the etch rate and difficulty in obtaining a uniform mixture. ${ }^{(39)}$

The eutectic etchant can be used to etch $\{100\},\{110\}$ and \{111\}Ga surfaces of VGF-grown GaAs crystals, but fails on the \{111\}As surface. On the $\{111\}$ As surface, after eutectic etching, appears some polygonal crystal-like structures (black pits) on the whole wafer (Fig.39). This appearance was found on all the \{111\}As surfaces for Si-doped, $\mathrm{Zn}$-doped and undoped GaAs specimens. No published and authoritative explanation can found for this point. It has been mentioned that there exists a difference in the etching behavior between the $\{111\} \mathrm{Ga}$ and $\{111\}$ As planes in Section 3.2. The $\{111\}$ As planes are proposed to be chemically very reactive because they have an unshared pair of electrons, whereas the 


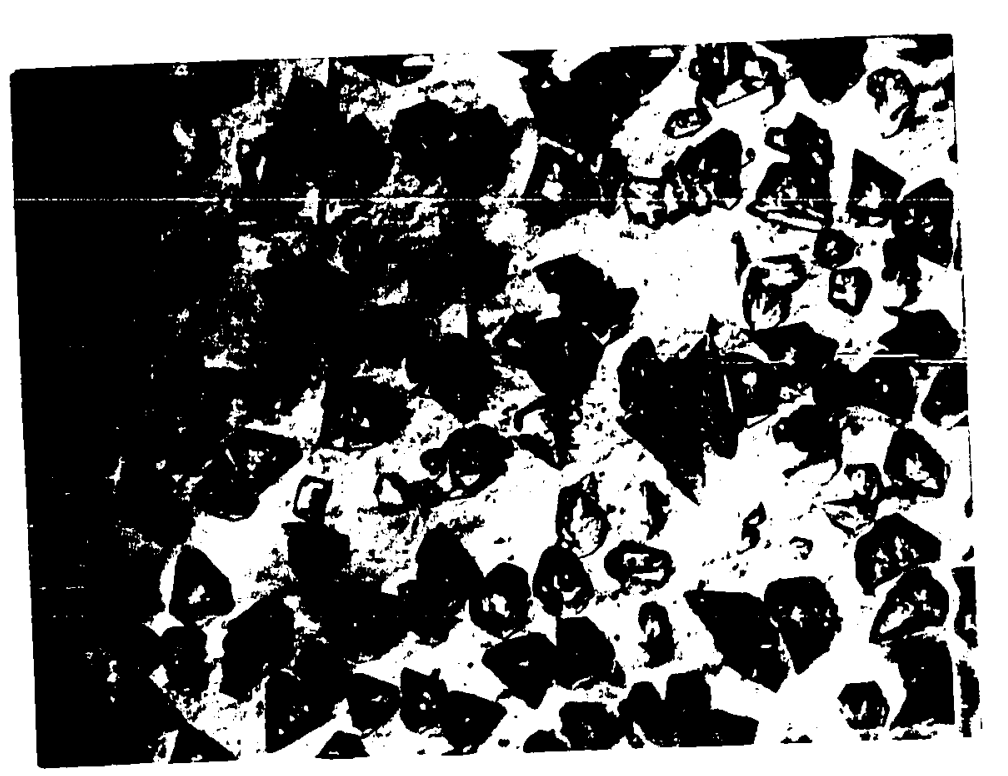

Figure 39. Polygonal, crystal-like etch structures (black pits) on \{111\} As surface by eutectic etching, 200X.

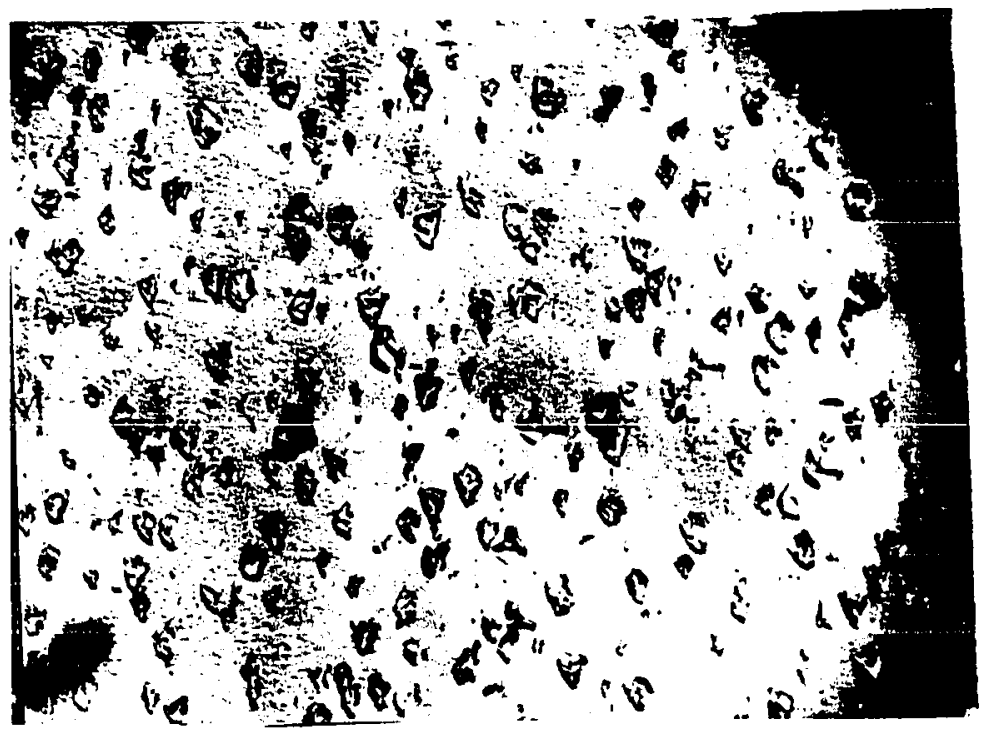

Figure 40 . Etch pits on a $\{111\} \mathrm{Ga}$ surface of undoped SI GaAs by eutectic etching, $200 \mathrm{X}$. 
\{111\}Ga planes have not. ${ }^{(43)}$ Therefore, my assumption is that because the $\{111$ \} As plane is not perfect after the preparation of samples, some small layers must be locally missing. This means that some Ga layers mix on the $\{111\}$ As surface. With the different etching rates for both, on the surface will appear a lot of polygonal pits, which are supposed to be the locations of As layers. This assumption can also be confirmed on the $\{111\} \mathrm{Ga}$ and $\{100\}$ faces. Figure 40 shows the etched $\{111\} \mathrm{Ga}$ surface of a undoped SI GaAs sample. Some polygonal pits, which have a lower density and smaller size than those of the $\{111\}$ As surface, are revealed. The polygonal pits on the $\{110\}$ surface have a slightly different feature from those of the $\{111\}$ surfaces. The pits have a long tiny tail along the $<111>$ crystallographic orientation and make the surface very rough. From the pits with directional long tails, the preferential etching of the $\{110\}$ surface also shows some directional feature which is believed to be due to the different etch rates between $\mathrm{Ga}$ sites and As sites.

To follow the above-described order, the work will still give the etching results and some discussions following the different crystallographic orientations. 


\subsection{1. $\{100\}$ Surface}

The etch patterns developed on the $\{100\}$ GaAs surfaces are shown in Fig.41. For a given orientation, the type of crystals Sidoped n-type, $\mathrm{Zn}$-doped p-type, $\mathrm{Cr}$-doped and undoped did not appear to change the structure of the etched dislocations. The size of the etch pits was dependent on the time in the melt and melting temperature. The dislocation etch patterns were similar to those formed by molten $\mathrm{KOH}$ etching.

Typical etched structures revealed by the eutectic etchant on the $\{100\}$ plane of a VGF GaAs crystal were mainly classified as follows: hexagonal pyramid pits, 30-40 $\mu \mathrm{m}$ in diameter (A of Fig.42); oval pattern pits, 20-30 $\mu \mathrm{m}$ (B of Fig.42); rough surface morphology, 10-20 $\mu \mathrm{m}$ (Fig.41 (b)); raised structures, 10-60 $\mu \mathrm{m}$ (C of Fig.42).

The hexagonal pyramids are dislocation pits. These inverted pyramids have sharp pits, and elongate to $<100\rangle$ or $<110\rangle$ crystallographic directions. Oval pits, which are thought to be related to segregation of the impurities, ${ }^{(40)}$ were observed in all kinds of GaAs crystals including $\mathrm{Si}$-doped, $\mathrm{Zn}$-doped, Cr-doped and undoped VGF GaAs crystals. 

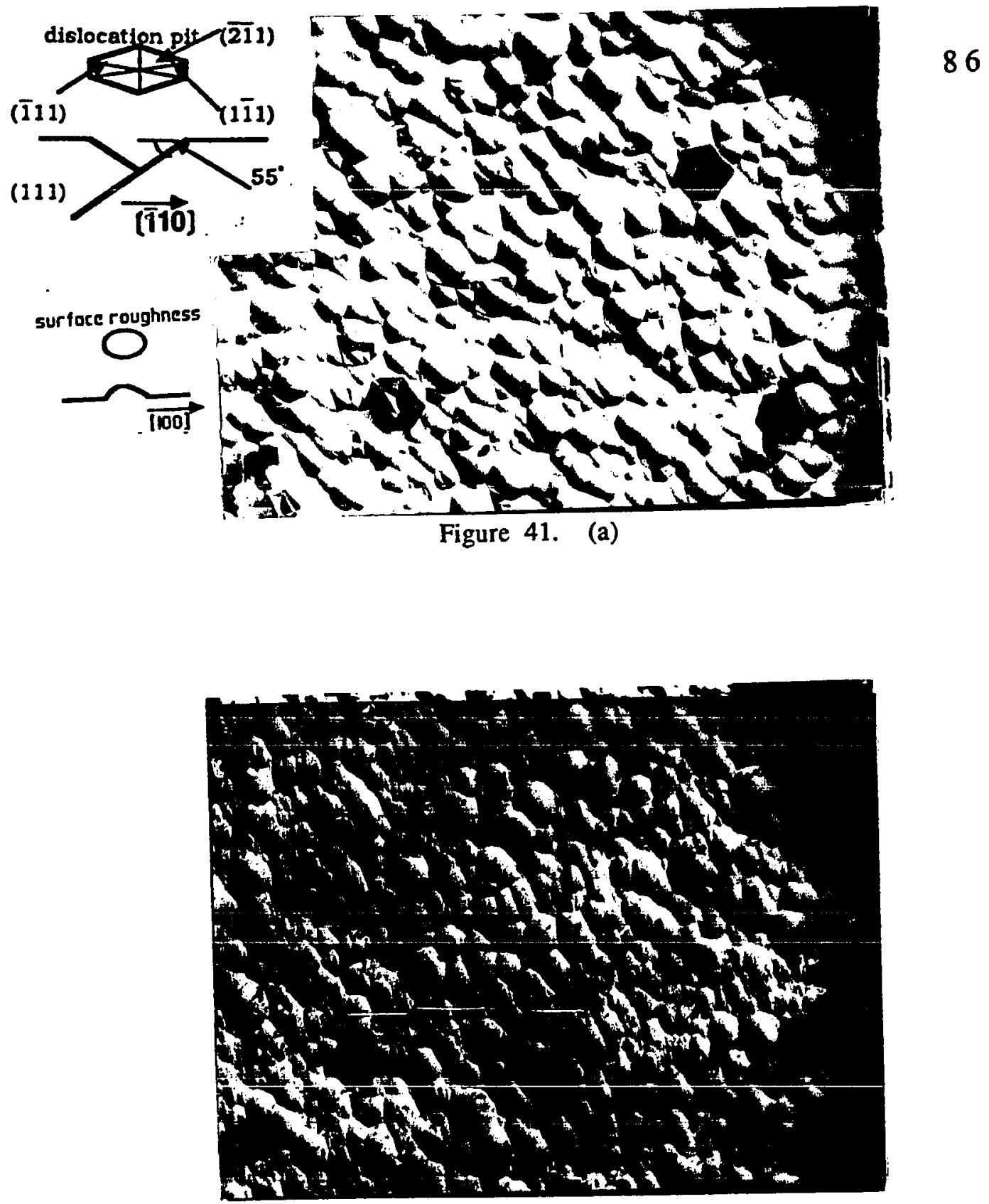

Figure 41. (b)

Figure 41. Dislocation etch pits and surface roughness on Si-doped, \{100\} GaAs by eutectic etching. (a). low Si-doped $\left(n_{c} \equiv 10^{17}\right.$ ) sample, 200X. (b). high Si-doped $\left(n_{c}>10^{18}\right)$ sample, $200 X$. 
The etched patterns of Si-doped, $\mathrm{Zn}$-doped, $\mathrm{Cr}$-doped and undoped GaAs crystals are shown in Fig.41 (b), Fig.43 (a), (b), and (c), respectively. Remarkable surface roughness was observed on the etched planes of Si-doped, $\mathrm{Zn}$-doped, and $\mathrm{Cr}$-doped GaAs crystals, whereas the etched surface of undoped GaAs was relatively smooth. H. Miyuiri et al. ${ }^{(40)}$ found that some etched surface roughness only occurred when dopant levels were higher than some certain levels. For example, Si-doped crystal with $\mathrm{Si}$ concentrations of more than $2 \times 10^{16} \mathrm{~cm}^{-3}$ had a rough etched surface; on the other hand, in Inand B-doped GaAs, surface roughness was observed only when In and $B$ levels were higher than $10^{18} \mathrm{~cm}^{-3}$. Figure 41 (a) shows the etched morphology of Si-doped GaAs crystal with $\mathrm{Si}$ concentration about $10^{17} \mathrm{~cm}^{-3}$. Compared with Fig.41 (b) $\left(\mathrm{c}_{\mathrm{Si}}>10^{18} \mathrm{~cm}^{-3}\right)$, the degree and hillock size of the etched surface roughness in Fig. 41 (a) may be less than those shown in Fig.41 (b). All the results suggest that surface roughness can be ascribed to impurities and that the degree of roughness depends on the kind and the concentration of the impurities.

Raised structures, as shown in Fig.42, were observed in undoped SI material as well as samples doped with silicon and zinc. The reason for the raised structures on a $\{100\}$ surface has not been very well established. One explanation is that the raised structures are antiphase domains similar to those observed in many ordered 


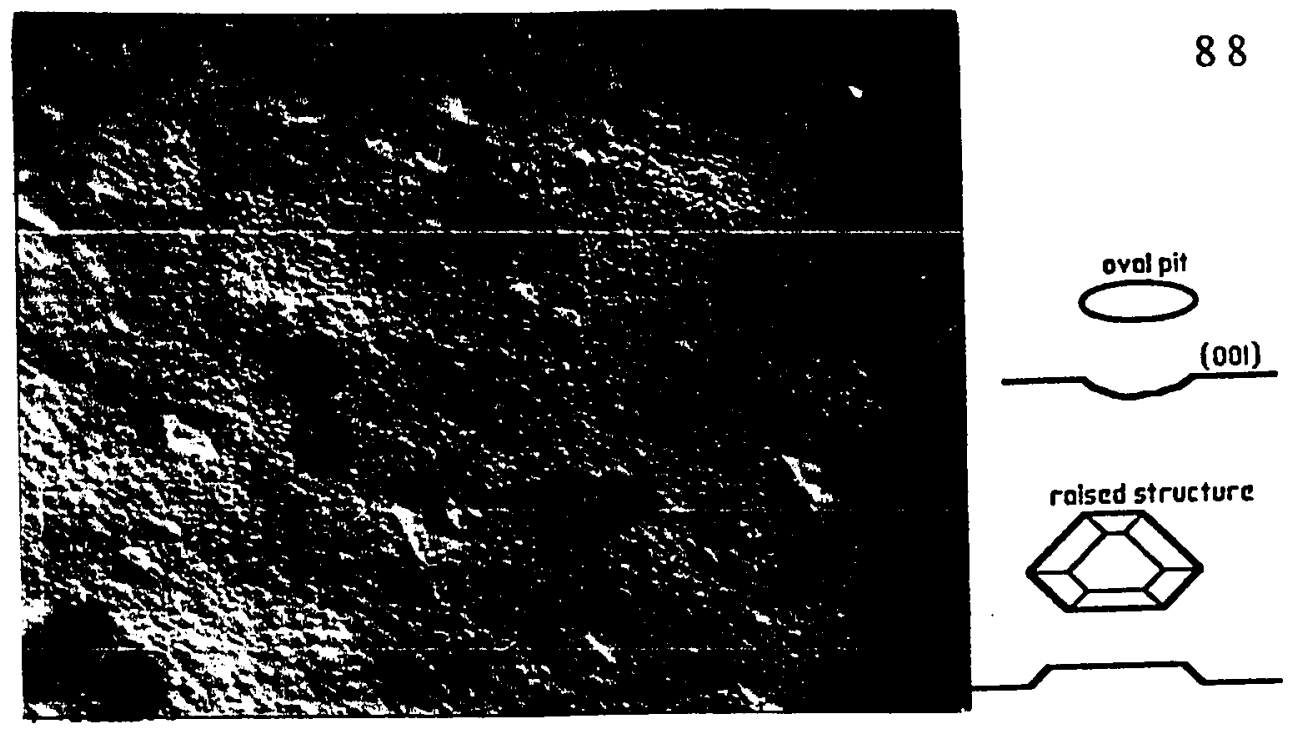

Figure 42. Typical etch structures on the $\{100\}$ surface by eutectic etching, $\mathrm{Zn}$-doped, 200X. A-type pits are hexagonal pyramid pits. B pits are oval pits, $C$ pits are raised structures.

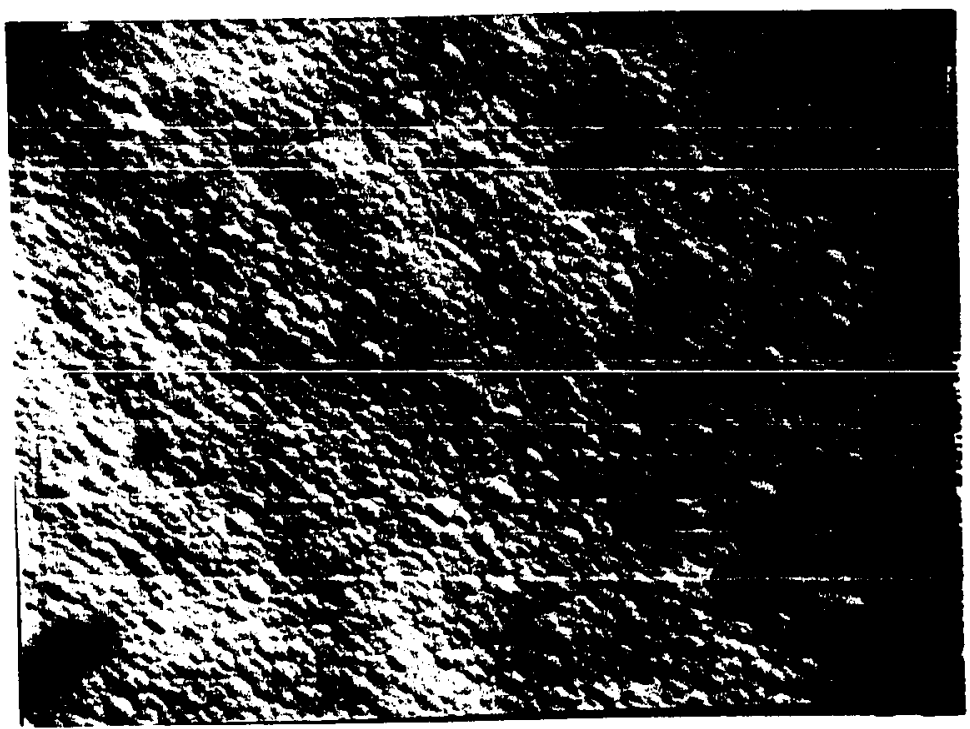

Figure 43. (a) 


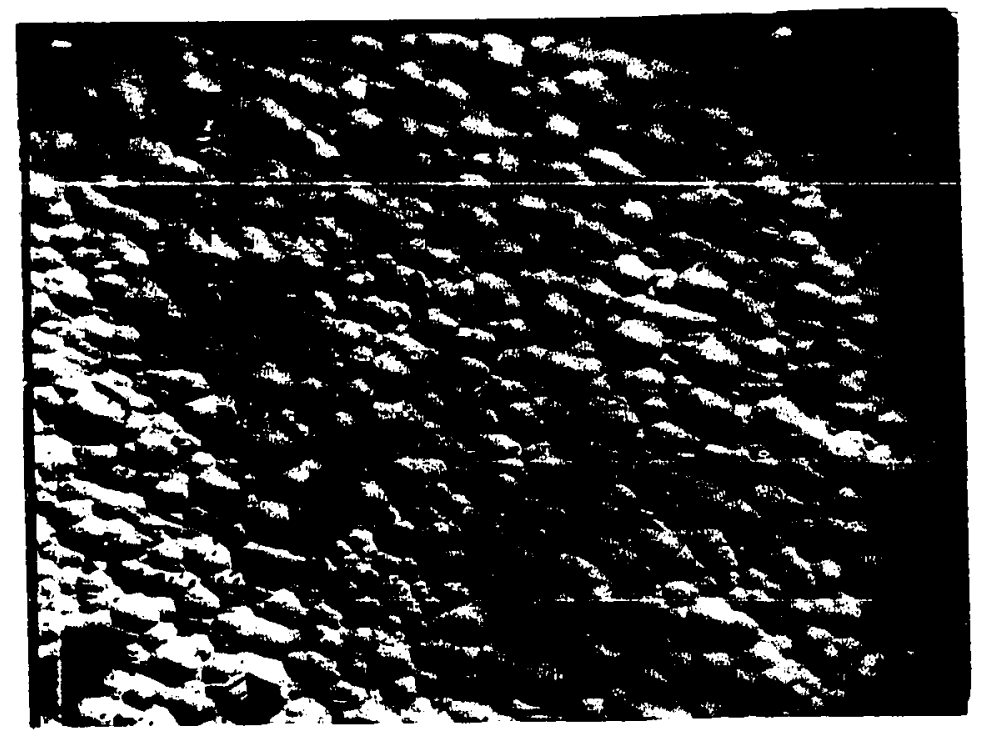

Figure 43. (b)

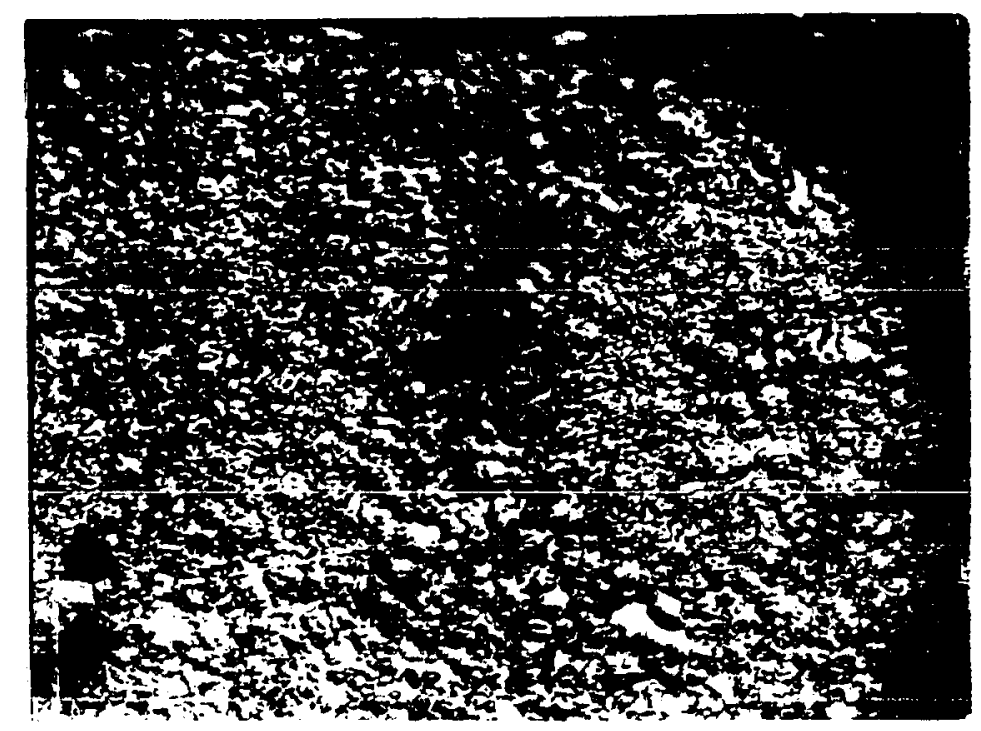

Figure 43. (c)

Figure 43. Surface morphology on $\{100\}$ surfaces by eutectic etching. (a). Zn-doped, 200X. (b) Cr-doped, 200X. (c). undoped, 200X. 
and disordered metal alloy systems. ${ }^{(61)}$ Lessoff found that the etch pits, in the raised structures, appear different from those in the main surface. ${ }^{(42)}$ The long axis of the etch pit differs by $90^{\circ}$ depending on whether the pit is in the main body of the surface or is in the raised areas. However, no etch pits on the raised areas can be found in my etched samples.

Lessoff also gave an explanation about the cause of the raised structure on the GaAs crystal. ${ }^{(42)}$ He thinks that during crystal growth the disordering of the lattice can give rise to small antiphase nuclei if the thermal conditions are proper. The formation of an antiphase superlattice is related to the relative size of the nearest neighbor atoms and the Fermi energy of the resultant structure. In growth of GaAs there may be sufficient non-equilibrium thermal conditions to allow the formation of the antiphase domains. Such defects could occur if, in a small area, a layer of atoms was missing or a layer of atoms was deposited on a layer of the same atoms, or if the impurity concentration is changed in a small area. Then crystalline material grown on that segment of the crystal would have a different rate of etching. 


\subsection{2. $\{110\}$ Surface}

In general, the $\{110\}$ surfaces of the VGF GaAs crystal are rough after eutectic etching, but the dislocation etch pits still can be distinguished from the surface. Like $\mathrm{KOH}$ etching, eutectic etching gives the $\{110\}$ surface the triangular shaped etch pits (P) (dislocation pits) (Fig.44). The size of pits is about $50 \mu \mathrm{m}$ after 30 min etching at $350^{\circ} \mathrm{c}$.

The another kind of etch pits, which is similar to polygonal inlay pits of $\{111\}$ As etched surface but have a long tiny tail along the $\langle 111\rangle$ direction, covered the whole surface of etched samples. This may be due to the different etch rate between $\mathrm{Ga}$ sites and As sites.

The eutectic etchant generally is not successful on $\{110\}$ surfaces of VGF GaAs crystals.

\subsection{3. $\{111\} \mathrm{Ga}$ Surface}

Several types of etch structures can be revealed on $\{111\} \mathrm{Ga}$ surfaces, which include (1) triangular shaped pits with the longer angle tipped to one of the $\langle 110\rangle$ directions, $20-30 \mu \mathrm{m}$ (A in Fig.45 (a)); (2) oval pits elongated in the $\langle 110\rangle$ directions, $10-15 \mu \mathrm{m}$ (B in Fig.45 (a)); (3) polygonal pits, $2-15 \mu \mathrm{m}$ (Fig.45 (a)); and 


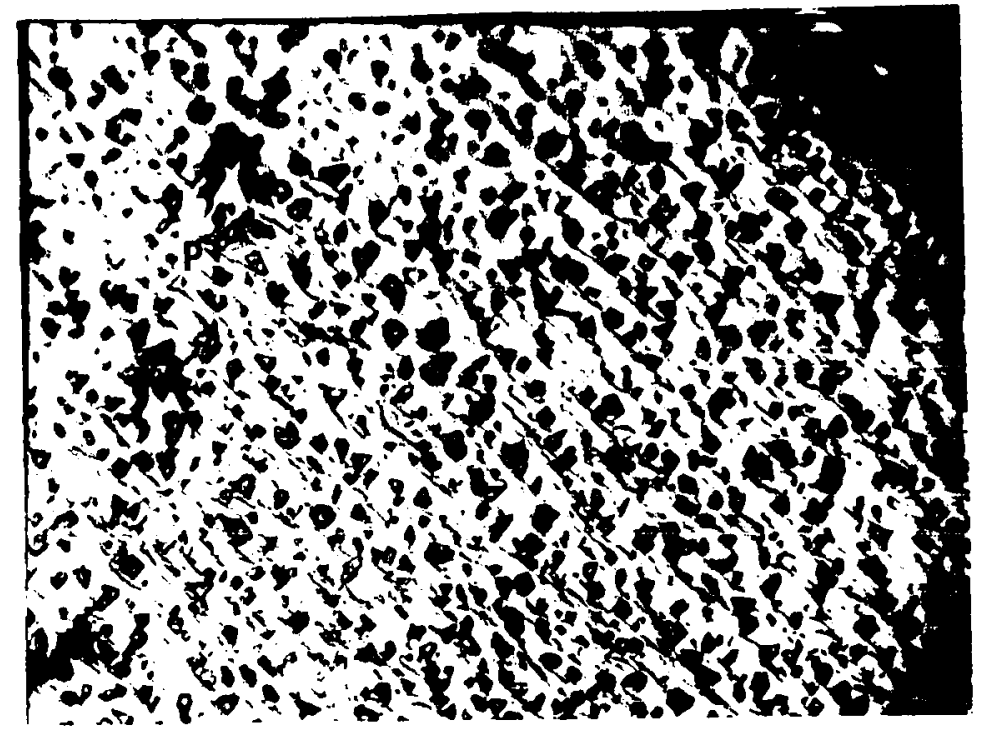

Figure 44. Etch pits on $\{110\}$ surface by eutectic etching, undoped, $200 \mathrm{X}$. 


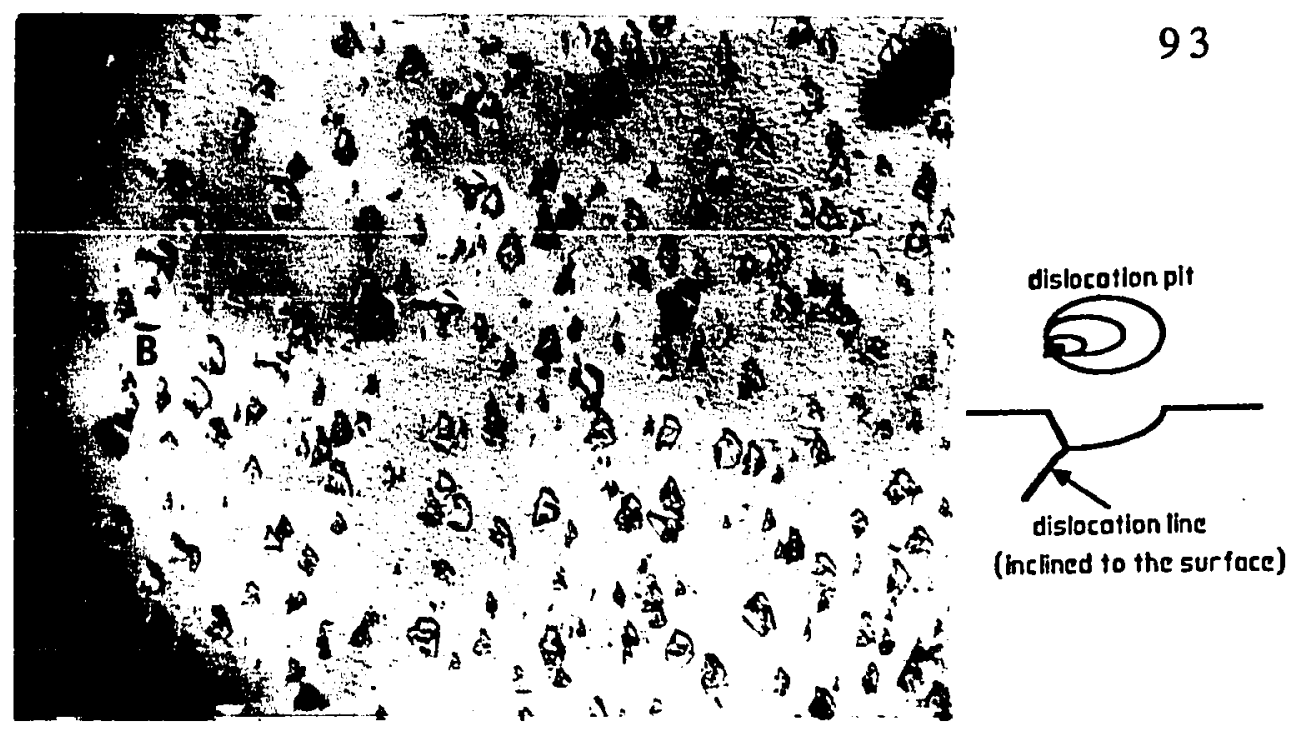

Figure 45. (a)

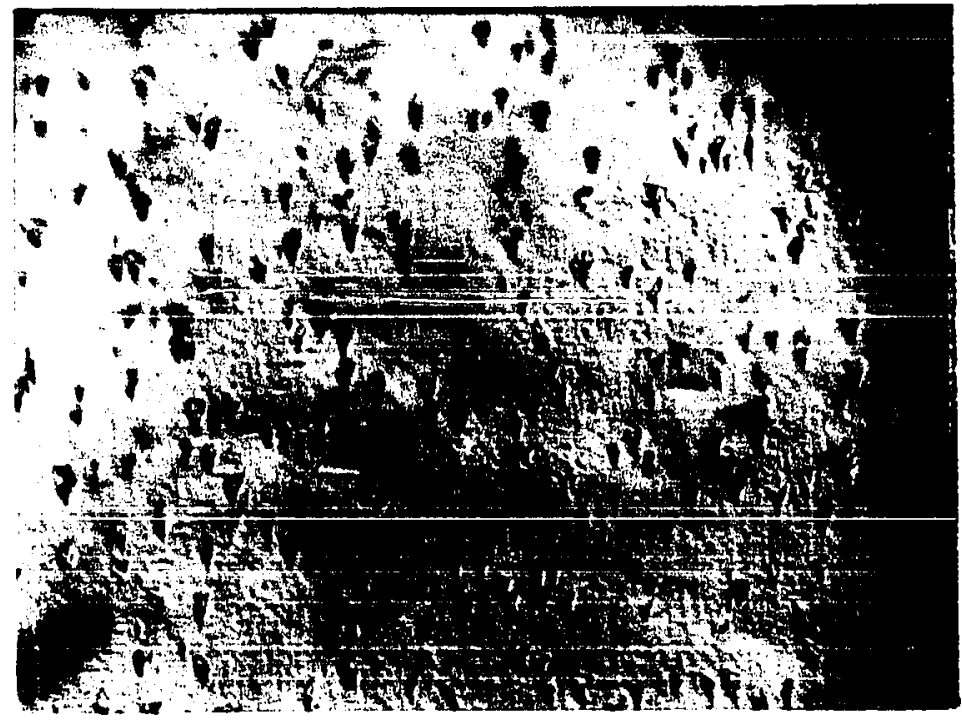

Figure 45. (b)

Figure 45 . Etch structures on a $\{111\} \mathrm{Ga}$ surface by eutectic etching. (a). undoped sample, A pits are dislocation pits and B pits are oval pits, $200 \mathrm{X}$. (b). Si-doped sample, $200 \mathrm{X}$. 


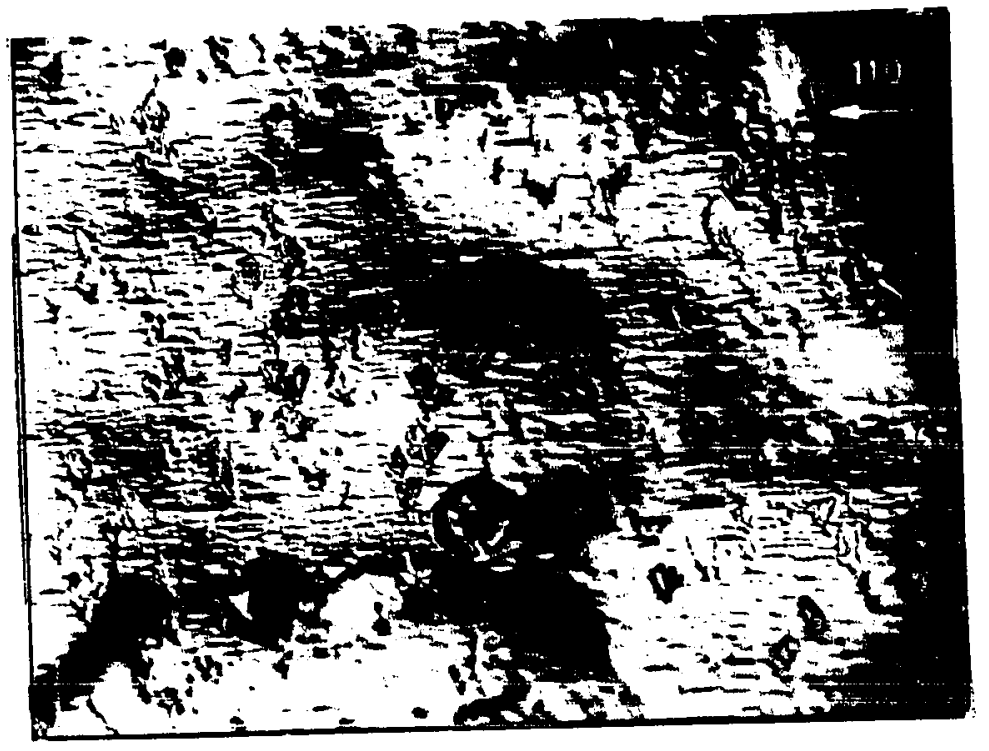

Figure 46. Etch pits on Si-doped $\{111\} \mathrm{Ga}$ surface. The needle-like pits cover the whole picture, $200 \mathrm{X}$. 
(4) needle-like ridges, about $25 \mu \mathrm{m}$ long (Fig.46).

The triangular pits, on which there are veins, are dislocation pits. The pit shape is different from that on $\{100\}$ etched faces due to dislocations inclined to the surface. Oval pits can be found in all the GaAs samples, which is believed to be related to segregation of the impurities. The above-described pits are also found on the $\{100\}$ surface of GaAs, but no raised structure was found on the etched $\{111\} \mathrm{Ga}$ faces of VGF crystals.

The polygonal pits on the $\{111\}$ Ga surface are much fewer than those on the $\{111\}$ As surface. The reason for their origins may follow the assumption I have mentioned before.

Some needle-like ridges can be locally revealed on the undoped and Si-doped $\{111\} \mathrm{Ga}$ surfaces of GaAs. The cause or nature of this structure has not been identified. The structure may be only a kind of etch structure concerned with surface damage after etching.

Figure 45 shows the etched $\{111\} \mathrm{Ga}$ surfaces of undoped and Si-doped VGF GaAs crystals. Like the situation of $\{100\}$ planes, the surface of undoped sample is smoother than that of the Si-doped sample, which also confirms that the degree of surface roughness depends on the concentration of impurities. 
96

4.4.4. Summary

Eutectic etched structures on GaAs crystals are summarized in Table 5. 
Table 5. Summary of etched structures in GaAs single crystals by eutectic etching

\begin{tabular}{|c|c|c|c|c|}
\hline $\begin{array}{l}\text { Names of } \\
\text { etched } \\
\text { structures }\end{array}$ & $\begin{array}{l}\text { Shape } \\
\text { and } \\
\text { size }\end{array}$ & $\begin{array}{l}\text { (Probable) } \\
\text { Origin }\end{array}$ & $\begin{array}{l}\text { Revealed on } \\
\text { crystallographic } \\
\text { surfaces }\end{array}$ & Explanations \\
\hline $\begin{array}{l}\text { Hexagonal } \\
\text { etch pit }\end{array}$ & $\begin{array}{l}<110> \\
30-40 \mu \mathrm{m} \\
\text { long }\end{array}$ & Dislocation & $\{100\}$ & $\begin{array}{l}\text { Dislocation normal to the } \\
\text { surface }\end{array}$ \\
\hline $\begin{array}{l}\text { Triangular } \\
\text { etch pit }\end{array}$ & $D_{20-50 \mu \mathrm{m}}$ & Dislocation & $\{110\},\{111\} \mathrm{Ga}$ & $\begin{array}{l}\text { Dislocation inclined to the } \\
\text { surface }\end{array}$ \\
\hline Oval pit & $\bigcirc_{10-30 \mu \mathrm{m}}$ & $\begin{array}{l}\text { Segregation } \\
\text { of impurity }\end{array}$ & $\{100\},\{111\} \mathrm{Ga}$ & $\begin{array}{l}\text { Observed on all kinds of } \\
\text { GaAs single crystals }\end{array}$ \\
\hline $\begin{array}{l}\text { Surface } \\
\text { roughness }\end{array}$ & $\begin{array}{c}0 \\
5-20 \mu \mathrm{m}\end{array}$ & Impurity & $\{100\},\{111\} \mathrm{Ga}$ & $\begin{array}{l}\text { The degree of roughness } \\
\text { depends on the kind and the } \\
\text { concentration of impurities. }\end{array}$ \\
\hline $\begin{array}{l}\text { Needle-like } \\
\text { ridge }\end{array}$ & $\overrightarrow{25 \mu \mathrm{m} \text { long }}$ & Surface damage & $\{111\} \mathrm{Ga}$ & $\begin{array}{l}\text { The damage may be produced } \\
\text { on the working process. }\end{array}$ \\
\hline $\begin{array}{l}\text { Polygonal } \\
\text { pit }\end{array}$ & $\overbrace{5-25 \mu \mathrm{m}}$ & Small As layers & $\{110\},\{111\} \mathrm{Ga}$ & Not identified \\
\hline $\begin{array}{l}\text { Raised } \\
\text { structure }\end{array}$ & $\square_{10-60 \mu \mathrm{m}}$ & $\begin{array}{l}\text { Anti-phase } \\
\text { domain }\end{array}$ & $\{100\}$ & \\
\hline
\end{tabular}




\section{CONCLUSION}

From the results of this investigating work, it is possible to make the following conclusions:

(1). Four chemical etching methods described in this investigation, which are $\mathrm{A} / \mathrm{B}$ etching, 3:1:1 $\mathrm{H}_{2} \mathrm{SO}_{4}: \mathrm{H}_{2} \mathrm{O}_{2}: \mathrm{H}_{2} \mathrm{O}$ photoetching, $\mathrm{KOH}$ etching and eutectic etching, are successfully used to reveal defects, such as dislocations, precipitates, growth striation, impurity segregation and even antiphase domains on the VGF GaAs single crystal substrates. But the stacking faults were not found by using these etching methods. According to the published literature research I did, only one finding was that stacking faults on $\{100\}$ were revealed by $\mathrm{A} / \mathrm{B}$ etching on epitaxial films. ${ }^{(19)}$

(2). A/B etching and 311 photo-etching can give similar etching patterns and etch features. However, using $A / B$ etching to reveal dislocations, precipitates "decorating" dislocation lines and impurity segregation is better than using 311 photo-etching because the $\mathrm{A} / \mathrm{B}$ etch is principally more sensitive to strain and chemical effects such as the impurity atmosphere near dislocations and impurity segregation. Otherwise, the etch structures by $A / B$ etching are more often identified and more accurately reflect the defects on the GaAs 
crystal. 311 photo-etching can be used to reveal the growth striations of GaAs crystal because of its best images of growth striations.

(3). $\mathrm{KOH}$ etching and hydroxide eutectic etching ( $\mathrm{KOH}: \mathrm{NaOH} 1: 1$ ) have the same etching behavior. The $\mathrm{KOH}$ etch is only effective in revealing dislocations intersecting the free surface so that the $\mathrm{KOH}$ etching is normally used to analyze the dislocation densities and dislocation distribution on the GaAs substrates. Etch pit density (EPD) on $\{100\}$ surfaces basically corresponds to the dislocation density by one-to-one. Eutectic etching can be used not only to reveal dislocations, but also to reveal microscopic defects in doped semi-conducting and undoped semi-insulating VGF GaAs crystals. By eutectic etching, some microscopic defects such as impurity segregation, rough surface morphology responding to impurities, and antiphase domains may be observed. Otherwise, the eutectic etched surface of undoped VGF GaAs crystals exhibited a relatively smooth morphology, whereas a rough etched surface was observed in VGF GaAs crystals doped with $\mathrm{Si}\left(\mathrm{c}_{\mathrm{n}}>10^{17} \mathrm{~cm}^{-3}\right)$, and $\mathrm{Zn}\left(\mathrm{c}_{\mathrm{p}}>10^{19} \mathrm{~cm}^{-3}\right)$. This means that people can roughly distinguish the types or kinds of GaAs crystal by observing the etched surface morphology.

(4). An important etch rate determining factor for GaAs is the crystallographic orientation of the surface and the non-equivalence 
of $\{111\}$ faces. The differently etched, low index surfaces such as $\{100\},\{110\},\{111\} \mathrm{Ga}$ and $\{111\}$ As will basically exhibit the different etch structures, which make it easy to distinguish the crystallographic orientation of surfaces according to the etch structures. The non-equivalent structures of the $\{111\} \mathrm{Ga}$ and \{111\}As GaAs surfaces are revealed by their different behavior in a variety of etchants. Generally, A/B etching, 311 photo-etching and $\mathrm{KOH}$ etching give the different size and shape of etch structures on the opposite \{111\}Ga and \{111\}As surfaces; the eutectic etching, however, can only etch the $\{111\} \mathrm{Ga}$ faces but not the $\{111\}$ As faces.

(5). The relative etching rates for the etchants used in this work basically keep a constant. On the cursory examination, the $\{110\}$ face is found to be the fastest etch face for all kinds of etchants, followed by other surfaces for different etchants. The results are summarized in Table 6.

(6). The work of this investigation is only a basic study concerning the defects of GaAs single substrates and chemical revealing methods and the work is also limited in scope. Of course, there are many chemical etching methods for revealing the defects in GaAs crystals other than the methods mentioned in this work. 
Table 6. Etching rates with different etchants

\begin{tabular}{|c|l|l|l|}
\hline etchant & 1st & 2nd & 3rd \\
\hline A/B & $\{110\}$ & $\{111\}$ & $\{100\}$ \\
\hline 311 & $\{110\}$ & $\begin{array}{l}\{100\}, \\
\{11\}\} \text { almost same rate }\end{array}$ \\
\hline KOH & $\{110\}$ & $\{100\}$ & $\{111\}$ \\
\hline Eutectic & $\begin{array}{c}\{110\}, \\
\text { same rate }\end{array}$ & $\{100\}$ & \\
\hline
\end{tabular}




\section{REFERENCES}

1. R.E. Williams, Gallium Arsenide Processing Techniques, Artechhouse, Inc. Dedham, MA, 1984.

2. D.J. Stirland and B.W. Straugham, "A Review of Etching and Defect Characterization of Gallium Arsenide Substrate Material", Thin Solid Film, 31 (1976) p139.

3. J.W. Faust, Jr., in The Surface Chemistry of Materials and Semiconductors, ed. by H.C. Gatos, (Wiley, New York, 1966) p151.

4. E.S. Meieran, "Transmission Electron Microscope Study of Gallium Arsenide", J. Appl. Phys., 36 (1965) p2544.

5. M. Hirata, S. Takeda et al, "Formation of Point Defect Clusters and the Nature of Point", in Thirteenth International Conference on Defects in Semiconductors, ed. by L.C. Kimerling and J.M. Parsey, Jr. ( The Metallurgical Society of AIME, 1984) p359.

6. G.T. Brown and C.A. Warwick, "On the Interpretation of Defect Etching Behavior of Undoped, Semi-insulating, Liquid Encapsulated Czochralski GaAs Substrates", J. Electrochem. Soc., 133 (1986) p2576. 
7. H.S. Leipner, H.R. Hoche, and J. Schreiber, "Microplastic Strain Mechanisms for GaAs and InP", Bull. Acad. Sci. USSR Phys. Ser. (USA) 51 (1987) p1498.

8. P. Franzosi and G. Salviati, "X-ray and SEM Investigation of Crystal Defects in n-type, p-type and Semi-insulating GaAs", Acta Physica Hungarica, 57 (1985) p251.

9. R.S. Gvodover, V.I. Petrol, et al, "Investigation of Structural Defects of Gallium Arsenide Crystals in the Cathodoluminescence Regime of a Scanning Electron Microscope", Radio Eng. \& Electron. Phys., (USA) 29 (10) 1984, p134.

10. J. Angillelo, R.M. Potemski, et al, "Surface Stacking Fault Determination with X-ray Standing Wave", J. Appl. Phys.. 45 (1975) p2315.

11. M.P. Scott, in Defect Recognition and Image Processing in III-V Compound, ed. by J.P. Filland ( Elsevier, New York, 1985) p41.

12. K. Sumino, et al, in Defects and Properties of Semiconductors: Defect Engineering, ed. by J. Chikawa, et al (KTK, Scientific Publishers, Tokyo, 1987) p3. 
13. M. R. Brozel, E.T. Foulkes, et al , in Defect Recognition and Image Processing in III-V compounds, ed by J.P. Filland ( Elsevier, New York, 1985) p177.

14. T. Ogawa, in Defect Recognition and Image Processing in III-V Compounds, ed. by J.P. Filland ( Elsevier, New York, 1985) p1.

15. H.C. Gatos and M.C. Lavine, "Characteristics of the (111) Surfaces of the III-V Intermetallic Compounds", J. Electrochem. Soc., 107 (1960) p427.

16. J.G. White and W.E. Roth, "Polarity of Gallium Arsenide Single Crystals", J. Appl. Phys., 30 (1959) p946.

17. D.B. Holt, "Defects in Epitaxial Films of Semiconducting Compounds with the Sphalerite Structure", J. Mater. Sci., 1 (1966) p280.

18. J. Schneider, in Defects in semiconductors II, ed. by S. Mahajan and J. W. Corbett ( North-Holland, New York, 1983 ) p227.

19. M.S. Abrahams and C.J. Buiocchi, "Etching of Dislocations on the Low-index Faces of GaAs", J.Appl. Phys., 36 (1965) p2855. 
20. J.P. Hirthe and J.Lothe, Theory of Dislocations, McGraw-Hill, New York, 1968, p353.

21. M. Tanaka and B. Jouffrey, "Dissociated dislocations in GaAs Observed in High Electron Microscopy", Phil. Mag. A50 (1984) P733.

22. E.D. Jungblut, "A Review of Bulk and Process-induced Defects in GaAs Semiconductor", Motall. Trans, 1 (1970) p575.

23. T. Iizuka, "Some Observations of Large Imperfections in Highly Te-doped GaAs Crystal", J. J. Appl. Phys., 7 (1968) p485.

24. P.B. Hirsch, A. Howie, et al., Electron Microscopy of Thin Crystal, Butterworths, London, 1965.

25. G. Eckhardt, "Precipitates in Gallium Arsenide Single Crystals", J. Appl. Phys., 33 (1962) p1016.

26. D.T.J. Hurle, "Constitutional Supercooling During Crystal Growth from Stirring Melts", Solid-State Electron., 3 (1961) p37.

27. S. Miyazawa, "Striation Etching of Undoped, Semi-insulating LECgrown GaAs", J. Crystal Growth, 57 (1982) p459. 
28. T.M. Buck in The Surface Chemistry of Metals and Semiconductors, ed. by H.C. Gatos ( Wiley, New York, 1966) p107.

29. D.F. Kyser and M.F. Millea, "Etching of Gallium Arsenide with Nitric Acid", J. Electrochem. Soc., 111 (1964) p1 102.

30. J.G. White, And W.C. Roth, "Polarity of Gallium Arsenide Single Crystals", J. Appl. Phys., 30 (1959) p946.

31. J.L. Richards and A.J. Crocker, "Etching Pits in Gallium Arsenide", J. Appl. Phys., 31 (1960) p611.

32. S. Iida and K. Ito, "Selective Etching of Gallium Arsenide Crystals in $\mathrm{H}_{2} \mathrm{SO}_{4}: \mathrm{H}_{2} \mathrm{O}_{2}: \mathrm{H}_{2} \mathrm{O}$ System", J. Electrochem. Soc.., 118 (1971) p768.

33. F. Kuhn-Kuhnenfeld, "Selective Photo-etching of Gallium Arsenide", J. Electrochem. Soc., 119 (1972) p1063.

34. E. Sirtl and A. Adler, "Chromsaure-Flusssure Als Spezifisches System Zur Atzgrubenenitwicklung Auf Silizium", Z. Metallkd, 52 (1961) p529. 
35. E.S. Meieran, "Transmission Electron Microscope Study of Gallium Arsenide", J. Appl. Phys., 36 (1965) p2544.

36. G.H. Olsen, M.S. Abrahams, et al., "Asymmetric Cracking in III-V Compounds", J. Electrochem. Soc., 121 (1974) P1650.

37. M.J. Cardwell and D.J. Stirland, Reported at 5th Int. Symp. on GaAs and Related Compounds, Deanville, 1974.

38. Y. Ishii, S. Miyazawa and S. Ishida, "Threshold Voltage Scattering of GaAs-MESFETS Fabricated on LEC-grown Semi-insulating Substrates", IEEE Trans. Electron Devices ED-31 (1984) p800.

39. H. Lessoff and R. Gorman, "A Eutectic Dislocation Etch for Gallium Arsenide", J. Electronic Materials, 13 (1984) p733.

40. H. Miyairi, S. Ozama, et al., "Observation of Microscopic Defects in Dislocation-Free GaAs Crystal by Eutectic Etching", J. Crystal Growth, 76 (1986) p388.

41. W.F. Tseng, H. Lessoff, and R. Gorman, "Morphology of Defects in GaAs Revealed by Eutectic Etch", J. Electrochem. Soc., 132 (1988) p3067. 
42. H. Lessoff, "Non-uniform Etching of Single Crystal GaAs", Materials Letters, 3 (1985) p251.

43. H. C. Gatos and M. C. Lavine, "Etching and Inhibition of the (111) Surfaces of the III-V Intermetallic Compounds--InSb", J. Phys. Chem. Solids, 14 (1960) p169.

44. J. C. Dyment and G. A. Rozgonyi, "Evaluation of a New Polish for Gallium Arsenide Using a Peroxide-Alkaline Solution", J. · Electrochem. Soc.., 11 (1964) p1425.

45. J. G. Grabmaier and C. B. Watson, "Dislocation Etch Pits in Single Crystal GaAs", Phys. Status Solidi, 32 (1969) K13.

46. J. Hornstra, "Dislocations in the Diamond Lattice", J. Phys. Chem. Solids, 5 (1958) p129

47. G. T. Brown and C. A. Warwick, "On the Interpretation of Defect Etching Behavior of Undoped, Semi-insulating, Liquid Encapsulated Czochralski GaAs", J. Electrochem. Soc.., 133 (1986) p2576.

48. T. S. Noggle, B. F. Day, F. A. Sherrill and F. W. Young, Jr., "Stereo Images from Berrman X-ray Topographs of Copper Crystals", Bull. Am. Phys. Soc., 10 (1965) p324. 
49. D. J. Stirland and R. Ogden, "A Dislocation 'Etch-Memory' Effect in Gallium Arsenide", Phys. Status Solidi (a), 17 (1973) K1.

50. A. G. Cullis, P. D. Augustus, and D. J. Stirland, "Arsenic precipitation at Dislocations in GaAs Substrate Material", J. Appl. Phys., 51 (1980) p2556.

51. D. J. Stirland, P. D. Augustus, M. R. Brozel, and E. J. Foulkes, in Semi insulating III-V Materials, eds. by D. C. Look and J. S. Blakemore (Shiva Publishing, Kah-nee-ta, U.S.A.,1985) p91.

52. D. T. J. Hurle, "Constitutional Supercooling During Crystal Growth from Stirring Melts", Solid-state Electron, 3 (1961) p37.

53. R. N. Thomas et al in Semiconductors and Semimetals, Vol. 20 Semi-Insulating GaAs, ed. by R. K. Willarson et al. (Academic Press, Inc., New York, 1984) p50.

54. M. S. Abrahams and C. J. Buiocchi, "Dislocations and Precipitates in GaAs Injection Lasers", J. Appl. Phys., 37 (1966 P1973.

55. M. S. Abrahams and J. I. Pankove, "Orientation Effect in GaAs Injection Lasers", J. Appl. Phys., 37 (1966) p2596. 
56. D. C. Miller and G. A. Rozgonyi in Handbook on Semiconductors, Vol. 3, ed. by S. P. Keller (North-Holland Publishing Company, New York, 1980) p217.

57. E. D. Bourret, M. G. Tabache and J. W. Becman, "Silicon and Indium Doping of GaAs Measurements of the Effects of Doping on Mechanical Behavior and Relation with Dislocation Formation", J. Crystal Growth, 85 (1987) p275.

58. J. M. Parsey, J. Lagowski and H. C. Gatos, in Proc. Symp. on III-V Optoelectrnic Epitaxy and Device Related Processes. eds. by W. J. Keramidas and S. Mahajan (Electro-chem. Soc., NJ, 1983) p61.

59. J. Lagawki, H. C. Gatos, et al., "Fermi Energy Control of Vacancy Coalescence and Dislocation Density in Melt-Grown GaAs", Appl. Phys. Letters, 45 (1984) p680.

60. A. J. R. de Koch, W. T. Stacey and W. M. Van de Wijgert, "Effect of Doping on Microdefect Formation in As-grown Dislocation-Free Czochraski Silicon Crystals", Appl. Phys. Letters, 34 (1979) p611.

61. W. B. Pearson, The Crystal Chemistry and Physics of Metals and Alloys, Wiley-Interscience, New York, 1972. 


\section{1}

62. C. V. King in The Surface Chemistry of Metals and

Semiconductors, ed. by H. C. Gatos, (John Wiley \& Sons, Inc., New York, 1960) p357. 


\section{APPENDIX}

The appendix lists the safety data for some etching chemicals used in this project. All the data were obtained from the material safety data sheet by EM SCIENCE.

1. Bromine $\left(\mathrm{Br}_{2}\right)$

- FIRE AND EXPLOSION HAZARD DATA

-. Extinguishing Media: Use water spray to cool containers: otherwise, any suitable for adjacent material.

-. Special Hazards and Procedures: Wear self-contained breathing apparatus and protective clothing (Neoprene or Rubber).

-. Unusual Fire and Explosion Hazards: Fire can result from spontaneous chemical reaction with reducing materials. A very powerful oxidizer.

-REACTIVITY DATA

-. Conditions to Avoid: Contact with combustible matter and reducing materials

.- Materials to Avoid: Acids, bases, and other (Al, Ti, Hg, K, reducing agents, organic solvents)

\section{- SPILL OR LEAK PROCEDURES}

Wear respiratory and body protection. Add soda ash solution and inert absorbent (sand) to spill and take up and containerize for disposal. 
- health hazaRd data

.. Threshold Limit Value: $2 \mathrm{mg} / \mathrm{m}^{3} / 15 \mathrm{M}$ ceil (NIOSH)

.- Effects of Overexposure: Can irritate or burn eyes, skin and tissue. Do not ingest -- Corrosive.

-. First Aid Procedures:

Eyes: wash with water; get medical attention.

Skin: wash with soap/water; get medical attention.

Inhalation: remove to fresh air; get medical attention.

Ingestion: get medical attention.

- SPECIAL PROTECTION INFORMATION

Protect eyes and skin with safety goggles and gloves.

- SPECIAL HANDLING AND STORING PRECAUTIONS

Store away from acids in tightly sealed container.

2. Chromium Trioxide $\left(\mathrm{CrO}_{3}\right)$

- FIRE AND EXPLOSION HAZARD DATA

.. Extinguishing Media: Use water; however, the decomposing material will form a hot, viscous foam; exercise caution against possible steam explosion.

-. Special Hazards and Procedures: Wear self-contained breathing apparatus. Wear full protective clothing.

-. Unusual Fire and Explosion Hazards: Powerful oxidizing material. Containers may explode when involved in fire. 


\section{-REACTIVITY DATA}

-. Conditions to Avoid: Will ignite on contact with acetic and alcohol.

.. Materials to Avoid: Reducing agents, oils, greases, organic and oxidizable materials.

-. Hazardous Decomposition Products: $\mathrm{Cr}_{2} \mathrm{O}_{3}$

\section{- SPILL OR LEAK PROCEDURES}

Scoop into container for proper disposal; flush area with water.

\section{- HEALTH HAZARD DATA}

.. Threshold Limit Value: $0.025 \mathrm{mg} / \mathrm{cu} . \mathrm{m}$.(as Cr) (TWA)

TXDS: orl-hmn LDLo: $50 \mathrm{mg} / \mathrm{kg}$ ihl-hmn TCLo: $110 \mu \mathrm{g} / \mathrm{m}^{3} / 3 \mathrm{y}$ toxic effects: carcinogenic

-. Effects of Overexposure: RECOGNIZED and CARCINOGEN per NTP and IARC. Caustic to skin and mucous membranes. Contact with eyes may result in loss of sight. Harmful if inhaled or swallowed. Causes lung, kidney and liver damage (chronic or massive acute exposure).

-. First Aid Procedures:

Eyes: Immediately flush thoroughly with water at least 15 minutes.

Skin: Flush thoroughly with water ; remove contaminated shoes; remove contaminated clothing at once and launder before reuse.

Inhalation: remove to fresh air. 
Ingestion: Do not induce vomiting; get immediate medical attention.

\section{- SPECIAL PROTECTION INFORMATION}

Material must be handled or transferred in an approved fume hood or with equivalent ventilation. Protective gloves (PVC, Viton, or equivalent) must be worn to prevent skin contact. Safety glasses with side shields must be worn at all times. NIOSH approved respirator may be required if TLV is exceeded.

\section{- SPECIAL HANDLING AND STORING PRECAUTIONS}

Keep container tightly closed and protected against physical damage and moisture contamination. Store in a dry, well ventilated area away from combustible, organic or readily oxidizable materials. Avoid storage on wooden floors. Do not breathe dust or solution mist. Do not get in eyes, on skin, or on clothing. Do not take internally.

\section{Hydrofluoric Acid (HF)}

\section{- FIRE AND EXPLOSION HAZARD DATA}

-• Extinguishing Media: Water

-. Special Hazards and Procedures: Wear self-contained breathing apparatus and full protective clothing with face shield. When heated, emits highly corrosive.

-. Unusual Fire and Explosion Hazards: fumes of fluorides. May react, possibly violently, with: acetic anhydride; 2-aminoethanol; ammonium hydroxide; bismuthic acid; calcium oxide; chlorosulfonic 
acid; ethylene diamine; ethyleneimine; fluorine; nitric acid\&lactic acid; oleum; sodium; sodium hydroxide; sulfuric acid; vinyl acetate.

\section{-REACTIVITY DATA}

-. Materials to Avoid: Water \& steam, Glass, concrete, silica, many organic materials, alkalies, leather, rubber.

-• Hazardous Decomposition Products: Reaction with certain metals may produce Hydrogen gas.

\section{- SPILL OR LEAK PROCEDURES}

Flush with water; neutralize with lime; wash with water again; ventilate area.

\section{- HEALTH HAZARD DATA}

.. Threshold Limit Value: $0.5 \mathrm{mg} / \mathrm{m}^{3}$ (TWA)

- Effects of Overexposure: Skin contact can cause eczematous dermatitis, ulcers. Dust inhalation harmful to respiratory passages and lungs. Harmful if swallowed.

-. First Aid Procedures:

Eyes: flush thoroughly with water immediately

Skin: wash with soap and water

Inhalation: remove to fresh air

Ingestion: if conscious, induce vomiting

\section{- SPECIAL PROTECTION INFORMATION}

Provide adequate general mechanical and local exhaust ventilation. Protect eyes and skin with safety goggles and gloves. Wear dust respirator if dust concentration is heavy. Do not get in eyes, on skin, or on clothing. 


\section{- SPECIAL HANDLING AND STORING PRECAUTIONS}

Keep container closed and protected from physical damage.

Store in a well ventilated area. Wash thoroughly after handling.

4. Potassium Hydroxide (KOH)

- FIRE AND EXPLOSION HAZARD DATA

-• Extinguishing Media: N/A

-. Special Hazards and Procedures: None

-• Unusual Fire and Explosion Hazards: None

\section{-REACTIVITY DATA}

-. Conditions to Avoid: Contact with strong acid solution may cause violent reaction.

-. Materials to Avoid: Acids

- SPILL OR LEAK PROCEDURES

Neutralize with acetic acid and take up for proper disposal.

- HEALTH HAZARD DATA

-. Threshold Limit Value: TWA: 1 ppm (for 90\% $\mathrm{H}_{2} \mathrm{O}_{2}$ )

-. Effects of Overexposure: Vapor may irritate or inflame eyes, skin. respiratory tract.

-. First Aid Procedures:

Eyes: flush thoroughly with water; get medical attention. 
Skin: wash with soap/water; get medical attention for persistent dermatitis.

Inhalation: remove to fresh air; get medical attention. Ingestion: get medical attention.

\section{- SPECIAL PROTECTION INFORMATION}

Provide adequate general mechanical and local exhaust ventilation.Protect eyes and skin with safety goggles and gloves.

\section{- SPECIAL HANDLING AND STORING PRECAUTIONS}

Keep container closed. Store in a cool area away from incompatible materials. Wash thoroughly after handling.

5. Sodium Hydroxide $(\mathrm{NaOH})$

- FIRE AND EXPLOSION HAZARD DATA

-. Extinguishing Media: Use water any suitable for surrounding material.

-. Special Hazards and Procedures: Wear self-contained breathing apparatus.

.. Unusual Fire and Explosion Hazards: None indicated

-REACTIVITY DATA

-. Conditions to Avoid: Splattering or splashing

-. Materials to Avoid: Acids, metals, organic halogens, nitro compounds, $\mathrm{Al}, \mathrm{Sn}, \mathrm{Zn}$. 


\section{- SPILL OR LEAK PROCEDURES}

Neutralize with $6 \mathrm{M} \mathrm{HCl}$, dilute with water.

- HEALTH HAZARD DATA

-. Threshold Limit Value: $2 \mathrm{mg} / \mathrm{m}^{3} / 15 \mathrm{M}$ ceil (NIOSH)

-. Effects of Overexposure: Can irritate or burn eyes, skin and tissue. Do not ingest -- Corrosive.

-. First Aid Procedures:

Eyes: wash with water; get medical attention.

Skin: wash with soap/water; get medical attention.

Inhalation: remove to fresh air; get medical attention.

Ingestion: get medical attention.

- SPECIAL PROTECTION INFORMATION

Protect eyes and skin with safety goggles and gloves.

- SPECIAL HANDLING AND STORING PRECAUTIONS

Store away from acids in tightly sealed container.

6. Sulfuric Acid $\left(\mathrm{H}_{2} \mathrm{SO}_{4}\right)$

- FIRE AND EXPLOSION HAZARD DATA

-. Extinguishing Media: Dry chemical or sand. Do not use water or foam.

-. Special Hazards and Procedures: Wear self-contained breathing apparatus, full face shield and full protective clothing (Rubber or Neoprene). 
-. Unusual Fire and Explosion Hazards: Reacts with most metals to form hydrogen gas which can form explosive mixtures with air. May ignite combustible material on contact.

\section{-REACTIVITY DATA}

-. Conditions to Avoid: Adding water to acid can cause violet, exothermic reaction, possibly causing fire. Can react violently with alkalies.

-. Materials to Avoid: Water, basses, oxidizers, reducing agents. metal powders, carbides, acetic acid, combustible material.

-. Hazardous Decomposition Products: $\mathrm{SO}_{\mathrm{x}}$, Hydrogen (in presence of metals)

\section{- SPILL OR LEAK PROCEDURES}

Cover with sand; neutralize with soda ash or lime; scoop up and containerize for disposal.

\section{- HEALTH HAZARD DATA}

.- Threshold Limit Value: TLV air; $3 \mathrm{ppm}$ (vapor) recm std air (HF): TWA $215 \mathrm{mg}(\mathrm{F}) / \mathrm{m}^{3}$

TXDS: ihl-hmn LCLo: $50 \mathrm{ppm} / 30 \mathrm{M}$ ihl-man TCLo: $110 \mathrm{ppm} / 1 \mathrm{M}$ ipr-rat LDLo: $25 \mathrm{mg} / \mathrm{kg}$

-. Effects of Overexposure: Dilute solutions may not give any indication of pain or visible effect until hours after skin exposure, during which time the acid has penetrated the skin causing possible destruction of tissue and development of skin ulcers. Extremely irritating and corrosive to skin, eyes, mucous membranes; will 
penetrate skin and attack underlying tissues and bone. Ihl-ulcers of upper respiratory tract. Skin-severe, slow-to-heal burns, gangrene. Any form of exposure (ihl, inges, or burns $>25$ sq. in.) may cause secondary hypocalcemia; if treatment is delayed, death may result.

-. First Aid Procedures:

Skin/Eyes: Immerse in running water $15 \mathrm{~min}$; pay attention to skin under nails. Remove contaminated clothing; soak affected area in $0.13 \%$ iced aqueous soln of Zephiran or $0.2 \%$ iced aqueous soln of Hyamine.

Inhalation: remove to fresh air; administer oxygen immed; get medical attention..

Ingestion: Do not induce vomiting; drink large quantities of water then $2 \mathrm{oz}$ milk or milk of magnesia; get immediate medical attention.

\section{- SPECIAL PROTECTION INFORMATION}

Exhaust ventilation is essential. Wear full protective clothing including self-contained breathing apparatus, safety goggles, face shield, gloves, acid-resistant clothing, rubber shoes soled with neoprene.

\section{- SPECIAL HANDLING AND STORING PRECAUTIONS}

Keep container tightly closed and out of sunlight. Isolate from other storage. Store in a cool, dry, well ventilated area on blocks or pallets in an area with a drain. Protect against physical damage. Maintain constant temperature (avoid temperature fluctuations). Storage tanks are subject to indiscriminate hydrogen blistering; the thickness of tank steel should be measured by non-destructive testing at least annually. In addition, periodic visual inspection of tank interior regularly. 